\title{
Corrosion Models for Predictions of Performance of High-Level Radioactive-Waste Containers
}

\author{
J.C. Farmer \\ G.E. Gdowski \\ R.D. McCright
}

Manuscript Date: September 1, 1990

Publication Date: November 1, 1991

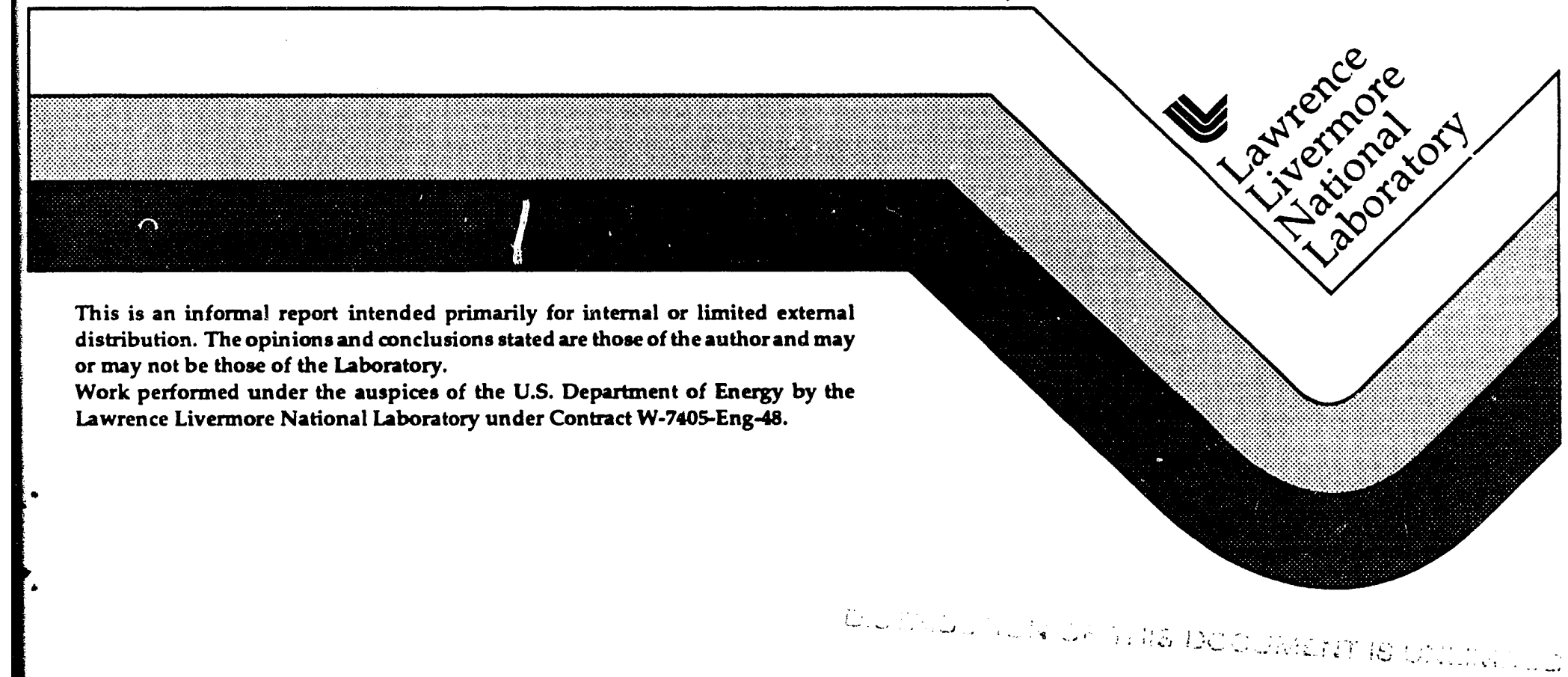




\section{DISCLAIMER}

This document was prepared as an acccount of work sponsored by an agency of the United States Government. Neither the United States Government nor the University of California nor any of their employees, makes any warranty, express or implied, or assumes any legal liability or responsibility for the accuracy, completeness, or usefulness of any information, apparatus, product, or process disclosed, or represents that its use would not infringe privately own rights. Reference herein to any specific commercial products, process, or service by trade name, trademark, manufacturer, or otherwise, does not necessarily constitute or imply its endorsement, recommendation, or favoring by the United States Government or the University of California. The views and opinions of auth rrs expressed herein do not necessarily state or reflect those of the United States Government or the University of California, and shall not be used for advertising or product endorsement purposes.

This report has been reproduced directly from the best available copy.

Available to DOE and DOE contrartors from the Office of Scientific and Technica! Information

P.O. Box 62, Oak Ridge, TN 37831

Prices available from (615) 576-8401, FTS 626-8401

Available to the public from the

National Technical Information Service

U.S. Department of Commerce

5285 Port Royal Rd.

Springfield, VA 22161 
UCID -21756

DE92 004467

Corrosion Models for Predictions of Performance of High-Level Radioactive-Waste Containers

\author{
J. C. Farmer \\ Livermore, Calif. \\ G. E. Gdowski
KMI Energy
Livermore, Calif.
}

Lawrence Livermore National Laboratory

R. D. McCright

Lawrence Livermore National Laboratory

Livermore, Calif. 


\section{Contents}

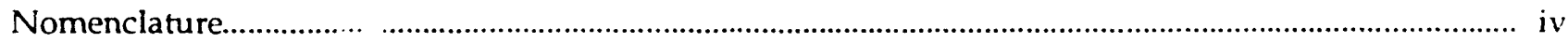

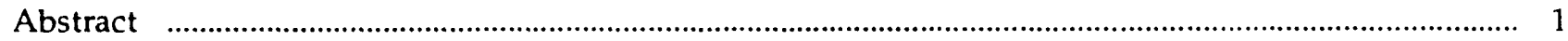

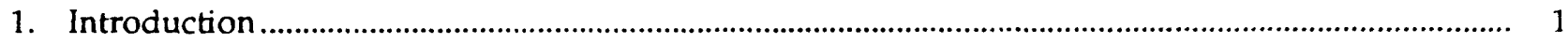

2. Vapor-Phase Corrosion..................................................................................................................... $\quad 7$

3. Aqueou -Phase Corrosion ......................................................................................................... 9

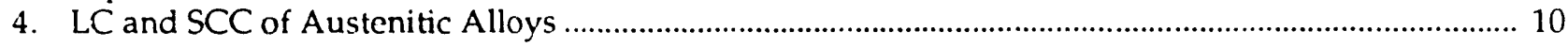

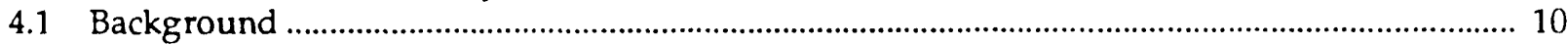

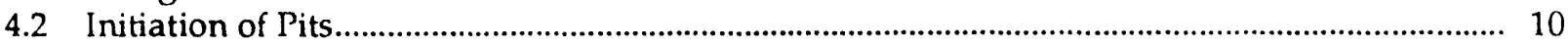

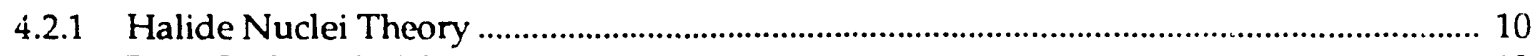

4.2.2 Point Defect Model ........................................................................................................ 12

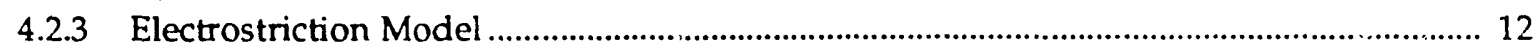

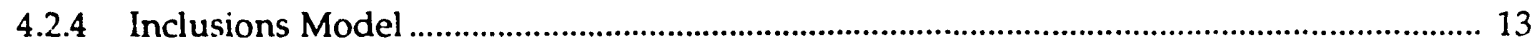

4.3 Propagation of Pits .................................................................................................................... 14

4.3.1 Pit Growth with an Active Surface at the Base of the Pit .................................................. 14

4.3.2 Pit Growth Limited by Salt Film ............................................................................... 16

4.4 Crack Initiation at Pits Having Critical Depth ........................................................................ 17

4.5 Sensitization of the Austenitic Alloys......................................................................................... 18

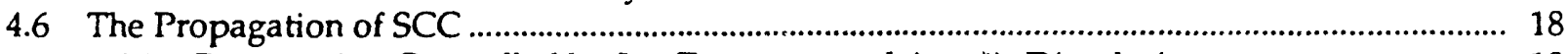

4.6.1 Propagation Controlled by Ion Transport and Anodic Dissolution................................. is

4.6.2 Models Involving Film Fracture at the Crack Tip ........................................................... 20

5. LC and SCC of Copper-Based Alloys .................................................................................................. 22

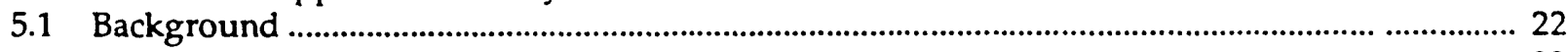

5.2 Pitting of Copper-Based Alloys ................................................................................................ 22

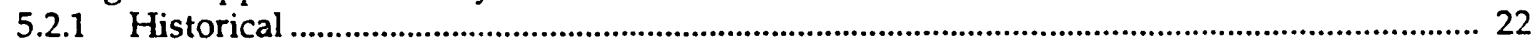

5.2.2 Classification of Pitting Mechanisms ………......................................................................... 22

5.2.3 Two Mechanisms for the Pitting of Copper ....................................................................... 23

5.2.4 Pit Chemistry ........................................................................................................................ 23

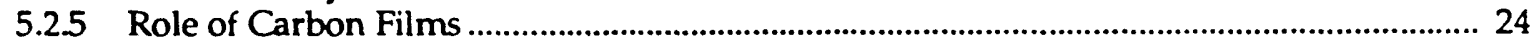

5.3 SCC of Copper-Based Alloys ............................................................................................................ 25

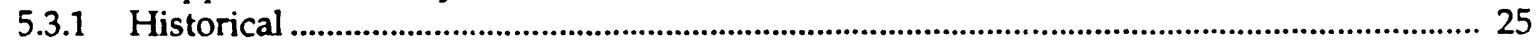

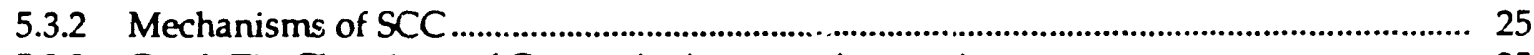

5.3.3 Crack Tip Chemistry of Copper in Aqueous Ammonia ..................................................... 25

5.3.4 Crack Tip Chemistry of Copper in Nitrite Solutions .......................................................... 26

5.3.5 Crack Tip Chemistry of Aluminum Bronze in Steam........................................................... 2i

5.3.6 Crack Tip Chemistry of Cupronickel in Aqueous Environments ..................................... 27

5.4 Propagation of SCC in Copper-Based Alloys................................................................................ 28

5.4.1 Crack Propagation Due to Stress-Induced Failure of Oxide Films................................... 28

5.4.2 Crack Propagation Due to Film-Induced Cleavage of the Base Metal................................ 29

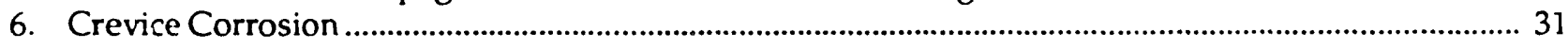

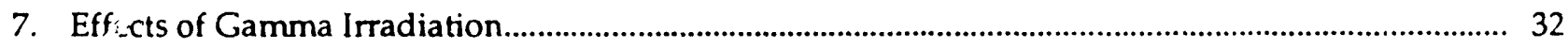

7.1 Possible Effect on Resistance to Pitting .................................................................................... 32

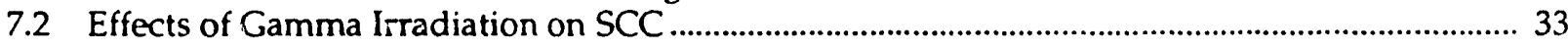

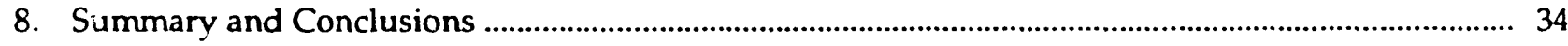

9. Acknowledgments......................................................................................................................... 34

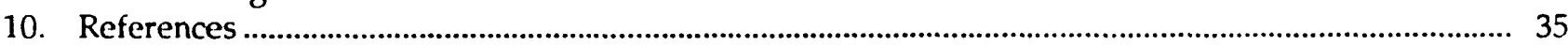




\section{Nomenclature}

$F$

$G_{\text {ก }}$

$i_{0}$

$i_{c}$

if

$i_{L}$

$i_{\mathrm{M}}$

$i_{p}$

$i(t)$

I

$I_{\mathrm{ca}}$

J 0

$k_{\mathrm{i}}$

$K$

$\mathrm{KG}_{\mathrm{CC}}$

$K_{\text {crit }}$

KISCC

$l_{\text {max }}$

L

$L_{\mathrm{p}}$

$m$

$M$

$M_{M}$

half the major axis of the elliptical pit, or pit depth [Eq. (30)]

activity of carbon [Eq. (35)]

activity of chromium [Eq. (35)]

pre-exponential constant [Eq. (6)]

critical pit depth [Eq. (32)]

constant [Eq. (29)]

minor axis of the elliptical pit, or pit width [Eq. (30)]

concentration of metal salt in the bulk electrolyte [Eq. (24)]

salt concentration in the bulk electrolyte nutside of the pit [Eq. (19)]

(1) saturation concentration of metal salt in the electrolyte [Eq. (24)]; (2) atom percent of solute in the alloy [Eq. (90)]

(1) equilibrium spacing [Eq. (89)]; (2) interatomic spacing

(1) diffusivity of the salt in the electrolyte [Eq. (24)]; (2) diffusivity of ions in the salt film [Eq. (28)]

diffusivity of the metal cation in the electrolyte [Eq. (19)]

crack propagation rate

microcrack propagation rate

pit growth rate

crack tip strain rate [Eqs. (54) and (84)]

(1) electric field [Eq. (89)]; (2) depth of the interatomic potential; (3) electrochemical

potential; (4) Young's modulus

activation energy [Eq. (88)]

critical pitting potential

corrosion potential

activation energy [Eq. (6)]

Faraday's constant

flow stress

exchange current density [Eq. (27)]

critical anodic current density [Eq. (92)]

current density associated with growth of the salt film [Eq. (27)]

limiting current density inside the pit [Eq. (25)]

anodic current density at the base of the pit [Eq. (19)]

passive current density [Eq. (92)]

dissolution current density at a crack tip [Eq. (50)]

diffusional flux [Eq. (24)]

diffusion flux of cation vacancies in the passive film

dissolution current density of the fresh surface [Eq. (50)]

kinetic rate constants [Eq. (6)]

(1) stress intensity factor; (2) equilibrium constant [Eq. (34)]

equilibrium constant for formation of $\mathrm{Cr}_{23} \mathrm{C}_{6}$ [Eq. (34)]

critical stress intensity factor for mechanical fracture

threshold stress intensity factor for initiation of SCC !Eq. (29)]

maximum crack length at fracture [Eq. (87)]

thickness of the passive oxide or tarnish film [Eqs. (15) and (82)]

passive length in crevice [Eq. (92)]

(1) oxide thickness [Eqs. (1-5)]; (2) metal atom introduced into a passive film at the metal/film interface

atomic weight of the metal [Eq. (26)]; (2) molecular weight of the passive oxide film [Eq. (53)]

metal cation in cation site 


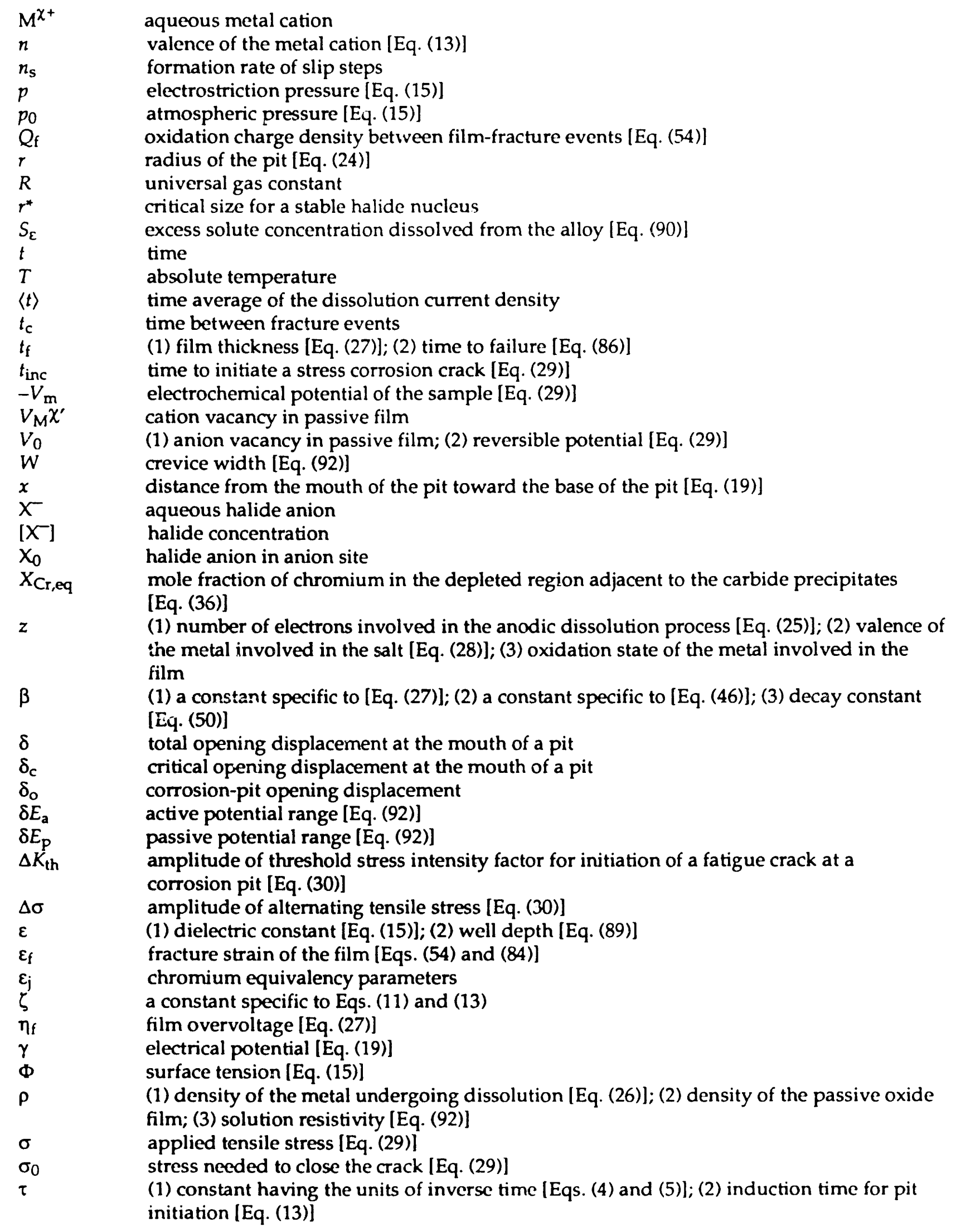




\title{
Corrosion Models for Predictions of Performance of High-Level Radioactive-Waste Containers
}

\begin{abstract}
The present plan for disposal of high-level radioactive waste in the U.S. is to seal it in containers before emplacement in a geologic repository. A proposed site at Yucca Mountain, Nevada, is being evaluated for its suitability as a geologic repository. The containers will probably be made of either an austenitic or a copper-based alloy. Models of alloy degradation are being used to predict the long-term performance of the containers under repository conditions. The models are of uniform oxidation and corrosion, localized corrosion, and stress corrosion cracking, and are applicable to worst-case scenarios of container degradation. This paper reviews several of the models.
\end{abstract}

\section{Introduction}

Two types of high-level radioactive-waste packages are proposed for in the prospective repository at Yucca Mountain, Nevada. About 30,000 packages will contain spent fuel, and about 14,000 packages will contain processed-glass waste forms. Figure 1 shows conceptual designs of these waste packages [1].
Currently, six candidate materials are being considered for fabrication of the waste package containers [2]. These materials are three austenitic alloys and three copper-based alloys, as shown in Table 1. The austenitic alloys are Types 304L and 316L stainless steels and high-nickel Alloy 825. The copper-based alloys are CDA 102

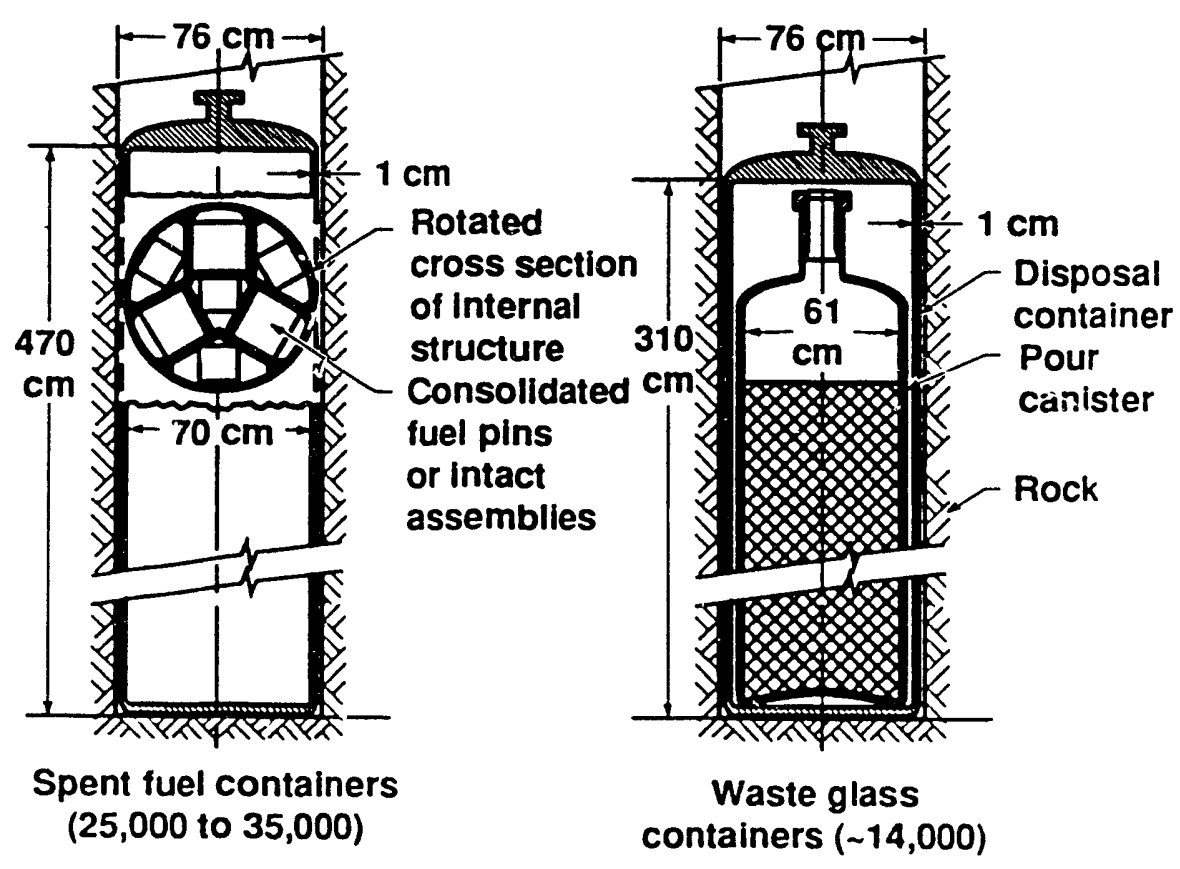

Figure 1. Conceptual designs of two types of high-level radioactivewaste packages for emplacement in a geologic repository [1]. 
Table 1. The six candidate materials for high-level radioactive-waste containers.

\begin{tabular}{lcc}
\hline \multicolumn{1}{c}{$\begin{array}{c}\text { Common alloy } \\
\text { name }\end{array}$} & $\begin{array}{c}\text { Common industry } \\
\text { designation }\end{array}$ & $\begin{array}{c}\text { Unified numbering } \\
\text { system designation }\end{array}$ \\
\hline Type 304L stainless steel & AISI 304L & S30403 \\
Type 316L stainless steel & AISI 316L & S31603 \\
Alloy 825 & Alloy 825 & N08825 \\
Oxygen-free copper & & \\
$7 \%$ aluminum bronze & CDA 102 & C10200 \\
70/30 copper nickel & CDA 613 & C61300 \\
\hline
\end{tabular}

(oxygen-free copper), CDA 613 (aluminum bronze), and CDA 715 (cupronickel). Tables 2 and 3 show the compositions and the mechanical properties of these materials.

The material having the best predicted overall performance in the repository will be selected for fabrication of the containers. This material mus' perform well in the following categories:

i. Mechanical strength and toughness.

2. Fabricability and cost.

3. Metallurgical phase stability.

4. Resistance to:

- Hydrogen embrittlement and hydrogen-induced degradation.

- Uniform oxidation and dissolution.

- Pitting.

- Crevice corrosion.

- Stress corrosion cracking (SCC).

- Radiation-enhanced degradation.

- Microbiologically induced degradation.

Data from current experimental testing of the candidate materials and from the literature will be used as a basis of comparison. We have compiled a large volume of published data and used it to establish a tentative ranking within each alloy farriiy $[3,4]$. Tables 4 and 5 show these rankings for resistance to various forms of corrosion. The rankings may change as more experimental data become available.

Federal law requires that the containers provide "substantially complete containment" for a period of 300 to $1000 \mathrm{yr}$, with a very slow, controlled release of radionuclides allowed for the next $9000 \mathrm{yr}[5,6]$. Models of vapor- and aqueous-phase corrosion of the containers will be needed to assure "substantially complete containmen:t" of the encapsulated high-level radioactive waste. We have found and documented several models that satisfy this need. These models are outlined here and elsewhere [7]. We are currently developing models and determining parameters from experimental data. These models will ultimately be incorporated into performance assessment codes.

The repository at Yucca Mountain will be located in an unsaturated zone 700 to $1400 \mathrm{ft}$ above the water table and 300 to $1200 \mathrm{ft}$ below ground. Containers will probably be subject to both dry and wet environments during emplacement. Figure 2 shows an example of a calculated temperature profile of a spent-fuel waste package placed in a vertical borehole [8].

Vapor-phase corrosion is anticipated to be the dominant degradation mode during the first part of the containment period, when the surface temperature of the containers will be above the unconstrained boiling point $\left(96^{\circ} \mathrm{C}\right)$ at the elevation of Yucca Mountain. As the temperature decreases with time, the possibility of aqueousphase corrosion increases, depending on the thermal power load in the container and the thermal power density in the repository. There is a significant difference in thermal power loading between spent-fuel and glass-waste-form packages. There is also variation in thermal decay with the isotopic content and age of the waste and the configuration of the waste emplaced in the container. Because of the lower thermal output of glass-waste-form packages, container surface temperatures will drop to the boiling point isotherm sooner than in the case of spent-fuel waste packages. In fact, as shown in Fig. 2, the 
Table 2. Compositions of the candidate materials.

(a) Austenitic materials

\begin{tabular}{|c|c|c|c|c|c|c|c|c|c|}
\hline Alloy & $\begin{array}{c}C \\
(\max )\end{array}$ & $\begin{array}{c}\mathrm{Mn} \\
(\max )\end{array}$ & $\begin{array}{c}P \\
(\max )\end{array}$ & $\begin{array}{c}S \\
(\max )\end{array}$ & $\underset{(\max )}{\mathrm{Si}}$ & $\begin{array}{c}\mathrm{Cr} \\
\text { (range) }\end{array}$ & $\begin{array}{c}\mathrm{Ni} \\
\text { (range) }\end{array}$ & & $\begin{array}{c}\text { Other } \\
\text { elements }\end{array}$ \\
\hline $304 \mathrm{~L}$ & 0.030 & 2.00 & 0.045 & 0.030 & 1.00 & $\begin{array}{l}18.00 \\
20.00\end{array}$ & $\begin{array}{c}8.00- \\
12.00\end{array}$ & $\mathrm{~N}:$ & $0.10 \max$ \\
\hline $316 \mathrm{~L}$ & 0.030 & 2.00 & 0.045 & 0.030 & 1.00 & $\begin{array}{l}16.00- \\
18.00\end{array}$ & $\begin{array}{l}10.00 \\
14.00\end{array}$ & $\begin{array}{r}\text { Mo: } \\
\text { N: }\end{array}$ & $\begin{array}{l}2.00-3.00 \\
0.10 \max \end{array}$ \\
\hline 825 & 0.05 & 1.0 & $\begin{array}{l}\text { Not } \\
\text { spec. }\end{array}$ & 0.03 & 0.5 & $\begin{array}{l}19.5- \\
23.5\end{array}$ & $\begin{array}{l}38.00 \\
46.0\end{array}$ & $\begin{array}{r}\text { Mo: } \\
\text { Ti: } \\
\text { Cu: } \\
\text { Al: }\end{array}$ & $\begin{array}{l}2.5-3.5 \\
0.6-1.2 \\
1.5-3.0 \\
0.2 \mathrm{max} \\
\end{array}$ \\
\hline
\end{tabular}

(b) Copper-based materials

\begin{tabular}{rllllllll}
\hline Alloy & $\mathrm{Cu}$ & $\mathrm{Fe}$ & $\mathrm{Pb}$ & $\mathrm{Sn}$ & $\mathrm{Al}$ & $\mathrm{Mn}$ & $\mathrm{Ni}$ & $\mathrm{Zn}$ \\
\hline CDA 102 & $\begin{array}{l}99.95 \\
(\min )\end{array}$ & - & - & - & - & - & - & - \\
CDA 613 & $\begin{array}{l}927 \\
(\text { nom) }\end{array}$ & $\begin{array}{c}3.5 \\
(\max )\end{array}$ & - & $0.2-0.5$ & $6.0-80$ & $\begin{array}{c}0.5 \\
(\max )\end{array}$ & 0.5 & - \\
CDA 715 & $\begin{array}{l}69.5 \\
(\text { nom })\end{array}$ & $0.4-0.7$ & $\begin{array}{c}0.5 \\
(\max )\end{array}$ & - & - & $\begin{array}{c}1.0 \\
(\max )\end{array}$ & $29.0-33.0$ & $\begin{array}{c}1.0 \\
(\max )\end{array}$ \\
\hline
\end{tabular}

Table 3. Mechanical properties of the candidate materials.

(a) Austenitic materials

\begin{tabular}{lcccc}
\hline \multicolumn{1}{c}{ Alloy } & $\begin{array}{c}\text { Tensiie strength } \\
(\mathrm{min}, \mathrm{psi})\end{array}$ & $\begin{array}{c}\text { Yield strength } \\
(\mathrm{min}, \mathrm{psi})\end{array}$ & $\begin{array}{c}\text { Elongation } \\
(\mathrm{min}, \%)\end{array}$ & $\begin{array}{c}\text { Reduction of } \\
\text { area (min, \%) }\end{array}$ \\
\hline 304L (annealed) & 70,000 & 25,000 & 30 & 40 \\
316L (annealed) & 70,000 & 25,000 & 30 & 40 \\
325 (annealed) & 85,000 & 35,000 & 30 & Not spec. \\
\hline
\end{tabular}

(b) Copper-based materials

\begin{tabular}{cccc}
\hline Alloy & $\begin{array}{c}\text { Tensile strength } \\
\text { (psi) }\end{array}$ & $\begin{array}{c}Y_{\text {i }} \text { ld strength } \\
\text { (psi) }\end{array}$ & $\begin{array}{c}\text { Elongation } \\
(\%)\end{array}$ \\
\hline CDA 102 (annealed) & 34,000 & 10,000 & 45 \\
CDA 613 (annealed) & 80,000 & 40,000 & 40 \\
CDA 715 (annealed) & 55,000 & 20,000 & 45 \\
\hline
\end{tabular}


Table 4. Tentative ranking of the austenitic candidate materials for resistance to various forms of degradation. These rankings are subject to change as more data become available.

\begin{tabular}{|c|c|c|}
\hline \multirow[b]{2}{*}{ Form of degradation } & \multicolumn{2}{|c|}{ Resistance } \\
\hline & Best & Worst \\
\hline Phase instability & 825 & $304 \mathrm{~L}$ \\
\hline Effects of hydrogen & $825,316 \mathrm{~L}$ & $304 \mathrm{~L}$ \\
\hline Uniform corrosion & $825,316 \mathrm{~L}$ & $304 \mathrm{~L}$ \\
\hline Pitting corrosion & 825 & $304 \mathrm{~L}$ \\
\hline Crevice corrosion & 825 & $304 \mathrm{~L}$ \\
\hline $\mathrm{SCC}$ & 825 & $304 \mathrm{~L}$ \\
\hline Radiation-enhanced degradation & 825 & $304 \mathrm{~L}$ \\
\hline Microbiologically enhanced degradation & 825 & $304 \mathrm{~L}$ \\
\hline
\end{tabular}

Table 5. Tentative ranking of the copper-based candidate alloys for resistance to various forms of degradation. These rankings, like those in Table 4, are subject to change as more data become available.

\begin{tabular}{|c|c|c|}
\hline \multirow[b]{2}{*}{ Form of degradation } & \multicolumn{2}{|c|}{ Resistance } \\
\hline & Best & Worst \\
\hline Phase instability & 102 & 715,613 \\
\hline Effects of hydrogen & 715 & 102 \\
\hline Uniform corrosion & 613 & 102 \\
\hline Pitting corrosion & 715,102 & 613 \\
\hline Crevice corrosion & 715,613 & 102 \\
\hline Local dealloying & 102,715 & 613 \\
\hline SCC & 715 & 102,613 \\
\hline Radiation-enhanced degradation & 613,102 & 715 \\
\hline Microbiologically enhanced degradation & 102 & 715,613 \\
\hline
\end{tabular}

boiling point isotherm for a typical spent-fuel package will not be reached until after $1000 \mathrm{yr}$ following emplacement.

Aqueous conditions may occur once the container surface temperature attains the boiling point isotherm and a sufficient flux of water reaches the container surface. Water enters through fractures in the host rock and passes through or along the borehole wall, liner, and other peripheral surfaces. Afier the container tempcrature drops below the boiling point isotherm, aqueous-phase corrosion becomes possible. Some containers may be subject to a
5 -L/yr flux of ground water. The ground water near Yucca Mountain is believed to contain approximately $10 \mathrm{ppm}$ chloride, $10 \mathrm{ppm}$ nitrate, $10 \mathrm{ppm}$ dissolved oxygen, $20 \mathrm{ppm}$ sulfate, and $120 \mathrm{ppm}$ bicarbonate. Refluxing of vadose water on the hot container surface could result in the formation of concentrated electrolytes. These and other species, shown in Table 6, play important roles in the localized corrosion (LC) and SCC of the candidate materials.

Gamma radiolysis may generate hydrogen peroxide, various oxides of nitrogen, nitric acid, and nitrous acid, which may also contribute to 


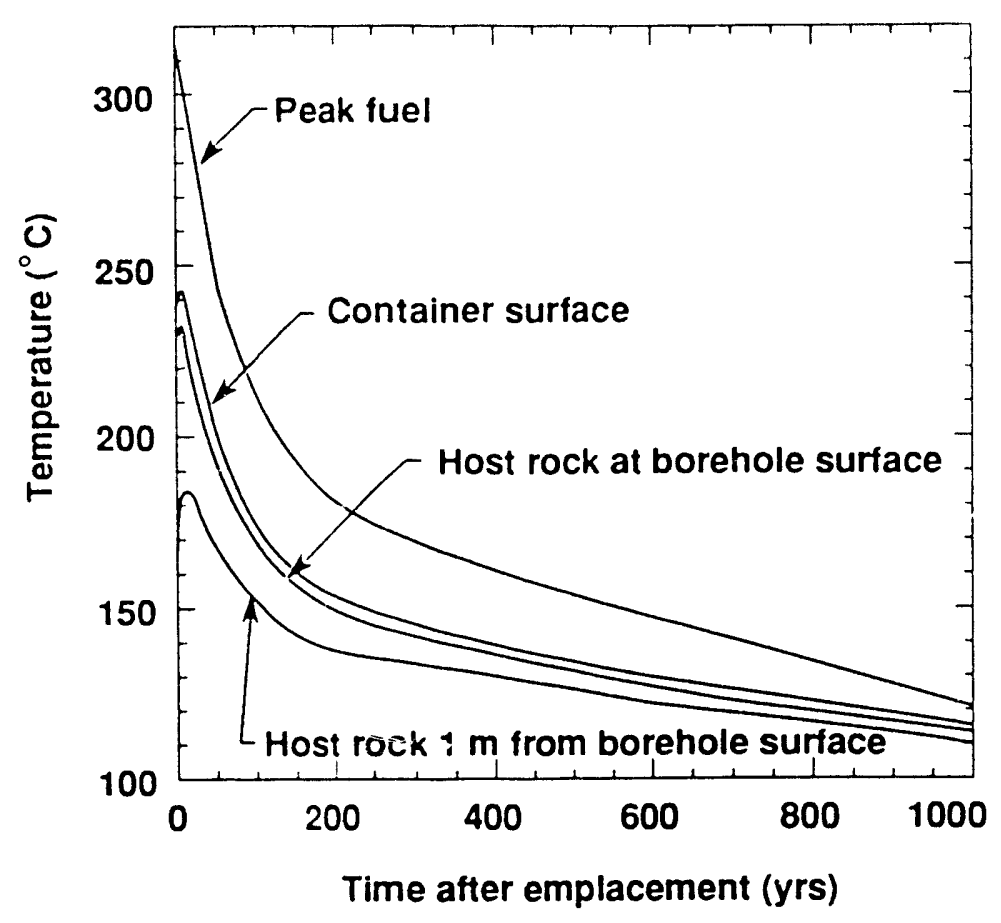

Figure 2. Calculated temperature profile for a vertical spentfuel package [8]. The spent fuel is from a pressurized water reactor; local power density is $57.0 \mathrm{~kW} / \mathrm{acre}$; aerial power density is $48.4 \mathrm{~kW} /$ acre; average package power at burial is $3.3 \mathrm{~kW}$ (10 yr out of reactur); container diameter is $0.7 \mathrm{~m}$; package diameter is $5 \mathrm{~m}$; and drift spacing $46.86 \mathrm{~m}$.

Table 6. Environmental species involved in LC and SCC of the candidate alloys.

\section{Austenitic alloys}

Promoters: $\mathrm{F}^{-}, \mathrm{Cl}^{-}, \mathrm{Br}^{-}, \mathrm{S}_{2} \mathrm{O}_{3}^{2-}$

Depolarizers: $\mathrm{O}_{2}, \mathrm{H}^{+}, \mathrm{Fe}^{3+}, \mathrm{Cu}^{2+}, \mathrm{Hg}^{2+}, \mathrm{H}_{2} \mathrm{O}_{2}, \mathrm{NO}_{2}^{-}$

Inhibitors: $\mathrm{NO}_{3}^{-} \mathrm{I}^{-}$

Copper-based alloys

Promoters of pitting: $\mathrm{S}^{2-}, \mathrm{HS}^{-}, \mathrm{HCO}_{3}^{-}, \mathrm{SO}_{4^{\prime}}^{-} \mathrm{Cl}^{-}$

Promoters of SCC: $\mathrm{NH}_{3}, \mathrm{NO}_{2}^{-}$

Depolarizers: $\mathrm{O}_{2}, \mathrm{H}^{+}, \mathrm{Fe}^{3+}, \mathrm{H}_{2} \mathrm{O}_{2}, \mathrm{NO}_{2}^{-}$ 
container corrosion [9]. Several of these possible species are listed in Table 7. Note that nitrous acid, $\mathrm{HNO}_{2}$, could serve as a source of nitrite and hydrogen ions, both of which promote SCC in copper.

The overall corrosion model for the metal container will consist of several integrated submodels. Figure 3 shows the submodels for vaporphase corrosion (first $1000 \mathrm{yr}$ ), and Fig. 4 for aqueous-phase corrosion. In the case of vaporphase corrosion, information on the environment, properties of materials, and mechanical forces acting on the containers are input to models of mechanical failure, uniform oxidation, and SCC. In the case of containers exposed to aqueous environments, the above information is input to models of mechanical failure, uniform corrosion, LC, and SCC.

Models of pitting and SCC can be categorized as either initiation models or propagation models. Initiation models are more important than propagation models on the time scales of interest to repository designers. Most of the models discussed here are applicable to worst-case scenarios in which a concentrated electrolyte contacts the container surface.

Table 7. Anticipated products of gamma radiolysis in aqueous solutions.

Temperature Products

\begin{tabular}{ll}
\hline Above boiling point & $\mathrm{HN}_{3}, \mathrm{~N}_{2} \mathrm{O}_{4}, \mathrm{NO}_{2}, \mathrm{~N}_{2} \mathrm{O}$ or $\mathrm{NO}, \mathrm{O}_{3}$. No $\mathrm{NH}_{3}$ is formed in the presence of $\mathrm{O}_{2}$. \\
Below boiling point & $\mathrm{HNO}_{3}$ and $\mathrm{HNO}_{2}$ in moisture film. $\mathrm{H}_{2} \mathrm{O}_{2}$ forms but is catalytically \\
& decomposed on $\mathrm{Cu}$ surface.
\end{tabular}

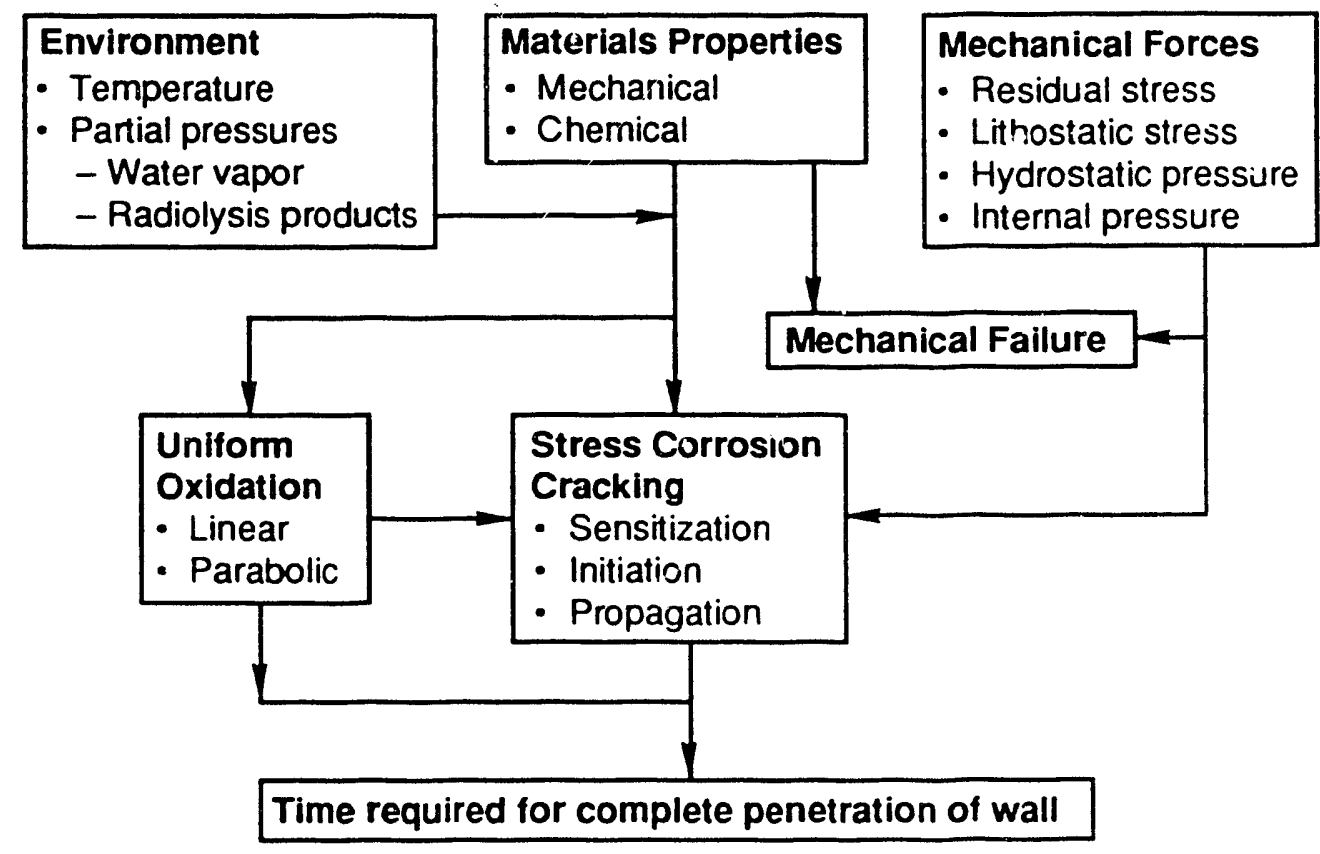

Figure 3. Schematic of the integrated submodels for vapor-phase corrosion of the containers. 


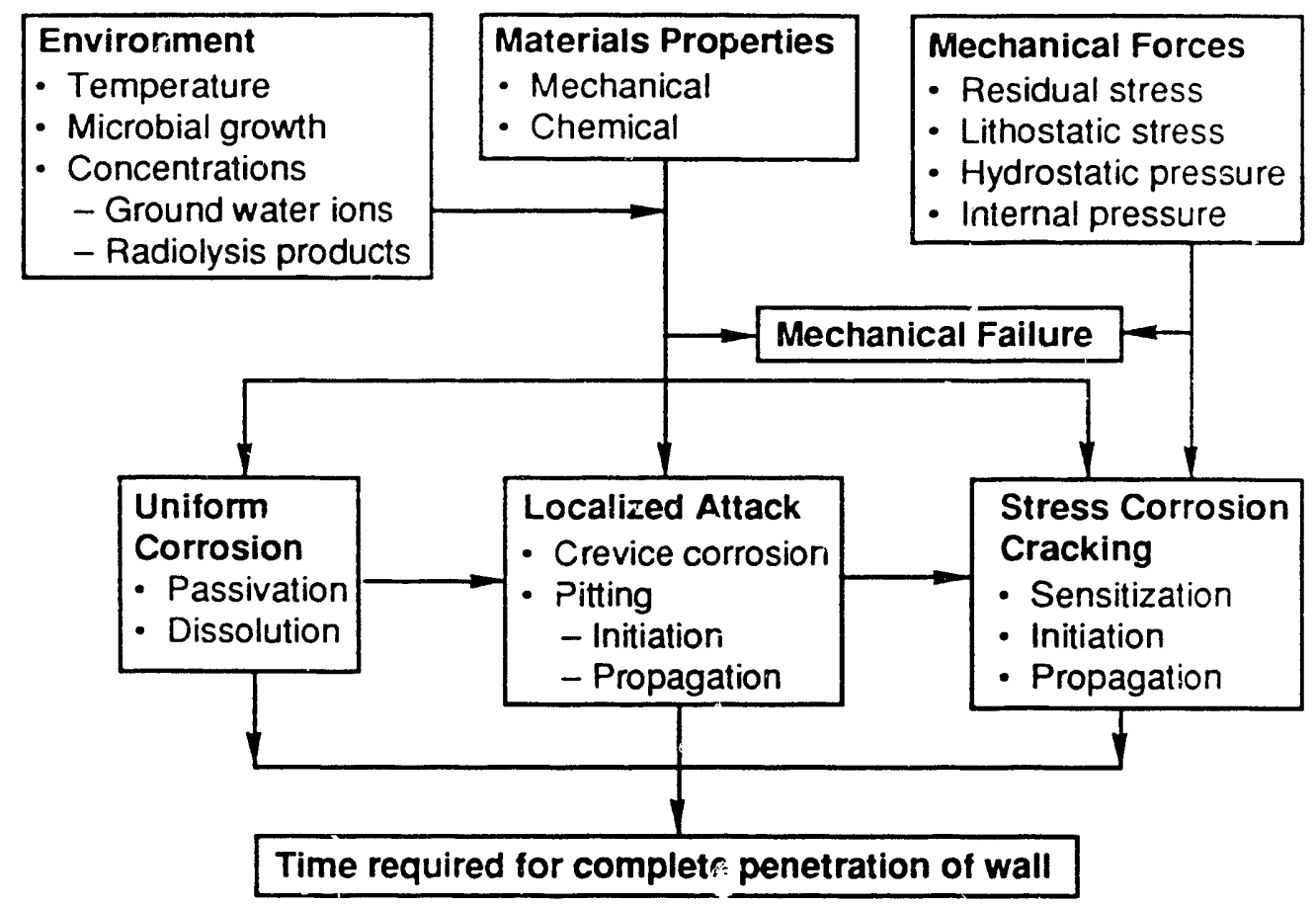

Figure 4. Schematic of the integrated submodels for aqueous-phase corrosion of the containers.

\section{Vapor-Phase Corrosion}

Experimental data on corrosion rates generated at Lawre nce Livermore National Laboratory (LLNL) are shown in Fig. 5. These data indicate that the lives of containers made of austenitic alloys will not be limited by uniform oxidation in wet air and saturated steam at elevated temperatures [10]. For example, only $1 \%$ of a $1-\mathrm{cm}$-thick austenitic container wall will bo oxidized after a 1000 -yr exposure to saturated steam at $100^{\circ} \mathrm{C}$, assuming a linear rate of oxide growth (worst-case scenario). The lives of containers made of copper-based alloys, however, may be limited by uniform oxidation under similar zonditions, as illustrated in Fig. 6 [10]. As much as $60 \%$ of a cuprenickel container wall could be oxidized during a 1000-yz exposure to wet air at $95^{\circ} \mathrm{C}$. As discussed by Gdowski and Bullen [11], several models have been used to predict rates of oxidation of copper and other alloys. These rate laws arc categorized as linear [Eq. (1)], parabolic [Eq. (2)], cubic [Eq. (3)], inverse

$$
\begin{aligned}
& m^{1}=k_{1} t \\
& m^{2}=k_{2} t \\
& m^{3}=k_{3} t \\
& m^{-1}=k_{4} \log \left(t / \tau_{1}+1\right) \\
& m^{+1}=k_{5} \log \left(t / \tau_{2}+1\right)
\end{aligned}
$$

where $m$ is the oxide thickness, $t$ is time, and $\tau_{1}$ and $\tau_{2}$ are constants having the units of time. The rate constants, $k_{i}$, are known to have an Arrhenius dependence on temperature:

$k_{i}=A_{i} \exp \left(E_{i} / R T\right)$

where $A_{i}$ is a preexponential constant and $E_{i}$ is activation energy. Typically, oxide growth obeys the parabolic rate law if oxidation is limited by the diffusion of cations or anions through the oxide film and if the oxide is completely adherent 


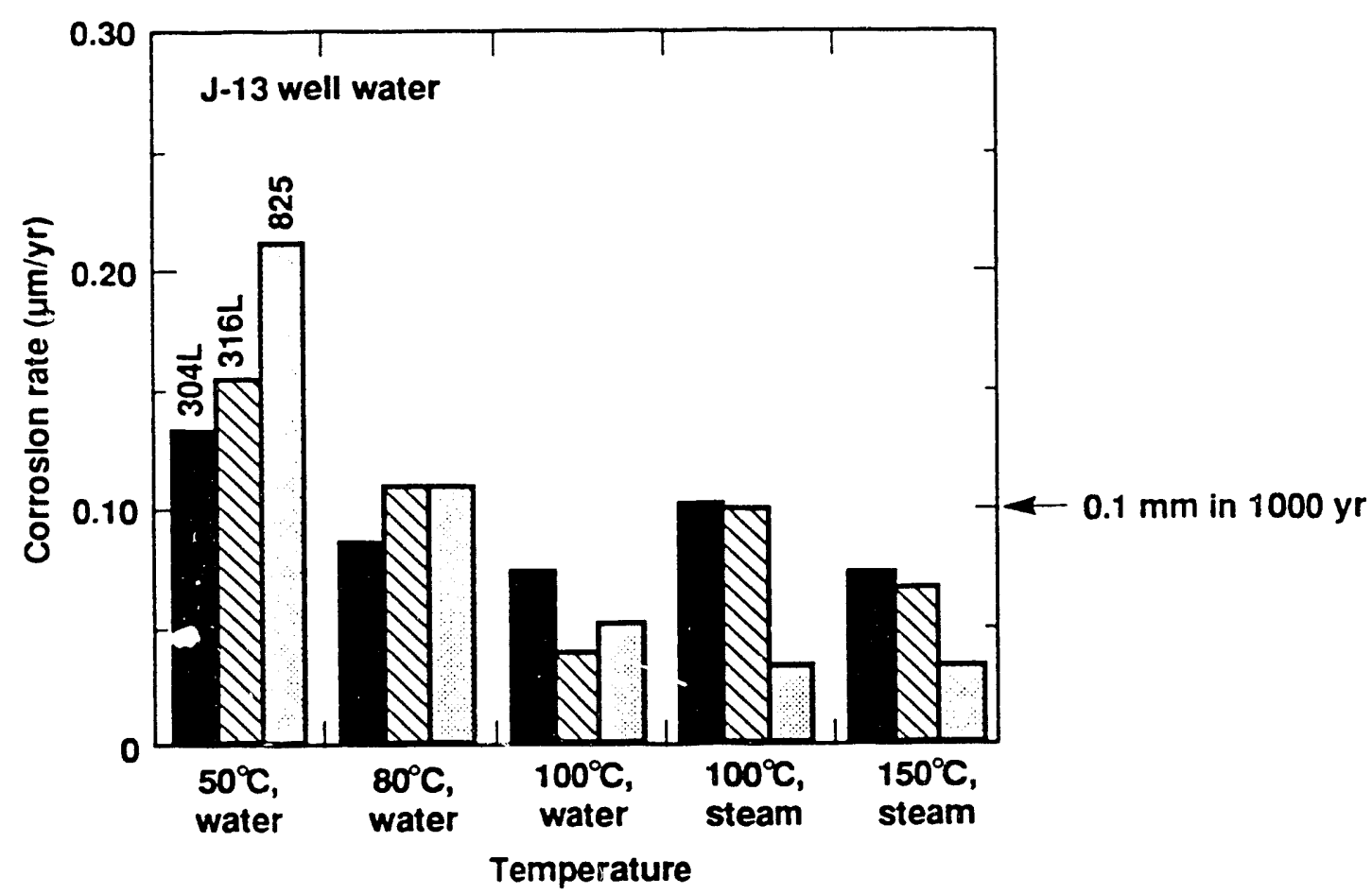

Figure 5. Corrosion rates of the austenitic candidate materials. These data, obtained from experiment, show that uniform oxidation and corrosion of the austenitic candidates will not limit container life [10].

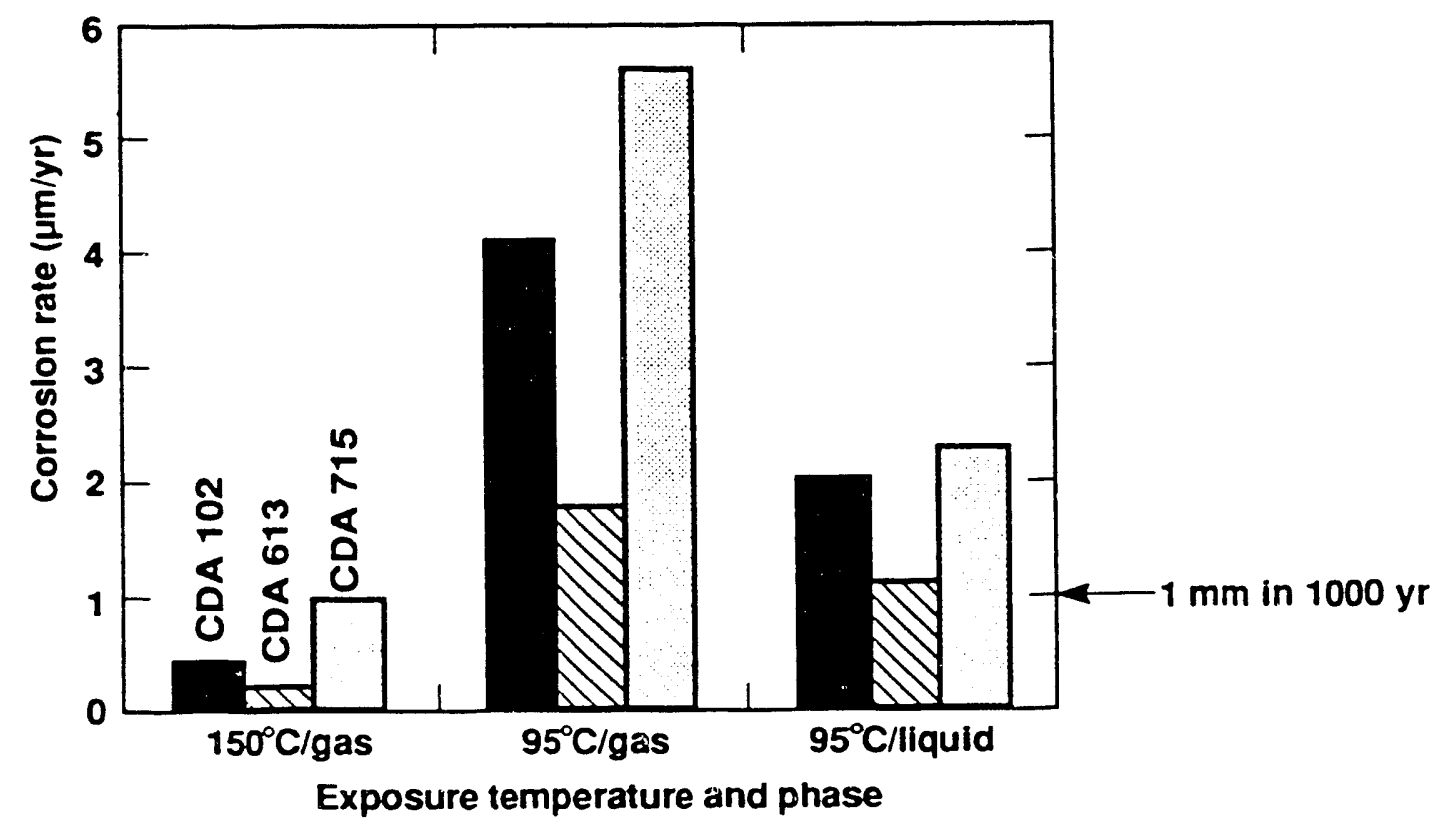

Figure 6. Corrosion rates of the copper-based candidate materials. Uniform oxidation and corrosion of these materials may limit container life [10]. 
and protective. If spawling of the oxide occurs, the overall rate of oxidation may appear to be linear.

SCC of several of the candidate materials has been observed in vapor-phase environments. The mechanisms involved in initiation and propagation of stress-corrosion cracks in these environ- inents may be analogous to the mechanisms operating in aqueous-phase environments. Such models will be discussed briefly in a subsequent section. In order to apply these models to vaporphase attacks, rates of spontaneous oxidation [Eq. (1) or (2)] would be substituted for rates of anodic oxidation at the crack tip.

\section{Aqueous-Phase Corrosion}

In the presence of an aqueous phase containing dissolved halide ions, oxygen, and other species, rates of LC are more likely to limit container life than rates of uniform oxidation or dissolution. Rates of uniform oxidation and dissolution in water and dilute solutions are typically orders of magnitude less than rates of pit propagation. For example, in a slightly acidic solution containing 100 ppm chloride, a pit could penetrate the wall of a container made of Alloy 825 in approximately $20 \mathrm{yr}$, provided the rate of propagation remained constant. Figure 7 show's data supporting this conclusion. Consequently, modeling of degradation under these circumstances should emphasize LC such as pitting.

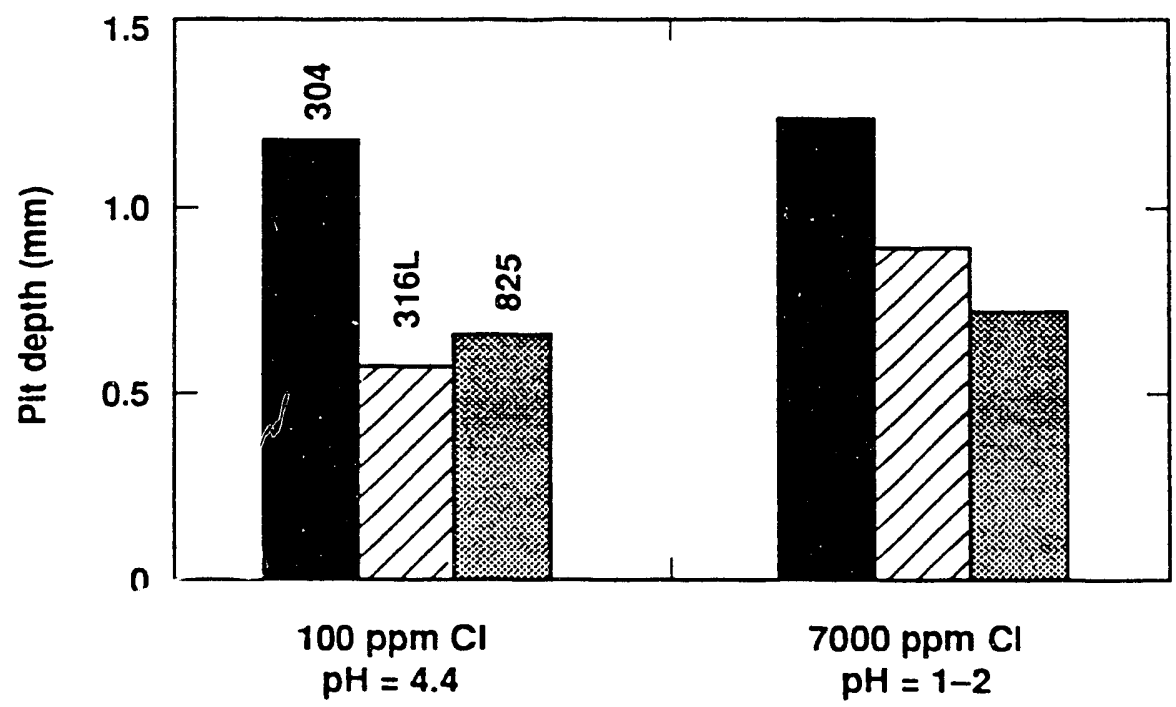

Figure 7. Pit penetration of the austenitic candidate materiais after 6 months of exposure [126]. In the environments specified, a pit ccald penetrate the wall of a $1-\mathrm{cm}$-thick container of Alloy 825 in about $20 \mathrm{yr}$. 


\section{LC and SCC of Austenitic Alloys}

\subsection{Background}

Penctration rates at local sites of corrosive attack are expected to be far more serious threats to container life than rates due to uniform atmospheric and aqueous phase corrosion. Ionic and molecular species present in aqueous environments (water and moisture films) can serve as promoters, depolarizers, or inhibitors of LC and SCC in austenitic materials [12, 13]. For example, $\mathrm{F}^{-}, \mathrm{Cl}^{-}, \mathrm{Br}^{-}$, and $\mathrm{S}_{2} \mathrm{O}_{3}^{2-}$ can induce localized breakdown of passive films, thereby initiating pit formation; such species are known as promoters.

Frequently, SCC initiates at pits. Anodic dissolution at the bases of pits and at crack tips can be enhanced by a number of depolarizers, including $\mathrm{O}_{2} \mathrm{H}^{+}, \mathrm{Fe}^{3+}, \mathrm{Cu}^{2+}$, and $\mathrm{Hg}^{2+}$. The cathodic reduction of depolarizers on surfaces outside of crevices, pits, and cracks can galvanically couple with anodic dissolution and oxidation processes that occur inside pits. In contrast to $\mathrm{Cl}^{-}$, ions such as $\mathrm{NO}_{3}, \mathrm{i}^{-}$, and acetate are known inhibitors of pitting and SCC of austenitic stainless steels. These inhibitors compete with halide ions for adsorption sites on the metal oxide film and base metal. In alkaline media, $\mathrm{OH}^{-}, \mathrm{H}^{+}$, and $\mathrm{PO}_{4}^{-}$can serve as promoter, depolarizer, and buffer, respectively.

A second factor required for SCC is mechanical stress. The stresses required are small, usually below the engineering yield stress, and are tensile in nature. The stresses can be externally applied, but residual stresses often cause SCC failures. A common misconception is that SCC is the result of stress concentration at corrosion-generated surface flaws (as quantified by the stress intensity factoi, $K$ ), and that when a critical stress intensity factor, $K_{\text {crit }}$ is reached, mechanical fracture results. Although stress concentration does occur at such flaws, it does not exceed the critical value required to cause mechanical fracture of the material in an inert environment $\left(K_{\mathrm{ISCC}}<K_{\text {crit }}\right)$.

\subsection{Initiation of Pits}

It is important to understand the dependence of pitting on various environmental conditions such as chloride concentration, $\mathrm{pH}$, and temperature. Models of pitting phenomena fall into two broad classes: initiation and propagation. Pit initiation models enable us to predict the effects of environment on quantities such as the critical pitting potential and induction time $[14,15]$. Once a pit is initiated, it is necessary to calculate the rate of propagation (penctration). Mass transport models enable us to calculate quantities such as $\mathrm{pH}$ inside the growing pit and the growth rate. The application of stochastic probability theory has made it possible to account for observed variances in critical pitting potential [16]. The rate of pitting can be determined from logarithmic plots of survival probability as a function of time. Statistical metheds have also been employed to estimate the distribution of pit depths [17]. Unfortunately, the limited scope of this paper precludes detailed coverage of these important topics.

\subsubsection{Halide Nuclei Theory}

Okada assumes that pit initiation on a stainless steel begins with the formation of a hemispherica! halide nucleus on the passive oxide film $[14,15]$. If the nucleus is stable and grows continuously, it will eventually breach the protective oxide. After dissolution of the metal halide, the underlying metal is exposed and undergoes rapid corrosive attack. This mechanism is illustrated in Fig. 8. The following reactions are assumed to $o c-$ cur at the interface between the halide nucleus and the passive oxide:

$$
\begin{aligned}
& \left.\mathrm{M}^{z+}(\text { oxide })+z \mathrm{X}-(\text { halide }) \rightarrow \mathrm{MX}_{z} \text { (halide }\right) \\
& \left.\left.\mathrm{O}^{2-} \text { (oxide }\right)+2 \mathrm{H}^{+}(\text {halide }) \rightarrow \mathrm{H}_{2} \mathrm{O} \text { (halide }\right)
\end{aligned}
$$

At the interface between the metal halide and the solution, these reactions are assumed:

$$
\begin{aligned}
& \mathrm{M}^{\mathrm{z}+} \text { (halide) } \rightarrow \mathrm{M}^{\mathrm{z}+} \text { (solution) } \\
& \mathrm{X}^{-} \text {(solution) } \rightarrow \mathrm{X}^{-} \text {(halide) }
\end{aligned}
$$

Okada has used two independent approaches to derive the same expressions for the critical pitting potential, $E_{C}$ the induction time, $\tau$, and the critical size for a stable halide nucleus, $r^{*}$. Note that the critical pitting potential is a linear function of the logarithm of the halide ion concentration, $\ln \left[\mathrm{X}^{-}\right]$:

$$
E_{\mathrm{C}}=\mathrm{constant}-(R T / \zeta F) \ln \left[\mathrm{X}^{-}\right]
$$



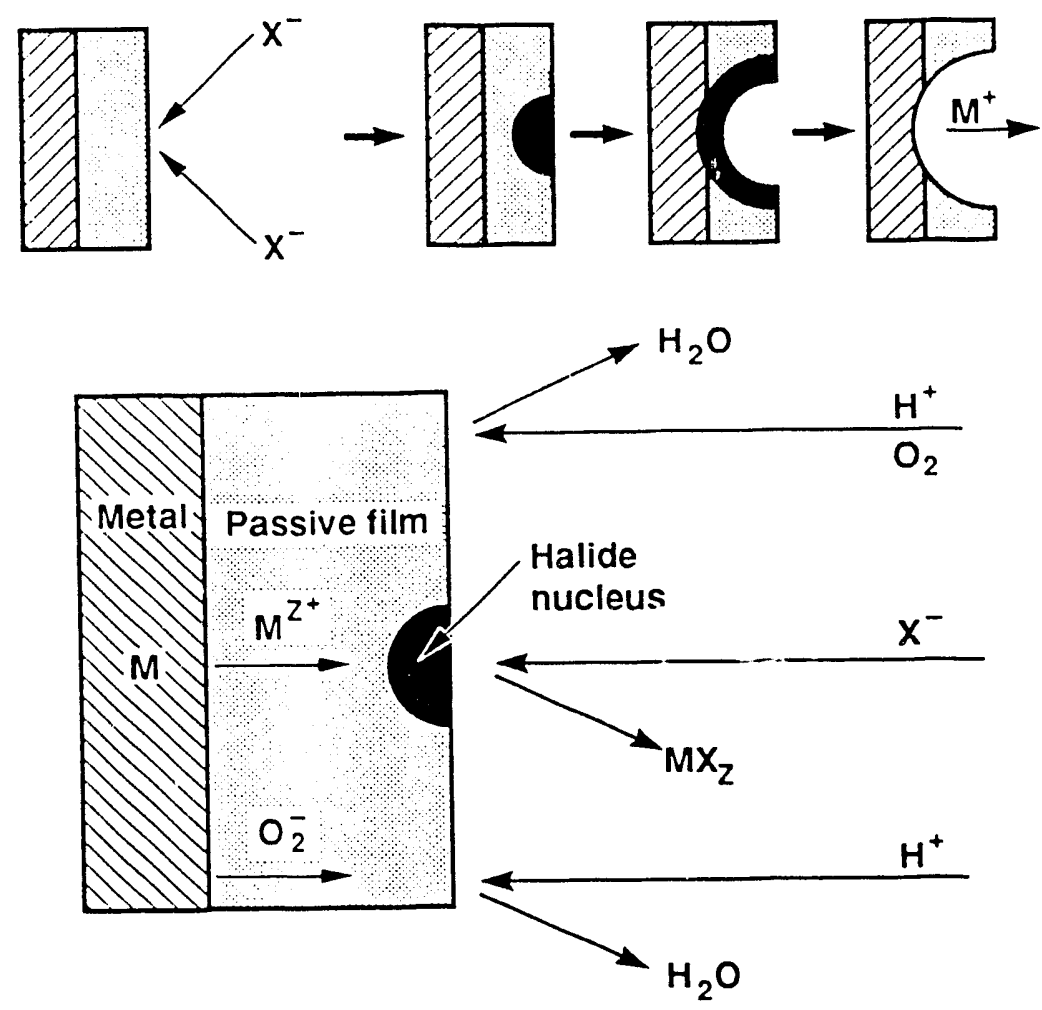

Figure 8. Okada's model for pit initiation assumes that pitting begins with the formation of a soluble halide nucleus on the passive film $[14,15]$.

where $R$ is the universal gas constant, $T$ is the absolute temperature, $\zeta$ is a constant, and $F$ is Faraday's constant. This relationship between the critical pitting potential and halide ion concentration is consistent with the experimental results of several research groups [18-20]. For example, variations of the pitting potential for Type 316 stainless steel in cellulose bleach solutions at $50^{\circ} \mathrm{C}$ have been correlated with chloride concentration, temperature, and $\mathrm{pH}$, as shown in Fig. 9 and Eq. (12) [20]. Note that the pitting potential calculated by Eq. (12) has the units of $\mathrm{mV}$, SCE:

$$
\begin{aligned}
E_{\mathrm{c}}=2570-5.81 T+0.07 T & \cdot \mathrm{pH} \\
& -0.49 T \cdot \log \left[\mathrm{Cl}^{-}\right]
\end{aligned}
$$

The induction time, $\tau$, is a function of both the halide ion concentration and the electrochemical potential, $E$ :

$$
\ln (\tau)=\text { constant }-2 n \cdot \ln \left[X^{-}\right]-(2 \zeta F E / R T)
$$

where $n$ is the valence of the metal cation. Note that Eq. (13) implies that the induction time increases exponentially as the chloride concentration decreases. As noted above, Okada has used two independent approaches to derive these expressions for the critical pitking potential and the induction time for pit initiation. The first ap-. proach begins with the general evolution criterion proposed by Glansdorff and Prigogine for irreversible thermodynamics [14]. The second approach assumes that small, localized anodic perturbations in the electrochemical potential are sufficient to nucleate patches of metal halide on the oxide film [15]. At relatively anodic potentials, the halide is more stable than the oxide.

Though the dependence of pitting potential on chloride, $\mathrm{pH}$, and temperature has been determined for Type 316 stainless steel, similar correlations have not been established for Types 304L and 316L stainless steels, Alloy 825, or the copper-based alloys. Correlations of induction time with potential, chloride, $\mathrm{pH}$, and temperature have not been established but are needed. 


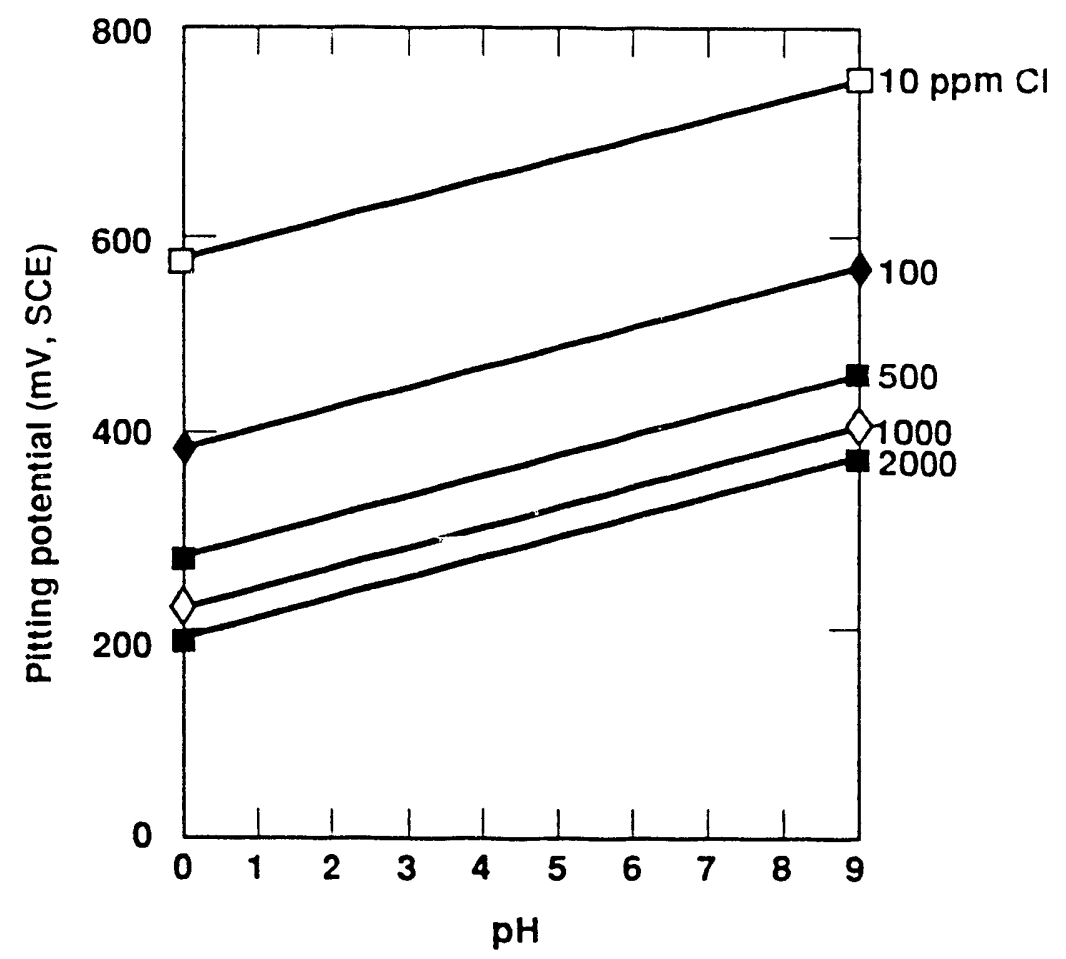

Figure 9. Variation of pitting potential of Type 316 stainless steel in cellulose bleach solution at $50^{\circ} \mathrm{C}$ [20]. This correlation, obtained by Matamata [20], is in perfect agreement with the theories of Okada and others $[14,15]$.

Such data will be crucial in corrosion models that will be used to predict container life.

The functional form of Eqs. (11) and (12) makes it possible to use factorial-designed experiments to determine the adjustable pirameters in the following expression with a minimum number of experiments:

$$
\begin{aligned}
& E_{\mathrm{c}}=a_{0}+a_{1} \ln \left[\mathrm{Cl}^{-}\right]+a_{2} \mathrm{pH}+a_{3} T \\
&+a_{12} \ln \left[\mathrm{Cl}^{-}\right] \cdot \mathrm{pH}+a_{13} \ln \left[\mathrm{Cl}^{-}\right] \cdot T+a_{23} \mathrm{pH} \cdot T \\
&+a_{123} \ln \left[\mathrm{Cl}^{-}\right] \cdot \mathrm{pH} \cdot T
\end{aligned}
$$

Note that Eq. (it) includes two-factor interactions known to be important. The measured responses in such a design are the $c$, rrosion, pitting, and repassivation potentials. This experimental strategy enables experime' ters to easily calculate the confidence intervals of parameters.

\subsubsection{Point Defect Model}

Equations having the same functional form as Eqs. (11) and (12) have been derived from the point defect model of pit initiation by Chao ei al. [21]. These investigators assume that oxyger. anions diffuse from the solution-film interface to the film-metal interface and result in continuous growth of the oxide film (Fig. 10). Metal cations are assumed to move in the opposite direction and undergo dissolution at the film-solution interface. Vacancies (metal holes) are believed to accumulate at the metal-film interface when the rate of vacancy generation exceeds the rate of submergence in the bulk oxide. Eventually, a void forms from a condensation of vacancies at the metal-film interface. The passive film collapses when the void grows to sufficient size.

In a similar fashion, factorial-designed experiments can also be used to determine the dependence of the incubation time on chloride, $\mathrm{pH}$, temperature, and potential. However, the design is slightly more complicated since there is an additional adjustable parameter, electrochemical potential.

\subsubsection{Electrostriction Model}

According to Sato [22], breakdown of the passive film may be due to electrostriction 


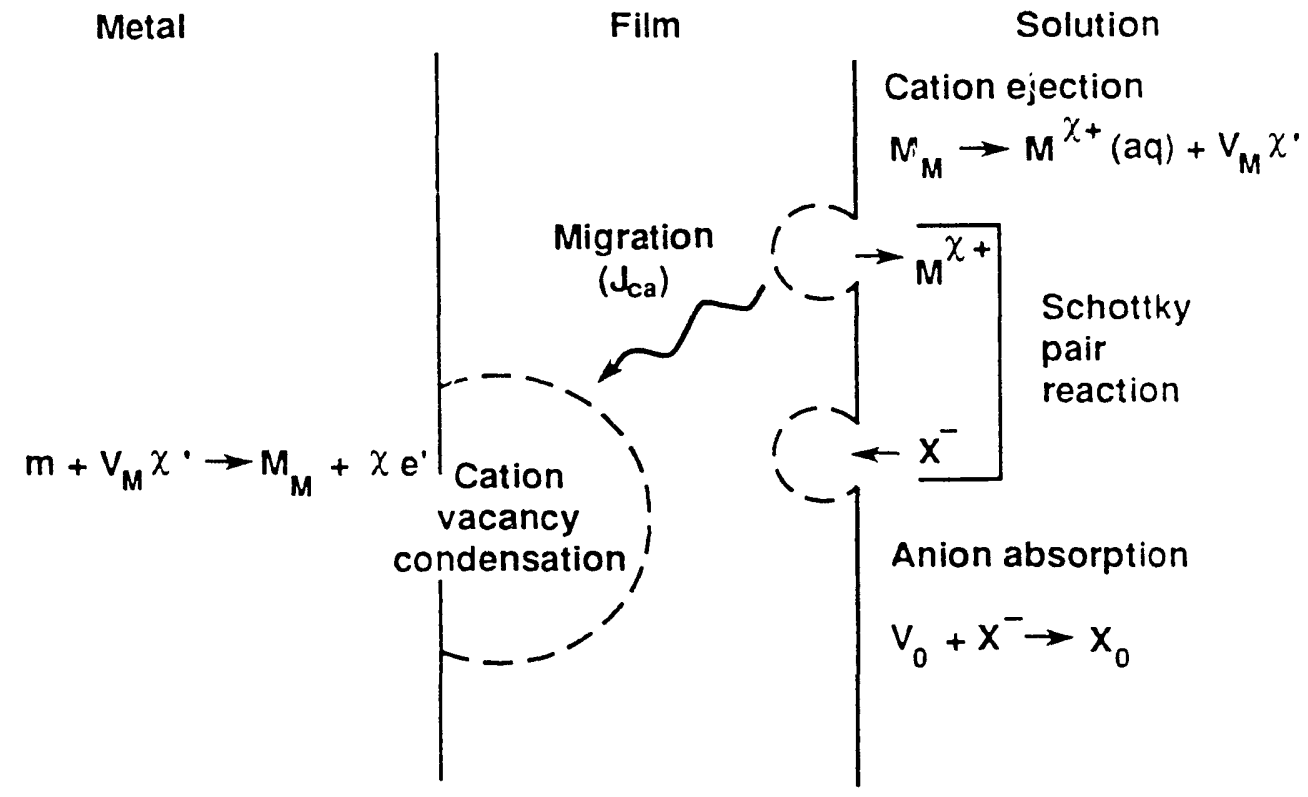

Figure 10. The point-defect model developed by Chao et al. [21] assumes that localized failure of the passive film is due to the condensation of cation vacancies at the metal/oxide-film interface. $M_{M}$ is a metal cation in a cation site, $\mathrm{M}^{\chi^{+}}$is an aqueous metal cation, $V_{M} \chi^{\prime}$ is a cation vacancy in the passive film, $X_{0}$ is the halide in an anion site, $X^{-}$is an aqueous halide anion, $V_{0}$ is an anion vacancy in the passive film, $m$ is the metal atom introduced into the passive film at the metal/film interface, and $J_{c a}$ is the diffusion flux of cation vacancies in the passive film.

pressure. The mechanical stress due to the electrostriction pressure is assumed to cause film rupture. This pressure can be calculated from Eq. (15):

$p-p_{0}=\varepsilon(\varepsilon-1) \cdot E^{2} / 8 \pi-\gamma / L$

where $p$ is the electrostriction pressure in the film, $p_{0}$ is the atmospheric pressure, $\varepsilon$ is the dielectric constant of the film, $E$ is the electric field, $\gamma$ is the surface tension, and $L$ is the thickness of the passive film. The first term on the right-hand side of the equation represents the electrostrictional effect, and the second the interfacial tension effect. According to Szklarska-Smialowska [23], electrostriction pressures from 10 to $100 \mathrm{~kg} / \mathrm{cm}^{2}$ are possible, which are sufficient for plastic deformation and breaking of the oxide film.

As discussed by Szklarska-Smialow'ska, Sato has also developed an electrocapillary breakdown model. Unfortunately, an explicit expression for the incubation time is not presented by Sato in either of his models. Furthermore, the dependence of the critical pitting potential on chloride concentration, $\mathrm{pH}$, and temperature is not obvious. Therefore, the results of the point defect and halide nuclei models appear to be more useful in the prediction of container life.

\subsubsection{Inclusions Model}

Pits can also nucleate at inclusions in the alloy surface. Manning et al. published a study in $198 \mathrm{~J}$ which determined the effects of sulfideinclusion morphology and composition; matrix; and environmental variables such as $\mathrm{pH}$, temperature, and $\mathrm{NaCl}$ concentration on resistance to pit initiation [24]. Pitting corrosion tests were performed on Types 304L, 316, and 316L stainless steels. The morphology of sulfide inclusions was altered with high-temperature heat treatments. 


\subsection{Propagation of Pits}

As discussed in Sec. 4.2, a pit can initiate at various types of sites on the passive film. Such sites include halide nuclei, voids, and sulfide inclusions. After the initial breakdown of the passive film, the pit may continue to grow. Several models of pit growth (propagation) have been developed. For example, in 1972 Pickering and Frankenthal [25] developed a mass transport model which assumes that the base of the pit is completely active (Fig. 11). Galvele extended the Pickering-Frankenthal model to include cases in which metal hydrolysis reactions occur at the base of the pit [26]. In contrast, 3eck and Alkire have developed a mass transport model for pit growth which assumes that the base of the pit is covered by a very resistive salt film [27]. Pit growth is limited by the film (Fig. 12).

\subsubsection{Pit Growth with an Active Surfac'e at the Base of the Pit}

The model of Pickering and Frankenthal assumes that the pit has an active metal surface at its base [25]. The pit envisioned in their model has insulated cylindrical walls and a conductive planar cap at the base (Fig. 11). They assume quasi-steady-state conditior.s and solve the

(a)

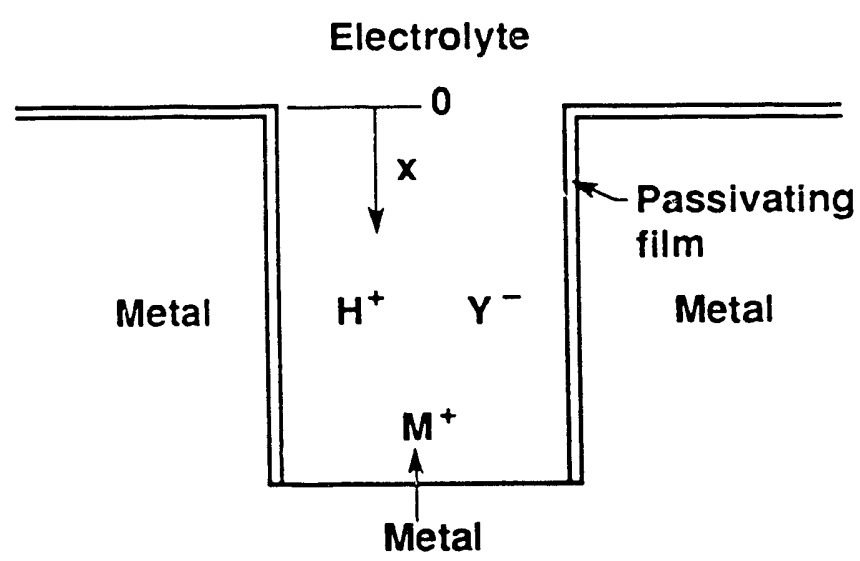

(b)

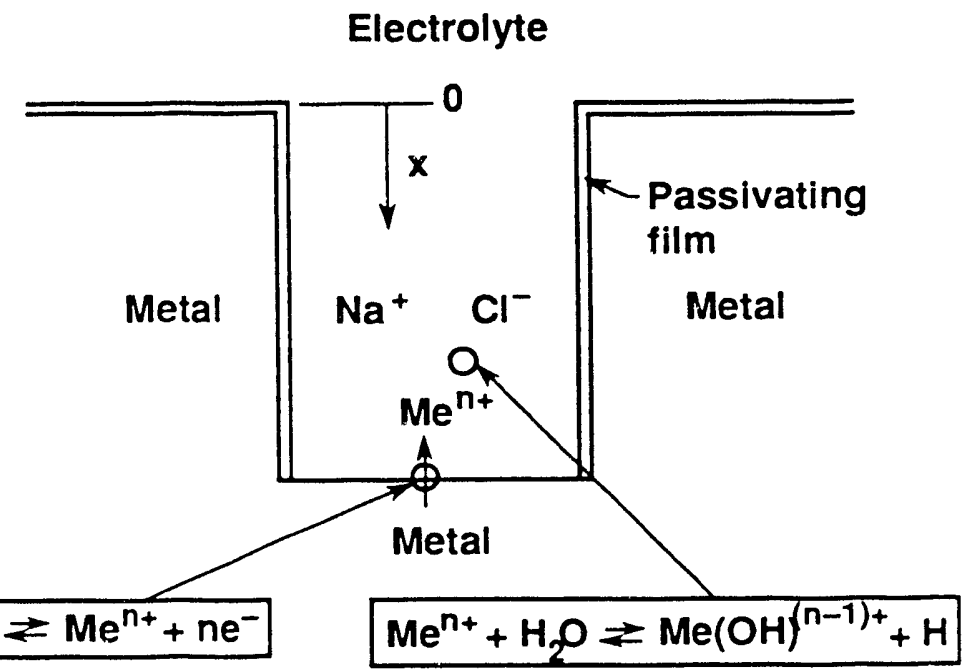

Figure 11. (a) The Pickering-Frankenthal model for propagation of a pit with an active metal base [28]. (b) The Galvele modification of the Pickering-Frankenthal model takes into account hydrolysis and suppression of the $\mathrm{pH}$ [26]. Both models assume quasi-steady-state conditions. 


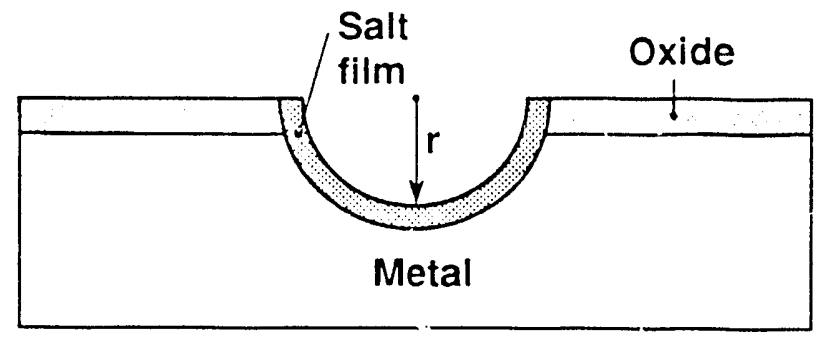

Figure 12. The Beck-Alkire nodel assumes that the surface of the hemispher cal pit is covered by a highiy resistive salt film [27]. This is a transient-mass-transport moc el.

Nernst-Einstein equation to detc:mine the onedimensional concentration and potential profiles inside the pit. Recall that the Nernst-Einstein equation defines the dependence of the ionic flux. on diffusivity and ionic mobility. Concentrations of halide anion, lydrogen cation, and metal cation as functions of the parameter $i_{M} x$ are given by Eqs. (16) through (18), respectively.

$C_{(Y)}=C^{0}+\left(i_{\left.M^{x} / 2 D_{\left(M^{+}\right)} F\right)}\right.$

$C_{\left(\mathrm{H}^{+}\right)}=\frac{2 D_{\left(\mathrm{M}^{+}\right)} F \cdot C^{2}}{2 D_{\left(\mathrm{M}^{+}\right)} \cdot C^{\circ}+i_{\mathrm{M}^{x}}}$

$C_{\left(M^{+}\right)}=\frac{4 D_{\left(M^{+}\right)} F \cdot C^{0} \cdot i_{M} x+\left(i_{M} x\right)^{2}}{2 D_{\left(M^{+}\right)} F\left(2 D_{\left(M^{+}\right)} F \cdot C^{o}+i_{M} x\right)}$

The ciimensionless potential, $F \Phi / R T$, where $\Phi$ is the electrical potential, is given in Eq. (19) as a function of the parameter $i_{M} x$ :

$F \Phi / R T=\ln \left[1+\left(i_{\mathrm{M}} x / 2 D_{\left(\mathrm{M}^{+}\right)} F \cdot C^{\circ}\right)\right]$

where $x$ is the distance from the mouth of the pit towards the base of the pit, $i_{M}$ is the current density at the base of the pit, $\mathrm{C}^{\circ}$ is the salt concentration in the bulk electrolyte outside of the pit, and $D_{\left(M_{+}\right)}$is the diffusivity of the metal cation in the electrolyte. $F, R$, and $T$ are Faraday's constant, the universal gas constant, and absolute temperature, respectively. Calculations based upon this model indicate that the concentrations of both metal cations and halide anions increase with increasing values of $i_{M} x$. The maximum concentration of these species is found at the base of the pit $(x=X)$. In contrast, the concentration of hydrogen cations is greatest at the mouth of the pit $(x=0)$ and has a value identical to that of the bulk electrolyte.
During pit growth, the total ionic concentration inside the pit is greater than that of the bulk electrolyte outside the pit. The potential gradient is such that the potential becomes more ano dic near the base of the pit.

In 1976 Galvele modified the PickeringFrankenthal model to include the effects of metal hydrolysis reactions on $\mathrm{pH}$ at the base of the pit (Fig. 11) [26]. Recall that the PickeringFrankenthal modol predicts that the concentration of hydrogen cations dec eases inside the pit during pit growth [25]. In other words, one would expect an increase in $\mathrm{pH}$ inside the pit. Unfortunately, Pickering and Frankenthal assumed that simple anodic dissolution of the aciive metal surface $\left(\mathrm{M} \rightarrow \mathrm{M}^{n+}+n \mathrm{e}^{-}\right)$was the only chemical reaction occurring at the base of the pit. Galvele's modification includes the following hydrolysis reaction:

$\mathrm{M}^{n+}+\mathrm{H}_{2} \mathrm{O} \leftrightarrow \mathrm{M}(\mathrm{OH})^{(n-1)^{+}}+\mathrm{H}^{+}$

By including this effect, Galvele has shown that significant $\mathrm{pH}$ suppression can occur inside the pit. A trend opposite to that predicted by the Pickering-Frankenthal model is predicted.

Galvele [26] points out that suppression of $\mathrm{pH}$ at the base of a pit to some critical level can prevent passivation. His arguments related to passive film stability are based on Pourbaix diagrams. Galvele gives evidence indicating that the current density during pit growth, $i_{\mathrm{M}}$, is approximately $1 \mathrm{~A} / \mathrm{cm}^{2}$, which is unusually high. His theory predicts $\mathrm{pH}$ suppression inside pits to critical levels for depths as small as $100 \AA$ $\left(X=10^{-6} \mathrm{~cm}\right)$, which is approximately the thickness of the passive film. A crack in the passivating oxide film would give a diffusion path long enough to reach the critical $\mathrm{pH}$.

Galvele [26] developed an expression for the critical pitting potential as a function of halide ion concentration from his expression for the potential profile, which is given as Eq. (21):

$$
\begin{aligned}
i_{\mathrm{M}^{\lambda}}=C^{0} \cdot D_{\left(\mathrm{M}^{+}\right)} F[(n+1) \exp (+F \Phi / R T) \\
+(n-1) \exp (-F \Phi / R T)-2 n]
\end{aligned}
$$

If the value of $i_{M} x$ is known, this expression can be used to evaluate the electrical potential, $\Phi$, under the experimental conditions of a pitting potential measurement. Assume that the parameter $i_{\mathrm{M}} x$ is kept constant while two pitting potential 
measurements, $\Phi_{1}$ and $\Phi_{11}$, are made at salt concentrations $\mathrm{C}_{1}$ and $\mathrm{C}_{\mathrm{ll}}$, respectively. The following proportionality is found:

$C_{1}^{o_{1}} \exp \left(F \Phi_{1} / R T\right)=C_{1 !} \exp \left(F \Phi_{I I} / R T\right)$

Equation (23) is obtained from Eq. (22) by taking logarithms:

$\Phi_{1}-\Phi_{1 I}=$ constant $-(R T / F) \ln \left(C^{\circ}{ }_{1}\right)$

This expression gives the change of electrical potential inside the pit when the pitting potential is measured as a function of the salt $(\mathrm{NaCl}$, for example) concentration. This electrical potential should be subtracted from the measured pitting potential value to get the real pitting potential. The parameter $\Phi_{1}-\Phi_{I I}$ is analogous to $E_{C}$. Note the similarity of Eqs. (11), (12), and (23) in terms of dependence on salt concentration.

Though the Pickering-Frankenthal model and the Galvele modification of that model allow us to understand variations of ion concentrations inside growing pits, an explicit expression for the pit depth as a function of time is not derived. In fact, the concentrations are expressed as functions of the confounded parameter $i_{M} x$. Consequently, such an approach to pit modeling is of very little use in predicting the life of high-level radioactivewaste containers in environments that may cause pitting. The penetration rate is proportional to $i_{\mathrm{M}}$ and was assigned assumed values by these authors.

\subsubsection{Pit Growth Limited by Salt Film}

Beck and Alkire have developed a simple mass transport model for the growth of hemispherical pits [27]. They assume that the initiation of pits on the surface of a passive metal occurs at flaws in the protective oxide film. Such a flaw could be either a halide nucleus generated by the mechanism proposed by Okada $[14,15]$ or a void generated by the point defect mechanism proposed by Chao ct al. [21]. These flaws have approximately the same dimension as the passive film thickness. Consequently, the local current density in a pit during the initial stages of growth is exceedingly high. Recall that Galvele presented evidence for local current densities as high as $1 \mathrm{~A} / \mathrm{cm}^{2}$. A salt film is likely to form on the inner concave surface of the hemispherical pit at such high current densities. The growth rate of a hemispherical pit (Fig. 12) in which the corrosion current is controlled by the rate of dissolution of a metal salt film is governed by Eq. (24):

$$
J=D\left(C_{s}-C_{b}\right)(1 / r+1 / \sqrt{\pi D t})
$$

where $/$ is the diffusional flux, $D$ is the diffusivity of the salt in the electrolyte, $C_{s}$ is the saturation concentration of metal salt in the electrolvte, $C_{b}$ is the concentration of metal salt in the bulk electrolyte, $r$ is the radius of the pit, and $\tau$ is the time (not the same quantity as the induction time discussed above). The term $1 / \sqrt{\pi D t}$ is important at short times when the penetration distance is small compared with the radius of the sphere (i.e., $t<$ $r^{2} / \pi D$ ). In contrast, this term becomes negligible ai long times during sustained pit growth. Equation (24) can be simplified for the typical case where the bulk concentration is negligible. In this case the limiting current density inside the pit, $i_{L}$, is given by Eq. (25):

$i_{\mathrm{L}}=z F D C_{\mathrm{s}} / r$

where $z$ is the number of electrons involved in the anodic dissolution process. The pit growth rate, $d r / d t$, is proportional to the limiting current density, $i_{L}$. Integration of the expression for $d r / d t$ yields Eq. (26), the pit radius as a function of time:

$r=\left[r_{1}{ }^{2}+2 D C_{s} M \tau / \rho\right]^{1 / 2}$

where $M$ is the atomic weight of the metal, and $\rho$ is the density of the metal undergoing dissolution.

As pointed out by Beck and Alkire, investigations of the one-dimensional pitting of titanium in bromide solutions have revealed that the growth of salt films on the surface of that metal obeys rate expressions based upon high-field conduction.

The current density associated with growth of the salt film is given by Eq. (27):

$i_{f}=i_{0} \exp \left(\beta \eta_{f} / t_{f}\right)$

where $i_{0}$ is the corresponding exchange current density, $\beta$ is a constant specific to Eq. (27), $\eta_{\mathrm{f}}$ is the film overvoltage, and $t_{f}$ is the film thickness. This expression can be rearranged for calculation of the salt film thickness:

$t_{\mathrm{f}}=\beta \eta_{\mathrm{f}} / \ln \left(z F D C_{\mathrm{s}} / i_{0} r\right)$

where $z$ is the valence of the metal involved in the salt, $D$ is the diffusivity of ions in the salt film, 
and $C_{s}$ is the saturation concentration of the salt in the bulk electrolyte. Beck and Alkire performed calculations that estimate $t_{f}$ to be approximately $77 \AA$ for a case where the pit radius, $r$, is $1 \mu \mathrm{m}$. It is important to note that this model, unlike those of Pickering and Frankenthal [25] and Galvele [26], gives an explicit expression for the pit size as a function of time. Therefore, when applicable, Eq. (28) can be used to predict failure of containers due to pitting.

\subsection{Crack Initiation at Pits Having Critical Depth}

Pits can serve as initiation sites for SCC. Buck and Ranjan have derived an expression for the time to initiate a stress corrosion crack, $t_{\text {inc }}$ [29]:

$t_{\text {inc }}=\frac{\left(K_{\text {isCC }}\right)^{2} \exp \left(-V_{\mathrm{m}} / V_{0}\right)}{\pi B\left(\sigma^{2}-\sigma_{0}^{2}\right)}$

where $K_{\text {ISCC }}$ is the stress intensity threshold for initiation of SCC, $\sigma$ is the applied stress, $\sigma_{0}$ is the stress needed to close the crack, $B$ is a constant, $-V_{\mathrm{m}}$ is the electrochemical potential of the sample, and $V_{0}$ is the reversible potential. This expression is based upon their crack-tip-rpening displacement (CTOD) model for crack initiation at a pit of critical depth. In this model, the microcrack propagation rate at the base of the pit, $d a_{\mathrm{m}} / d t$, is assumed to be linearly proportional to the opening displacement at the mouth of the pit, $\delta$. When $\delta$ exceeds a threshold value, $\delta_{c}+\delta_{0}$, a crack is initiated at the base of the pit. The critical opening displacement for initiation of SCC in the absence of "corrosion blunting" is $\delta_{c}$. Note that the quantity $\delta_{c}$ is proportional to $K_{15 C c}^{2} / \sigma_{n} E$, where $\sigma_{\mathrm{f}}$ is the flow stress, and $E$ is Young's modulus. The corrosion-pit opening displacement, $\delta_{0}$, is that required to prevent blunting of the base of the pit by corrosion.

Hagn has develuped a model for the initiation of corrosion fatigue (CF) cracks at pits [28]. In this model, pits are regarded as half-elliptical surface cracks since they have tiny fissures at their bottoms (Fig. 13). The following equation was derived from linear-elastic fracture mechanics for the stress intensity threshold, $\Delta K_{\text {th }}$, required to initiate a fatigue crack at a corrosion pit:

$\Delta K_{\mathrm{th}}=\Delta \sigma(\pi a)^{1 / 2} F(a, c)$

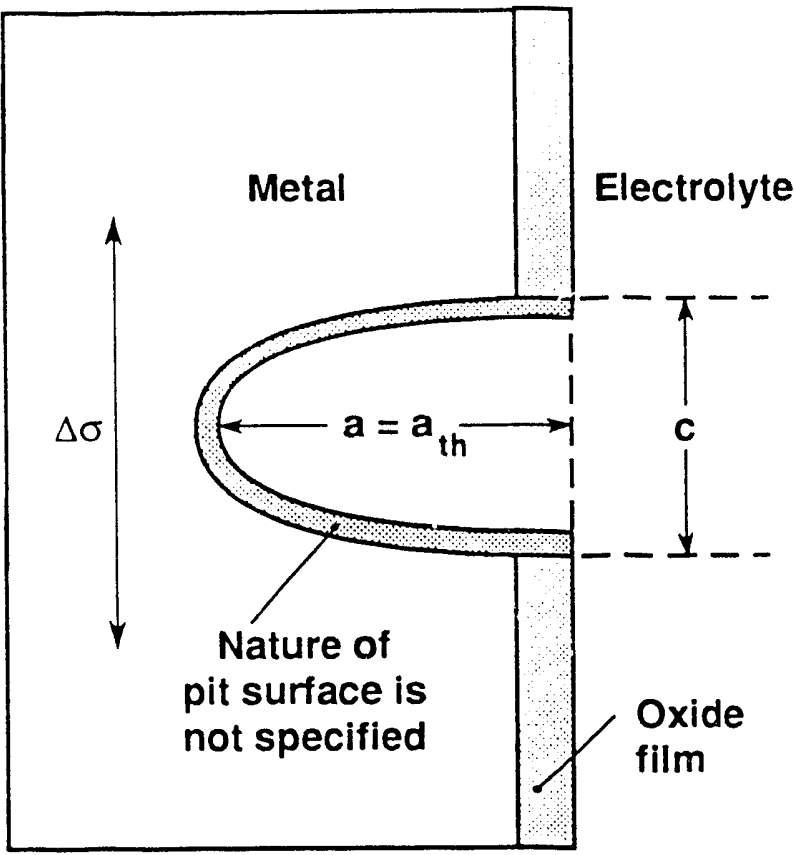

Figure 13. Hagn assumes that stress-corrosion cracks begin at half-elliptical pits having a critical depth, $a=a_{\text {th }}$ [28].

where $\Lambda \sigma$ is the alternating tensile stress, $a$ is the pit depth (half the major axis of the ellipse), $c$ is the minor axis of the ellipse, and $F(a, c)$ is a geometric factor calculated from $a$ and $c$. The exact expression for $F(a, c)$ is

$F(a, c)=\frac{1.13-0.07 \sqrt{a / c}}{\sqrt{1+1.47(a / c)^{1.64}}}$

Equation (29) can be arranged to calculate the critical pit depth, $a_{\text {th }}$ :

$a_{\mathrm{th}}=(1 / \pi)\left(\Delta K_{\mathrm{th}} / F(a, c) \cdot \Delta \sigma\right)^{2}$

Though this expression was developed for CF, Hagn claims that it may also be applicable to SCC. SCC can also begin in the absence of pitting by intergranular corrosion or slip-dissolution processes. Intergranular-corrosion-initiated SCC requires that the local grain-boundary chemistry differ from the bulk chemistry. This condition occurs in sensitized austenitic stainless steels or with the segregation of impurities such as phosphorus, sulfur, or silicon in a variety of materials. 
Slip-dissolution-initiated SCC results from local corrosion at emerging slip planes and occurs primarily in low-stacking-fault materials. The processes of crack initiation and propagation by the slip-dissolution process are very similar.

\subsection{Sensitization of the Austenitic Alloys}

Intergranular stress corrosion cracking (IGSCC) of austenitic stainless steels can occur when these materials are subjected to a sufficiently severe combination of stress, corrosive environment, and sensitizาtion, a term denoting increased susceptibility to attack following a thermal exposure that causes chromium-rich $\mathrm{M}_{23} \mathrm{C}_{6}$ carbides to precipitate at grain boundaries.

The phenomenon of sensitization has been the subject of extensive investigation. Chromium carbide precipitation in stainless steels occurs in the temperature range of 500 to $850^{\circ} \mathrm{C}(930$ to $1560^{\circ} \mathrm{F}$ ), with the rate of precipitation controlled by chromium diffusion [30]. A variety of metallurgical changes have been suggested as mechanisms for sensitization, but it is generally accepted that the principal feature responsible is a narrow chromium-depleted zone adjacent to the carbides. This mechanism was suggested in 1933 by Bain et al. [31] and has been further developed by Stawstrom and Hillert [32] and Tedmon et al. [33]. Tedmon et al. suggest that susceptibiiity to intergranular attack occurs when there is an essentially continuous zone in which the local chromium concentration is below about 13 at.\%. Chromium is the element responsible for the formation of stable passive films in stainless steels, and localized depletion of this element adjacent to grain boundaries results in the establishment of an active path (one which does not repassivate) into the bulk material.

The austenite chromium concentration in equilibrium with the $\mathrm{Cr}_{23} \mathrm{C}_{6}$ carbide depends most sensitively on the activity coefficient of chromium and on the activity of carbon, as expected from thermodynamic arguments. It is assumed that the diffusing chromium atom reacts with a coordinated carbon atom, which is represented by $(6 / 23) \mathrm{C}$ :

$\mathrm{Cr}+(6 / 23) \mathrm{C} \leftrightarrow \mathrm{CrC}_{6 / 23}$
The equilibrium constant for this reaction, $K_{\mathrm{Cr}}$, is related to the standard free energy of formation for this reaction, $\Delta G^{\circ} \mathrm{CrC}_{\mathrm{C}}$ by Eq. (34):

$\mathrm{K}_{\mathrm{CrC}}=\exp \left(-\Delta G^{\circ} \mathrm{CrC} / R T\right)$

where $R$ is the universal gas constant and $T$ is the absolute temperature. The equilibrium constant can also be written in terms of the activities of the two reactants, $a_{\mathrm{Cr}}$ and $a_{\mathrm{C}}$ :

$K_{\mathrm{CrC}}=1 /\left[a_{\mathrm{Gr}}\left(a_{C}\right)^{6 / 23}\right]$

From Eq. (35), an expression can be derived for the mole fraction of chromium in the depleted region adjacent to the carbide precipitates, $X_{C_{r, e q}}$ :

$X_{C r, e q}=1 /\left[K_{C r C} \gamma_{C r}\left(a_{C}\right)^{6 / 23}\right]$

This expression clearly show's that by decreasing the activity of carbon in the bulk alloy, $a_{C}$ the mole fraction of chromium in the depleted region is increased, thereby decreasing the tendency of an alloy to undergo sensitization. Of course, this is why Type $304 \mathrm{~L}$ is less prone to sensitization than Type 304.

In addition to lowering the carbon content of an austenitic alloy such as Type 304 or 316, it is possible to add stabilizing elements (strong carbide formers such as titanium and niobium). Note that the above development is an idealization which neglects the possible formation of carbides from iron, nickel, or stabilizing elements. A thermodynamic model has been developed by Fullman that accounts for these effects through the incorporation of chromium equivalency parameters, $\varepsilon_{j}$ [34]. Sufficient parameters have been included in Fullman's computational model to predict the effects of aluminum, cobalt, copper, manganese, silicon, titanium, vanadium, and tungsten on sensitization. The parameter $\varepsilon_{j}$ is defined as $-\left(\partial P_{C_{r}} / \partial P_{j}\right) X C_{r}$, the change in chromium content, $P_{\mathrm{Cr}^{\prime}}$ with respect to a change in element- $j$ content, $P_{\mathrm{j}}$.

\subsection{The Propagation of SCC}

Crack propagation models also can be categorized according to the state of passivity of the metal at the crack tip. In cases where the crack tip is not passivated and the strain rate is relatively 
low, propagation of SCC may be limited by the transport of ionic species along the length of the crack. Such transport models may be applicable to situations in which intergranular attack is encountered. For example, in a sensitized stainless steel, the chromium-depleted region adjacent to grain boundaries may serve as an active path into the bulk material. Other situations arise in which the crack tip is passivated. Under conditions such as these, crack propagation is believed to occur by a mechanism which involves fracture of the passive film.

\subsubsection{Propagation Controlled by Ion} Transport and Anodic Dissolution

Turnbull and Thomas [35] have developed a model of the electrochemical conditions in a static crack for steel in the active state based upon the quasi-steady-state mass transport of species by diffusion and ion migration (Fig. 14). Though their model was developed for SCC, it is ideally suited to the problems of intergranular attack in the absence of stress and crevice corrosion. This mass transport model assumes that the following reactions occur inside the crack:

$\mathrm{Fe} \rightarrow \mathrm{Fe}^{2+}+2 \mathrm{e}^{-}$

$\mathrm{Fe}^{2+}+\mathrm{H}_{2} \mathrm{O} \leftrightarrow \mathrm{FeOH}^{+}+\mathrm{H}^{+}$

$\mathrm{H}_{2} \mathrm{O} \leftrightarrow \mathrm{H}^{+}+\mathrm{OH}^{-}$

$\mathrm{H}_{2} \mathrm{O}+\mathrm{e}^{-} \rightarrow \mathrm{H}+\mathrm{OH}^{-}$

$\mathrm{H}^{+}+\mathrm{e}^{-} \rightarrow \mathrm{H}$

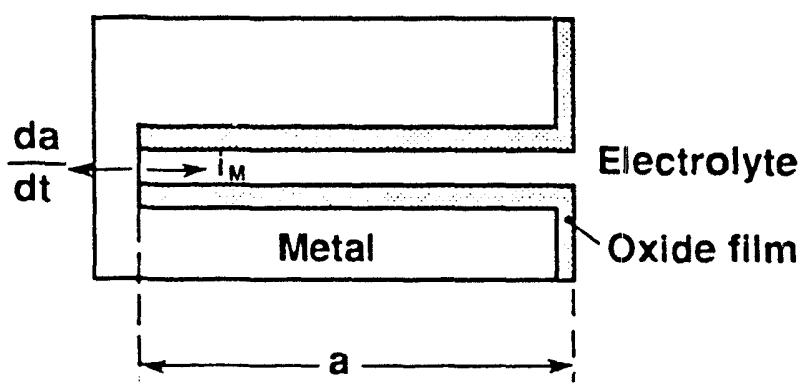

Figure 14. Propagation of a stress-corrosion crack with an active crack tip [35].
Reactions for the anodic dissolution and hydrolysis of the alloying elements are shown in Eqs. (42) and (43):

$\mathrm{M} \rightarrow \mathrm{M}^{n+}+n \mathrm{e}^{-}$

$\mathrm{M}^{n+}+\mathrm{H}_{2} \mathrm{O} \leftrightarrow \mathrm{M}(\mathrm{OH})^{(n-i)+}+\mathrm{H}^{+}$

Turnbull and Thomas also considered the buffering effect of $\mathrm{CO}_{2}$ in seawater, which is summarized in Eqs. (44) and (45):

$\mathrm{H}_{2} \mathrm{CO}_{3} \leftrightarrow \mathrm{H}^{+}+\mathrm{HCO}_{3}^{-}$

$\mathrm{HCO}_{3}^{-} \leftrightarrow \mathrm{H}^{+}+\mathrm{CO}_{3}^{2-}$

Since the ground water near the Yucca Mountain repository has relatively large concentrations of bicarbonate, such buffering effects are considered important.

In the case of structural steel BS 4360 50D in $3.5 \% \mathrm{NaCl}$ at $\mathrm{pH}$ values from 3 to 8.5 , the current density due to the anodic dissolution of metal at the crack tip has been found to obey Eq. (46):

$i_{M}=k_{M} \exp (\beta F E / R T)$

where $E$ is the electrochemical potential at the crack tip, and $\beta$ is a constant specific to Eq. (46). In this case $\beta=1, k_{M}=2.7 \times 10^{-7} \mathrm{~A} / \mathrm{cm}^{2}$, and $F / R T=38.92 V^{-1}$. Similarly, the rates of reduction of hydrogen ions and water are governed by Eqs. (47) and (48), respectively:

$i_{\mathrm{H}^{+}}=k_{\mathrm{H}^{+}} C_{\mathrm{H}^{+}} \exp \left(-\beta^{\prime} F E / R T\right)$

$i_{W}=k_{w} \exp \left(-\beta^{\prime \prime} F E / R T\right)$

In this case $\beta^{\prime}=0.5, k_{\mathrm{H}^{+}}=2 \times 10^{-5} \mathrm{~A} \cdot \mathrm{cm} / \mathrm{mol}$, $\beta^{\prime \prime}=0.5$, and $k_{W}=8 \times 10^{-14} \mathrm{~A} / \mathrm{cm}^{2}$. Note that the potential, $E$, is relative to a saturated calomel electrode (SCE).

Equation (49) is the general equation for conservation of species in the crack, based upon dilute solution theory:

$$
\begin{aligned}
\frac{\partial C_{\mathrm{i}}}{\partial t}+v \nabla C_{\mathrm{i}}=D_{\mathrm{i}} \nabla^{2} C_{\mathrm{i}} & \\
& +z_{\mathrm{i}}\left(\frac{F}{R T}\right) D_{\mathrm{i}} \nabla\left(C_{\mathrm{i}} \Phi\right)+R_{\mathrm{i}}
\end{aligned}
$$

where the second term on the left-hand side of the equation represents convective transport. The 
three terms on the right-hand side represent diffusion, electromigration, and generation or consumption of the species, respectively. Since there is a term for electromigration effects, rigorous solution requires that Laplace's equation must also be solved $[36,37]$. The authors assumed that the crack propagation rate was so slow that convective transport in the crack could be neglected. Furthermore, they assumed quasi-steady state, which eliminated the time derivative and reduced Eq. (49) to an ordinary differential equation.

Equation (49) was solved using Eqs. (46) through (48) as boundary conditions at the crack tip and along the walls of the crack. Ion concentrations in the bulk electrolyte outside of the crack served as boundary conditions at the crack opening. To facilitate numerical analysis, Turnbull and Thomas first converted the mathematical equations to a nondimensional form. Their early attempts to obtain a numerical solution of the equations ignored electromigration effects and made use of a computer algorithm in which the dependent variables were represented by finite Chebyshev series. However, only limited success was achieved with this approach. An improved technique was developed which converted the system of ordinary differential equations to nonlinear integral equations. A numerical solution could then be found by application of a variant of the Newton-Raphson iterative technique.

Turmbuli and Thomas performed simulations of steel BS $436050 \mathrm{D}$ in $3.5 \% \mathrm{NaCl}$. The potential of the external electrode (around crack opening) was assumed to be approximately $-700 \mathrm{mV}, \mathrm{SCE}$. The model predicted that the concentration of ferrous ions near the crack would be slightly higher than the equilibrium value. The hydrogen ion concentration varied very little over the length of the crack, except at the crack opening. Boundary conditions require hydrogen ion concentrations at the opening and in the bulk electrolyte to be equivalent. It was found that the potential drop changed slowly with distance from the crack tip, except at the crack opening. The validity of the model was checked experimentally by measuring the $\mathrm{pH}$ in an artificial crevice at various potentials.

\subsubsection{Models Involving Film Fracture at the Crack Tip}

Nakayama and Takano have applied a slipdissolution-repassivation (SDR) model to SCC of Type 304 stainless steel in a boiling $\mathrm{MgCl}_{2}$ solution [38]. Such a model may also be applicable to the SCC of copper and copper-based alloys and also involves the periodic rupture of the passive film at the crack tip (Fig. 15). They used slow strain rate testing (SSRT) to demonstrate that the SCC was dependent on strain rate, applied potential, and solution temperature. This behavior was qualitatively explained by considering both the formation rate of slip steps and the characteristics of their dissolution-repassivation. Furthermore, they used high-voltage electron microscopy

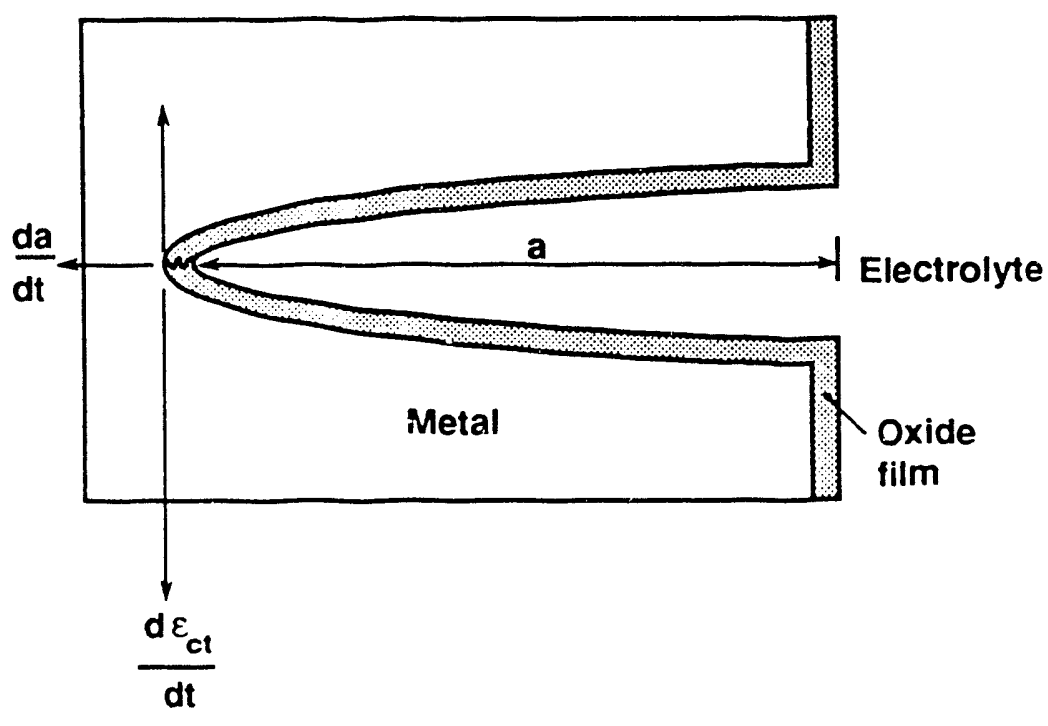

Figure 15. Propagation of a stress-corrosion crack with a passive tip by periodic film fracture [41]. 
(HVEM) to image crack tips and found that transgranular cracks propagate along active slip planes. Thus, they proved that the SDR mechanism is acceptable for the transgranular cracking of Type 304 stainless steel in $42 \% \mathrm{MgCl}_{2}$ solution. The SDR model can quantitatively predict the crack propagation rate as a furiction of applied potential and slip step formation rate.

Development of the SDR model begins with the expression for the dissolution current density, $i(t)$, at a crack tip for a single slip step. Note that $i(t)$ decays exponentialiy because of repassivation of the active surface at the crack tip, as described by Eq. (50):

$i(t)=f^{0} \exp (-\beta t)$

where $t$ is time, $\rho$ is the dissolution current density of the fresh surface at $t=0$, and $\beta$ is the decay constant. Equation (51) defines $\langle i\rangle$, the time average of the dissolution current density. The result is given as Eq. (52):

$\langle i\rangle=\int_{0}^{1 / n_{\mathrm{s}}} i(t) d t /\left(1 / n_{\mathrm{s}}\right)$

$\langle i\rangle=\digamma^{0} / \beta n_{\mathrm{s}}\left[1-\exp \left(-\beta / n_{\mathrm{s}}\right)\right]$

Note that $r_{\mathrm{S}}$ is the formation rate of siip steps. The crack propagation rate, da/dt, can then 'se calculated from Eq. (53):

$d a / d t=: M\langle i\rangle / 2 F \rho$

The molecular weight of the passive oxide film is represented by $M, z$ is thie oxidation state of the metal involved in the film, and $\rho$ is the density of the film. The film could be composed of species such as $\mathrm{Cr}_{2} \mathrm{O}_{3}, \mathrm{C}_{1}(\mathrm{OH})_{3}, \mathrm{Cr}(\mathrm{OH})_{2}, \mathrm{Fe}_{2} \mathrm{O}_{3}$, or $\mathrm{Fe}_{3} \mathrm{O}_{4}$.

The models developed by Andresen and Ford also assume that the propagation of SCC is due to the fracture of the passive film at the crack tip [39-41]. Their model indicates that the crack propagation rate is proportional to the crack tip strain rate, $d \varepsilon_{c t} / d t$, divided by the fracture strain of the film, $\varepsilon_{\mathrm{f}}$.

$d a / d t=\left(M Q_{\mathrm{f}} / z \rho F\right)\left[\left(d \varepsilon_{\mathrm{ct}} / d t\right) / \varepsilon_{\mathrm{f}}\right]$

The oxidation charge density between filmfracture events is represented by $Q_{f}$. As these authors point out, the effects of waier and mate- rial chemistry on $d a / d t$ can be represented by a single parameter, $n$ :

$d a / d t=f(n)\left(d \varepsilon_{c t} / d t\right)^{n}$

The relationship between $d a / d t$ and $\varepsilon_{\mathrm{ct}} / d t$ shown in Eq. (55) was derived from the powerlaw relationship that was found to exist between time and the anodic current density transient immiediately following fracture of the film. This transient is simply represented as $i_{\mathrm{a}}=a t^{-n}$ The primary objective of Andresen and Ford has veen to establish a scientific basis for determining $n$ as a function of corrosion potential, solution conductivity, and alloy composition (sulfur content, etc.).

The Andresen-Ford model is more elegant than that of Nakayama and Takano [38] in that mass transport inside the crack, as governed by Eq. (49), is also taken into consideration. In essence, the Andresen-Ford approach provides the advantages of both the Nakayama-Takano [38] and the Turnbull-Thomas [35] models. The Andresen-Ford model is in excellent agreement with experimental data obtained under conditions in boiling water reactors.

Note that Maier and Galvele have used the straining metal electrode technique as an SCC test for Type 304 stainless steel in $\mathrm{NaCl}+\mathrm{H}_{2} \mathrm{SO}_{4}$ solutions [42]. They conclude that a periodic film formation process (repassivation) does indeed occur during straining, which ir consistent with the model of Nakayama and Takano [38], as well as the models of Andresen and Ford [39-41].

" arshall and Burstein have studied the kinetics of : ie repassivation process on Types $304 \mathrm{~L}$ and $316 \mathrm{~L}$ stainless steels in detail using a scratch technique [43]. They concluded that the repassivation rate is controlled by ion conduction through the growing oxide film under high electric field.

Several cathodic reactions occur outside of the crack and are galvanically coupled with the anodic repassivation (and dissolution) of the crack tip. These include the reduction of oxygen and hydrogen ion:

$$
\begin{aligned}
& \mathrm{O}_{2}+\mathrm{H}_{2}+2 \mathrm{e}^{-} \rightarrow 2 \mathrm{OH}^{-} \\
& \mathrm{O}_{2}+4 \mathrm{H}^{+}+4 \mathrm{e}^{-} \rightarrow 2 \mathrm{H}_{2} \mathrm{O} \\
& 2 \mathrm{H}^{+}+2 \mathrm{e}^{-} \rightarrow \mathrm{H}_{2}
\end{aligned}
$$

Clearly, a relationship should exist between $d a / d t$ and $d \varepsilon_{c t} / d t$ if these models are valid. 
Unfortunately, a thorough review of the literature on SCC of the candidate materials has not revealed correlations relevant to the repository environment. However, such correlations have been established for sensitized microstructures under conditions found in boiling water reactors [44]. Jones show's such a cor. 'lation for furnace-sensitized Type 304 stainless steel in water with $0.2 \mathrm{ppm}$ dissolved oxygen at $288^{\circ} \mathrm{C}\left(550^{\circ} \mathrm{F}\right)$. In this case, da/dt was found to be proportional to the square root of $d \varepsilon_{\mathrm{ct}} / d t$.

\section{LC and SCC of Copper-Based Alloys}

\subsection{Background}

The copper-based candidate materials are sensitive to several species that might exist in the repository environment. Ions known to play an important role in pitting include $\mathrm{S}^{2-}, \mathrm{HS}^{-}, \mathrm{HCO}_{3}^{-}$, $\mathrm{SO}_{4}^{2-}, \mathrm{Cl}^{-}, \mathrm{Fe}^{3+}$, and $\mathrm{H}^{+}[45]$. Dissolved $\mathrm{O}_{2}$ is also very important. Pitting of copper and copperbased alloys can occur in both chloride and bicarbonate solutions. In addition to the reduction of oxygen, the reduction of ferric ion to ferrous ion can serve to depolarize anodic reactions involved in pitting and SCC. Consequently, it is also important to measure concentrations of ferric and ferrous ions in solutions used in testing copper-based alloys. The type of pitting observed depends on the $\left[\mathrm{HCO}_{3}^{-}\right]:\left[\mathrm{SO}_{4}^{2-}\right]$ ratio, so measurements of sulfate concentration are important.

\subsection{Pitting of Copper-Based Alloys}

\subsubsection{Historical}

Crspper tubes are used widely for potable and supply water. Campbell first described pitting of copper tubes in contact with water in 1950 [45]. Extensive investigations have since been conducted with various natural waters because of the practical importance of this problem. Not only can copper be damaged by pitting, but so can copper alloys such as brasses [46], bronzes [47], and some cupronickels-the 70/30 cupronickel (Cu-30Ni), for example [48]. Pitting of copper occurs not only in chloride-containing solutions, but in bicarbonate so!utions as well [49].

\subsubsection{Classification of Pitting Mechanisms}

According to Campbell, there are two types of pitting of copper in fresh water $[45,50,51]$. Numerous papers have been published on this topic, so it is helpful to categorize published work according to the type of pitting discussed. Such classification allows one to easily understand and correlate results. Campbell states that Type 1 pitting is usually associated with certain hard or moderately hard well waters. It is more likely to affect cold water pipes than hot water pipes and may cause perforation in only 1 or $2 \mathrm{yr}$. It is characterized by the formation of fairly large, welldefined pits usually containing soft crystalline cuprous oxide, and often cuprous chloride, beneath hard green mounds of calcium carbonate and basic copper carbonate. The surface between the pits is often covered with a shiny, dark red, water-formed cuprous oxide layer beneath a greenish deposit of hardness salts stained with traces of copper corrosion product. Type 2 pitting occurs only in certain soft-water areas and is practically unknown if the water temperature is below $60^{\circ} \mathrm{C}\left(140^{\circ} \mathrm{F}\right)$. It is characterized by deep pits of small cross section, containing very hard crystalline cuprous oxide and capped by small black or greenish-black mounds of cuprous oxide and basic copper sulfate. The surface between the pits usually carries a nearly black layer of waterformed oxide (a mixture of cupric and cuprous oxides) beneath a thin layer of silt deposited by the water. Some hot soft waters containing small amounts of manganese can produce a special form of Type 2 pitting in which the pits are larger than those formed during ordinary Type 2 pitting and the black deposit on the surrounding areas of the copper is largely manganesc dioxide.

According to Mattsson [52] and in contrast to Campbell [45], three types of pitting of copper can be distinguished. Three types of pitting are also discussed in the review by Szklarska-Smialowska [53]. "Type 1 occurs on annealed or half-hard tubes in culd tap water, caused by a continuous carbon film formed during bright annealing at the inner tube surface. Type 2 occurs on hard-drawn tubes in hot tap water of low $\mathrm{pH}(<7.4)$ and a low $\left[\mathrm{HCO}_{3}^{-}\right]:\left[\mathrm{SO}_{4}^{2-}\right]$ ratio $(<1)$. Type 3 occurs on hard, as well as annealed, tubes in cold tap water of nigh $\mathrm{pH}$, with low salt concentration; this pitting 
type is not caused by a continuous carbon film, and the reason for its formation is not yet known."

\subsubsection{Two Mechanisms for the Pitting of Copper}

According to Szklarska-Smialow'ska [53], two conceptual models exist concerning the pitting of copper. The first model postulates that on the surface of copper, oxygen reduction occurs on a large cathodic area, and pitting occurs on a small anodic area [54-56]. The second model presumes that oxygen reduction occurs above the pit, not on the surrounding area. Pitting is thought to occur when a cuprous chloride pocket forms below a porous, electrically conductive membrane that permits $\mathrm{CuCl}$ to diffuse through it. This membrane separates the anode from the cathode. It is suggested that pits initiate where $\mathrm{CuCl}$ formation occurs. Local accumulation of corrosion products, resulting from general (uniform) attark on the copper surface, is thought to produce pitting. This model is illustrated in Fig. $16[57,58]$. No quantitative mathematical model has been developed to predict rates of penetration due to this type of pitting.

\subsubsection{Pit Chemistry}

Cornwell et al. [59] suggested that the following chemistry is involved in the pitting of copper in aerated supply waters:

$\mathrm{Cu}^{+}+\mathrm{Cl}^{-} \rightarrow \mathrm{CuCl}$

CuCl hydrolyzes to form cuprous oxide, which is precipitated on the metal surface:

$$
2 \mathrm{CuCl}+\mathrm{H}_{2} \mathrm{O} \rightarrow \mathrm{Cu}_{2} \mathrm{O}+2 \mathrm{HC}
$$

The cathodic reaction supporting the anodic dissclution process is oxygen reduction:

$\mathrm{O}_{2}+2 \mathrm{H}_{2} \mathrm{O}+4 \mathrm{c}^{-} \rightarrow 4 \mathrm{OH}^{-}$

For corrosion to proceed, the hydroxyl ions produced at the cathodic sites must be removed. This occurs more readily in acid supply water or water that contains bicarbonate ions:

$\mathrm{OH}^{-}+\mathrm{HCO}_{3}^{-} \rightarrow \mathrm{CO}_{3}^{2-}+\mathrm{H}_{2} \mathrm{O}$

The last reaction causes precipitation of mixed calcium carbonate and basic copper carbonate scale.

Iron can also have a significant influence on the pitting of copper. As discussed by SzklarskaSmialowska [53], Kristiansen [60] studied pitting of copper in distilled water containing $10 \mathrm{mg} \mathrm{SO}_{4}^{2-}$ and $5 \mathrm{mg} \mathrm{CO} / \mathrm{L}$ with and without an iron ion addition, at temperatures of 45,50 , and $60^{\circ} \mathrm{C}$. In aerated neutral water, iron is present in the $\mathrm{Fe}^{3+}$ form. Ferric ions are reduced accorcing to the following reaction when deposited on a copper surface:

$\mathrm{Fe}^{3+}+\mathrm{Cu} \rightarrow \mathrm{Cu}^{+}+\mathrm{Fe}^{2+}$

Ferrous ions are again oxidized to $\mathrm{Fe}^{3+}$, causing further copper corrosion. Kristiansen [60] was able to establish (using radioactive ${ }^{59} \mathrm{Fe}$ ) that pits nucleated where iron was present on the metal surface. It was also found that the highest corrosion occurred at $50^{\circ} \mathrm{C}$, which was explained by the decomposition of the basic copper carbonate deposit and formation of a more protective copper oxide at higher temperatures. Pits were also found on copper when no iron had been

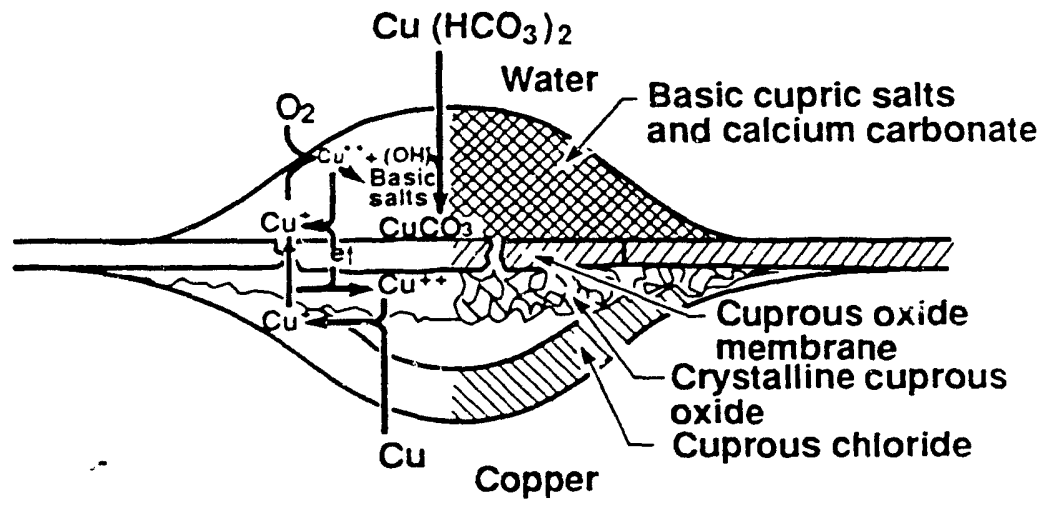

Figure 16. Lucey's proposed mechanism for the pitting of copper involves a porous cuprous oxide membrane $[57,58]$. 
added; however, the possibility of iron in the water could not be excluded.

In 1976 Marcel Pourbaix was selected as the Palladium Award Medalist of the Electrochemical Society [61]. During his address he reviewed much of his work on predicting potential-pH diagrams for copper and copper-based alloys. His work in this field was motivated by the International Copper Research Organization (INCRA). This organization asked Pourbaix to elucidate some fundamental electrochemical aspects of the pitting corrosion of copper tubes in cold water, which was a severe problem in the United States and in Belgium, Germany, the Netherlands, and the United Kingdom during the early 1960s [61-68].

Several diagrams relevant to the repository environment at Yucca Mountain have been presented by Pourbaix [61-68]. For example, one diagram represents the equilibria of the $\mathrm{Cu}-\mathrm{H}_{2} \mathrm{O}$ system at $25^{\circ} \mathrm{C}$ and shows regions of immunity, free corrosion, and passivation. The passive film is either $\mathrm{Cu}_{2} \mathrm{O}$ (cuprite), $\mathrm{CuO}$ (tenorite), or hydrated $\mathrm{Cu}_{2} \mathrm{O}_{3}$, depending upon potential and $\mathrm{pH}$. Note that cuprite or cuprous oxide, $\mathrm{Cu}_{2} \mathrm{O}$, forms at the most cathodic potentials, near the free corrosion potential. Another diagram shows the potential-pH diagram for the ternary system, $\mathrm{Cu}-\mathrm{Cl}-\mathrm{H}_{2} \mathrm{O}$, for solutions containing $355 \mathrm{ppm} \mathrm{Cl}^{-}$. Note that water from well J-13 at the Nevada Test Site contains approximately $10 \mathrm{ppm} \mathrm{Cl}^{-}$. In cases involving chloride, there are acidic regions where films of $3 \mathrm{Cu}(\mathrm{OH})_{2} \cdot \mathrm{CuCl}_{2}$ or $\mathrm{CuCl}$ form in addition to the oxides of copper.

Pourbaix also investigated the effect of $\mathrm{CO}_{2}$ and $\mathrm{SO}_{2}$ on copper in chloride-containing water. A diagram was generated for the quinary system, $\mathrm{Cu}-\mathrm{Cl}-\mathrm{CO}_{2}-\mathrm{SO}_{2}-\mathrm{H}_{2} \mathrm{O}$, at $25^{\circ} \mathrm{C}$. The aqueous phase is assumed to contain $229 \mathrm{ppm} \mathrm{CO}_{2}, 46 \mathrm{ppm} \mathrm{SO}_{3}$, and $22 \mathrm{ppm} \mathrm{Cl}^{-}$. The water in Brussels, Belgium, has similar concentrations. Furthermore, the stable form of copper in the presence of Brussels water $(\mathrm{pH} 8)$ is known to be $\mathrm{CuO}_{3} \cdot \mathrm{Cu}(\mathrm{OH})_{2}$, malachite, which is consistent with Pourbaix's calculations. In addition to cuprite, malachite, tenorite, and $\mathrm{Cu}_{2} \mathrm{O}_{3}$, calculations predict $\mathrm{CuCl}$ (nanterite) and $\mathrm{CuSO}_{4} \cdot n \mathrm{Cu}(\mathrm{OH})_{2}$, where $n$ can be either $\angle$ or 3 (antlerite and brochantite, respectively) in acidic regions. Pourbaix also performed calculations for the ternary system, $\mathrm{Cu}-\mathrm{CO}_{2}-\mathrm{H}_{2} \mathrm{O}$, at $25^{\circ} \mathrm{C}$. In addition to cuprite, tenorite, and $\mathrm{Cu}_{2} \mathrm{O}_{3}$, he predicted formation of $n \mathrm{CuCO}_{3}$. $\mathrm{Cu}(\mathrm{OH})_{2}$, where $n$ can be either 1 or 2 (molochite or azorite, respectively). His calculations for the $\mathrm{Cu}-\mathrm{SO}_{3}-\mathrm{H}_{2} \mathrm{O}$ system indicated that the oxides of copper tend to form in alkaline solutions, while cuprite, brochantite, antlerite, or $\mathrm{Cu}_{2} \mathrm{O}_{3}$ form in acidic solutions, depending upon potential. In acidic media and at practical potentials, copper dissolves as either $\mathrm{Cu}^{+}$or $\mathrm{Cu}^{2+}$. In contrast, the species responsible for dissolution in alkaline media is probably $\mathrm{CuO}_{2}^{-}$.

Angus and Angus have developed a new computational approach for the generation of Pourbaix diagrams which is based on the concept of virtual species [69]. Computation of the equilibrium composition was accomplished by treating the active element as a virtual species. For ideal solutions, the equation set may be solved sequentially rather than simultaneously for the concentrations of all species. For nonideal solutions, the method provides the basis for an efficient iterative solution. The procedure gives a simple test for phase stability and an algorithm for defining the boundaries of the regions of dominance of the dissolved species that is independent of concentration. Unfortunately, the virtual species approach is restricted to systems involving only one redox element, $M$, and to pure solid phases containing only $\mathrm{M}, \mathrm{H}$, and $\mathrm{O}$. No other solids, such as carbonates, or complexes, such as chlorides, were considered, though it is possible to do so. Angus and Angus calculated several potential-pH diagrams for the $\mathrm{Cu}-\mathrm{H}_{2} \mathrm{O}$ system, each for a different total concentration of dissolved copper $\left(10^{-8}, 10^{-6}\right.$, and $\left.1 M\right)$. These diagrams are comparable to Pourbaix's diagrams for the $\mathrm{Cu}-\mathrm{H}_{2} \mathrm{O}$ system.

\subsubsection{Role of Carbon Films}

The effect of carbon is explained differently by Lucey [57, 58] and Pourbaix [62]. In Lucey's theory, the effect of carbon is attributed to the. increased production rate of primary corrosion products and to the hindering of $\mathrm{CuCl}$ diffusion from the pit. According to Pourbaix, the corrosion potential of cc,pper coupled to a carbon film is increased to values at which pitting of copper occurs. The same effect would be obtained by coupling copper to a more noble metal. Campbell [70] has also suggested that the carbon films couple galvanically with the copper. The carbon films would provide large cathodic areas around small anodic surfaces of exposed copper. Localized anodic dissolution would result in pitting. He also discusses the reduction of dissolved oxygen at the cathodic areas and the possible ratecontrolling effects of carbon dioxide and calcium bicarbonate, both of which act as cathodic 
depolarizers by removing hydroxyl ions formed by reduction of oxygen.

\subsection{SCC of Copper-Based Alloys}

\subsubsection{Historical}

In the early days of corrosion research, scientists believed that pure metals were immune to SCC. However, researchers eventually discovered that copper is susceptible to this mode of failure. For example, Pugh et al. reported IGSCC of copper in nontarnishing ammoniacal solution [71], Pednekar et al. reported transgranular stress corrosion cracking (TGSCC) of copper in sodium nitrite solutions [72], and Escalante and Kruger reported IGSCC of copper in cupric acetate solutions without illumination [73]. More recently, Suzuki and Hisamatsu found that pure copper is susceptible to TGSCC in $0.05 \mathrm{M} \mathrm{NH}_{4} \mathrm{OH}$ solution at $70^{\circ} \mathrm{C}[74]$.

\subsubsection{Mechanisms of SCC}

IGSCC is generally thought to occur by mechanisms involving fracture of the passive film at the crack tip [75]. For example, the filmrupture model assumes that stress acts to open the crack and rupture the protective film. Then the freshly exposed metal dissolves, and the crack is extended. Suzuki and Hisamatsu have also used the film-rupture model to explain TGSCC of copper and alpha-brass exposed to ammoniacontaining environments [74]. They show that TGSCC of copper (and alpha-brass) is associated with the periodic rupture of the tarnish (anodic) film at the crack tip. After strain-induced rupture of the tarnish film, small quantities of current flow to the crack tip during anodic dissolution and repassivation. In addition to Suzuki and Hisamatsu's article in Corrosion Science [74], other versions of this study have been published by the same authors in Boshoku Gijutsu [76, 77]. All of these publications have been reviewed by Myers [78]. More recent work has indicated that the tarnish films at crack tips may grow after crack propagation into the base metal [79]. Such observations during TGSCC can be explained by a film-induced cleavage mechanism.

SCC of copper and copper-based alloys selected as candidates for the waste containers is not expected to be a significant problem since the ground water below the repository environment does not contain species known to promote SCC in these materials. However, such species (ammonia and nitrite) may be generated by biological activity and radiolysis. Therefore, we consider the possibility as a worst-case scenario.

\subsubsection{Crack Tip Chemistry of Copper in Aqueous Ammonia}

Bertocci and Pugh proposed that the anodic dissolution of copper and alpha-brass in aqueous environments that contain ammonia is due to the following sequential reactions [80]:

$$
\begin{aligned}
& \mathrm{Cu}+2 \mathrm{NH}_{3} \rightarrow \mathrm{Cu}\left(\mathrm{NH}_{3}\right)_{2}^{+}+\mathrm{e}^{-} \\
& 2 \mathrm{Cu}\left(\mathrm{NH}_{3}\right)_{2}^{+}+1 / 2 \mathrm{O}_{2}+\mathrm{H}_{2} \mathrm{O}+4 \mathrm{NH}_{3} \rightarrow \\
& 2 \mathrm{Cu}\left(\mathrm{NH}_{3}\right)_{4}^{++}+2 \mathrm{OH}^{-}
\end{aligned}
$$

Note the importance of oxygen in Eq. (65). The monovalent species is then regenerated at the surface by:

$$
\mathrm{Cu}\left(\mathrm{NH}_{3}\right)_{4}^{2+}+\mathrm{e}^{-} \rightarrow \mathrm{Cu}\left(\mathrm{NH}_{3}\right)_{2}^{+}+2 \mathrm{NH}_{3}
$$

In the case of SCC of copper or alpha-brass, anodic dissolution could occur at the crack tip after rupture of the tarnish film. A competing anodic reaction would result in repassivation of the surface:

$2 \mathrm{Cu}+\mathrm{H}_{2} \mathrm{O} \rightarrow \mathrm{Cu}_{2} \mathrm{O}+2 \mathrm{H}^{+}+2 \mathrm{e}^{-}$

Pugh et al. represented these chemical reactions with a slightly different set of equations in an earlier paper [81]. Galvanically coupled cathodic reactions may include the reduction of oxygen and hydrogen ion as well as the reduction of nitrite, which is discussed below.

$$
\begin{aligned}
& \mathrm{O}_{2}+\mathrm{H}_{2}+2 \mathrm{e}^{-} \rightarrow 2 \mathrm{OH}^{-} \\
& \mathrm{O}_{2}+4 \mathrm{H}^{+}+4 \mathrm{e}^{-} \rightarrow 2 \mathrm{H}_{2} \mathrm{O} \\
& 2 \mathrm{H}^{+}+2 \mathrm{e}^{-} \rightarrow \mathrm{H}_{2}
\end{aligned}
$$

It is important to note that much of the insight into the chemistry of SCC of pure copper in ammoniacal environments was gained from studies of season cracking of alpha-brasses, which are copper-zinc alloys [82-88].

Because of the role of $\mathrm{NH}_{3}$ in the SCC of copper, Pourbaix diagrams for the $\mathrm{Cu}-\mathrm{H}_{2} \mathrm{O}-\mathrm{NH}_{3}$ system are of interest and have been generated by Hoar and Rothwell [89]. Similar potential-pH diagrams are found in an earlier paper by Johnson and Leja [90]. Expanded portions of the potential-pH diagram generated by Hoar and 
Rothwell are shown in Fig. 17. On the basis of their calculations for pure copper, Hoar and Rothwell propose an SCC mechanism for alphabrass (and pure copper). Formation of a cuprous oxide film should begin on stressed copper at approximately $50 \mathrm{mV}$, NHE (normal hydrogen electrode) and at $\mathrm{pH} 7.2-7.3$. Microstrain of the ductile metal at places such as grain boundaries could break the brittle oxide; however, electrochemical action would repair it.

As the film thickens, the potential rises until the film becomes unstable at a potential of approximately $275 \mathrm{mV}, \mathrm{NHE}$. Note that the three regions of stability for $\mathrm{Cu}_{2} \mathrm{O}, \mathrm{CuSO}_{4} \cdot 3 \mathrm{Cu}(\mathrm{OH})_{2}$, and $\mathrm{Cu}\left(\mathrm{NH}_{3}\right)_{2}^{+}$intersect at approximately $275 \mathrm{mV}$, $\mathrm{NHE}$, and $\mathrm{pH}^{2} 7.2-7.3$ in Fig. 17. Repair of the oxide by electrochemical action now becomes more difficult, especially on yielding metal, and a fissure begins to propagate. At $\mathrm{pH} 7.2-7.3$, since the initial anodic product is soluble, the anodic action, especially at the rapidly yielding advancing edge of the fissure, becomes rapid. Although the sides of the advancing fissure may also begin to dissolve to $\mathrm{Cu}\left(\mathrm{NH}_{3}\right)_{2}^{+}$, the reaction removes $\mathrm{NH}_{3}$, and moderately protective $\mathrm{Cu}_{2} \mathrm{O}$ can again form there, so that the fissuring mode of attack, which requires rapid penetration of the advancing edge and little penetration on the sides, is maintained. In fact, at $275 \mathrm{mV}, \mathrm{NHE}$, and $\mathrm{pH} 7.2-7.3$, both soluble and insoluble products can form, so that active attack can readily occur on yielding metal and protective film formation on static metal. This process maintains the propagation of SCC.

\subsubsection{Crack Tip Chemistry of Copper in Nitrite Solutions}

Aaltonen et al. conducted linear-sweep, anodic polarization experiments, which give insight into the chemical mechanisms involved in SCC of copper in $0.3 \mathrm{M} \mathrm{NaNO}$ solutions [91]. These authors found that the dissolution of copper as $\mathrm{Cu}^{+}$occurs at potentials more anodic than $-230 \mathrm{mV}$; this is followed by the oxidation of $\mathrm{Cu}^{+}$ to $\mathrm{Cu}^{2+}$ at potentials more anodic than $-100 \mathrm{mV}$. The maximum current density was observed during the formation of $\mathrm{CuO}$ at $+100 \mathrm{mV}$. All potentials were measured relative to the saturated calomel electrode (SCE). Further increasing of potential results in the oxidation of $\mathrm{NO}_{2}^{-}$to $\mathrm{NO}_{3}^{-}$, which is evident in the polarization curve shown for platinum. On the basis of these data, Aaltonen et al. concluded that the following anodic and cathodic reactions occur on copper in nitrite solutions. First, there is the two-step anodic dissolution of copper, which is represented by Eqs. (71) and (72):

$$
\begin{aligned}
& \mathrm{Cu} \rightarrow \mathrm{Cu}^{+}+\mathrm{e}^{-} \\
& \mathrm{Cu}^{+} \rightarrow \mathrm{Cu}^{2+}+\mathrm{e}^{-}
\end{aligned}
$$
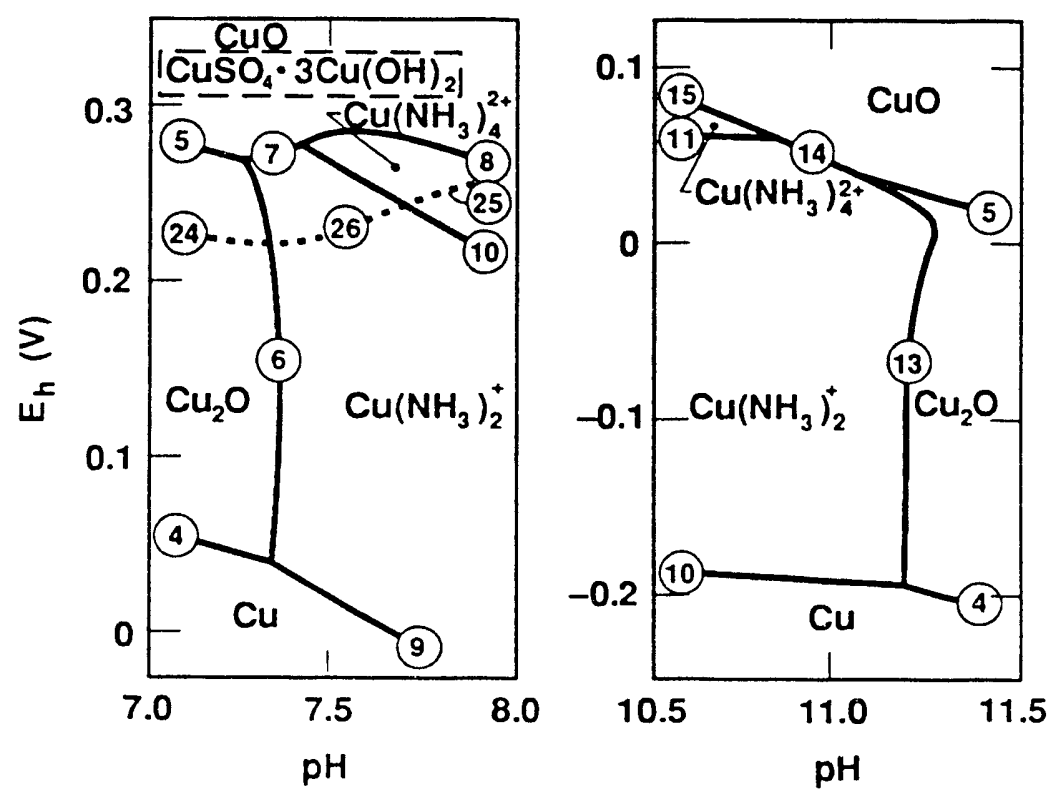

Figure 17. SCC of copper in moist ammoniacal environments is known to occur at two pH levels (7.3 and 11.3). The passive film is known to be unstable under these conditions [89]. 
This reaction is followed at more anodic potentials by the passivation of the copper surface with a film of cuprous oxide:

$2 \mathrm{Cu}+\mathrm{H}_{2} \mathrm{O} \rightarrow \mathrm{Cu}_{2} \mathrm{O}+2 \mathrm{H}^{+}+2 \mathrm{e}^{-}$

Note that the cuprous oxide film can be oxidized to form cupric hydroxide:

$$
\mathrm{Cu}_{2} \mathrm{O}+3 \mathrm{H}_{2} \mathrm{O} \rightarrow 2 \mathrm{Cu}(\mathrm{OH})_{2}+2 \mathrm{H}^{+}+2 €
$$

Cathodic reactions include the reduction of oxygen, as discussed in the previous section, and the reduction of nitrite. The degree of reduction is dependent on whether the reaction takes place on pure copper, on $\mathrm{Cu}_{2} \mathrm{O}$, or in the electrolyte.

$$
\begin{aligned}
& \mathrm{NO}_{2}^{-}+\mathrm{H}^{+}+\mathrm{e}^{-} \rightarrow \mathrm{NO}+\mathrm{OH}^{-} \\
& 2 \mathrm{NO}_{2}^{-}+4 \mathrm{H}^{+}+6 \mathrm{e}^{-} \rightarrow \mathrm{N}_{2}+4 \mathrm{OH}^{-}
\end{aligned}
$$

Newman and Burstein have reported ammonia formation by the cathodic reduction of nitrite and nitrate on copper [92]. The following reaction is given by Aaltonen et al. in an earlier paper [93]:

$\mathrm{NO}_{2}^{-}+7 \mathrm{H}^{+}+6 \mathrm{e}^{-} \rightarrow \mathrm{NH}_{3}+2 \mathrm{H}_{2} \mathrm{O}$

If this reaction occurred on copper, SCC induced by nitrite could actually be due to the presence of ammonia. In addition to serving as an SCC promoter, nitrite could serve as a depolarizer.

However, as pointed out by Aaltonen et al. in the more recent paper [91], the reduction of nitrite to ammonia as proposed by Newman and Burstein [92] was not observed on pure copper. The catalytic generation of nitrogen on copper may also occur and would probably follow reáction steps given in these equations [91]:

$$
\begin{aligned}
& 2 \mathrm{NO}_{2}^{-}+4 \mathrm{H}_{2} \mathrm{O}+8 \mathrm{e}^{-} \rightarrow \mathrm{N}_{2}^{2-}+8 \mathrm{OH}^{-} \\
& \mathrm{O}_{2}+2 \mathrm{Cu}^{+}+\mathrm{N}_{2}^{2-} \rightarrow 2 \mathrm{CuO}+\mathrm{N}_{2}
\end{aligned}
$$

The equations given in Ref. 91 are not balanced and have been corrected here. If Eq. (77) actually occurs, several steps must be involved since so many electrons are consumed. Note that the reduction of nitrite to molecular nitrogen, like the reduction of nitrite to ammonia, is believed to take place only on pure, nonoxidized copper surfaces. This reaction may provide some surface- active adsorbates necessary for SCC of pure copper. At the present time, the identity of the species responsible for SCC of copper in nitrite solutions is unknown.

\subsubsection{Crack Tip Chemistry of Aluminum Bronze in Steam}

Klement et al. [94] have found that aluminum bronze is susceptible to IGSCC in steam environments. They believe that IGSCC in this alloy is due to the segregation and subsequent oxidation of aluminum at grain boundaries. After rupture of the oxide at the crack tip, the following repassivation reaction may occur, resulting in the formation of hydrargillite, $\mathrm{Al}_{2} \mathrm{O}_{3} \cdot 3 \mathrm{H}_{2} \mathrm{O}$ :

$2 \mathrm{Al}+3 \mathrm{H}_{2} \mathrm{O} \rightarrow \mathrm{Al}_{2} \mathrm{O}_{3}+6 \mathrm{H}^{+}+6 \mathrm{e}^{-}$

In neutral water at $25^{\circ} \mathrm{C}$, this reaction has a standard potential of approximately $-1.13 \mathrm{~V}, \mathrm{SHE}$ [95]. If any condensate film exists near the crack tip to host the hydrogen ions, the repassivation reaction may be galvanically coupled with the reduction of oxygen to form water:

$\mathrm{O}_{2}+4 \mathrm{H}^{+}+4 \mathrm{e}^{-} \rightarrow 2 \mathrm{H}_{2} \mathrm{O}$

In neutral water at $25^{\circ} \mathrm{C}$, this reaction has a standard potential of approximately $1.229 \mathrm{~V}, \mathrm{SHE}$ [96]. This chemistry has not been verified.

Though Pourbaix diagrams have not been found for copper-aluminum and copper-nickel alloys, it is informative to study the diagrams for aluminum and nickel in Pourbaix's Atlas of Electrochemical Equilibria in Aqueous Solutions [95]. At $\mathrm{pH}$ values greater than 2, aluminum is passivated with a film of hydrargillite, $\mathrm{Al}_{2} \mathrm{O}_{3} \cdot \mathrm{H}_{2} \mathrm{O}$, at all potentials within the thermodynamic limits of water. In acidic media having a $\mathrm{pH}$ less than 2 , aluminum dissolves as $\mathrm{Al}^{3+}$. Similar behavior would be expected for aluminum bronze. The surface would probably become passivated with hydrargillite rather than cuprite because of the differences in their free energies of formation. The unusual stability of this passive film is responsible for the relatively low uniform oxidation and corrosion rates observed for aluminum bronze.

\subsubsection{Crack Tip Chemistry of Cupronickel in Aqueous Environments}

As shown by McGuire et al. [97], passive films formed on $\mathrm{Cu}-30 \mathrm{Ni}$ are composed primarily of nickel oxides or hydroxides, which is reasonable in light of the relative free energies of 
formation of all possible compounds. McGuire et al. could not distinguish between hydroxide and oxide species since hydrogen cannot be detected by Auger spectroscopy. Furthermore, it is very difficult to distinguish the two types of oxygen by the shape of their Auger peaks. The repassivation reaction near the corrosion potential is believed to involve the formation of $\mathrm{Ni}(\mathrm{OH})_{2}$.

In the case of nickel, the surface would probably be passivated with $\mathrm{Ni}(\mathrm{OH})_{2}, \mathrm{Ni}_{3} \mathrm{O}_{4}$, $\mathrm{Ni}_{2} \mathrm{O}_{3}$, or $\mathrm{NiO}_{2}$, depending upon potential and $\mathrm{pH}$. Though Pourbaix diagrams for copper-nickel and copper-aluminum alloys have not been predicted, Candela and Chang have presented a technique for predicting such diagrams for alloys in the gas phase [98].

\subsection{Propagation of SCC in Copper-Based Alloys}

As in the case of the austenitic alloys (stainless steel), crack propagation in copperbased alloys can arise from fracture of the passive film at the crack tip. In such cases, the filmrupture model has been found to be applicable. In addition to the film-rupture model, the filminduced cleavage model has been proposed for application to SCC of copper-based alloys. This model assumes that films at the crack tip can induce cleavage at the underlying base metal. These films can be tarnish films, monatomic adsorbate films, and dealloyed layers.

\subsubsection{Crack Propagation Due to Stress-Induced Failure of Oxide Films}

Suzuki and Hisamatsu have applied a filmfracture model to SCC of Cu in $\mathrm{NH}_{4} \mathrm{OH}$ [74].

Their work is especially interesting since the filmfracture strain, $\varepsilon_{f}$, was determined. Suzuki and Hisamatsu use a formulation of the film-fracture model developed by Forty and Humble [99] and McEvily and Bond [100] for SCC of alpha brass. The crack propagation rate, $d a / d t$, is assumed to be determined by the thickness of the tamish film at the crack tip, $L$, and the time between fracture events, $t_{c}$ :

$d a / d t=L / t_{c}$

The growth rate of the tarnish film has be ' $n$ found to obey the parabolic law and is probably controlled by the solid-state diffusion of cuprous ions through the tarnish (cuprous oxide):

$L=C\left(t_{c}\right)^{1 / 2}$

where $C$ is a rate constant for film growth. The value of $t_{c}$ can be calculated from the strain rate at the crack tip, $d \varepsilon_{\mathrm{ct}} / d t$, and the fracture strain of the film, $\varepsilon_{\mathrm{f}}$ :

$t_{c}=\varepsilon_{f} /\left(d \varepsilon_{c t} / d t\right)$

Therefore da/dt is linearly dependent on the rate constant for film growth and the square root of the strain rate:

$$
d a / d t=C\left[\left(d \varepsilon_{c t} / d t\right) / \varepsilon_{\mathrm{f}}\right]^{1 / 2}
$$

One should recall the square-root dependence discussed earlier. The time to failure is then given by:

$$
t_{\mathrm{f}}=l_{\max } /(d a / d t)
$$

where $l_{\max }$ is the maximum crack length at fracture. This can be expressed more explicitly as

$t_{\mathrm{f}}=\left(l_{\max } / C\right)\left[\varepsilon_{\mathrm{f}} /\left(d \varepsilon_{\mathrm{ct}} / d t\right)\right]^{1 / 2}$

One should note the similarity between Eq. (87) and the equations presented by Andresen and Ford [41] and Newman [101].

Suzuki and Hisamatsu performed direct measurements of the model parameter $\varepsilon_{f}$. Copper wires were anodically polarized in solutions of $0.05 \mathrm{M} \mathrm{NH}{ }_{4} \mathrm{OH}$ at $70^{\circ} \mathrm{C}$ and simultaneously tested by SSRT. Strain rates ranged from $1.0 \times 10^{-4}$ to $4.0 \times 10^{-5} \mathrm{~min}^{-1}$. They determined $\varepsilon_{\mathrm{f}}$ from the true strain at the onset of electrochemical current transients which were associated with film rupture. Incremental changes in the crack length, $a$, were monitored using acoustic emission. Crack extensions as small as $2 \mu \mathrm{m}$ were detected. Newman and Sieradzki have also used AE techniques to study SCC in alpha-brass [102]. Suzuki and Hisamatsu found that $\varepsilon_{\mathrm{f}}$ ranged from $1.1 \times 10^{-3}$ to $1.4 \times 10^{-3}$.

Suzuki and Hisamatsu also studied the timeto-failure in $0.05 \mathrm{M} \mathrm{NH}_{4} \mathrm{OH}$ solution at various solution temperatures $\left(40-70^{\circ} \mathrm{C}\right)$ [74]. They found an Arrhenius relationship between the reciprocal of time-to-failure, $t_{f}^{-1}$, and absolute temperature, $T$. The apparent activation energy 
of SCC was estimated to be approximately 8.4 to $19.2 \mathrm{~kJ} / \mathrm{mol}(35.2-80.4 \mathrm{kcal} / \mathrm{mol})$. Next, these authors used $\mathrm{x}$-ray analysis to determine that the tarnish film formed on pure copper was polycrystalline and predominantly $\mathrm{Cu}_{2} \mathrm{O}$. Furthermore, they found that the rate constant for film growth, $C$, exhibited Arrhenius behavior with an apparent activation energy, $E_{\mathrm{a}}$, of approximately $13.8 \mathrm{~kJ} / \mathrm{mol}(57.8 \mathrm{kcal} / \mathrm{mol})$ :

$C=C_{0} \exp \left(-E_{\mathrm{a}} / R T\right)$

This type of temperature dependence is believed to be due to the proportionality that exists between $C$ and the solid-state diffusion coefficient. Since the activation energies for film growth and crack propagation were very similar, Suzuki and Hisamatsu concluded that the observed rate of SCC was controlled by tarnish film growth.

\subsubsection{Crack Propagation Due to Film-Induced Cleavage of the Base Metal}

A theory proposed by workers from Brookhaven National Laboratory suggests that a brittle crack can initiate in a thin surface film and attain a velocity sufficient to propagate as a cleavage crack for significant distances into the unaffected substrate [103-105]. In addition to oxide and dealloyed layers, one can visualize other types of films. For instance, a surface hydride may be responsible for cracking in some of the strong hydride formers.

Pasikin et al. have used computer simulations of molecular dynamics in solids to model SCC due to film-induced cleavage [103]. In their paper, they concentrate on the following features associated with the SCC and embrittlement in environmental-alloy systems: (1) lowering of the critical applied stress intensity (or load) required to produce fracture; (2) change in fracture mode; and (3) variation of the critical load as a function of a parameter such as gas pressure or film thickness. They propose a model in which a reaction product in the form of a coherent film produces embrittlement. The film could be an oxide, a dealloyed layer, or a hydride. The magnitude of the critical load predicted by the model is used as a measure of embrittlement under various simulated conditions.

Embrittlement results from the nature and magnitude of the residual stresses introduced into the crack tip region by the presence of the film. These stresses are due to the mismatch in lattice parameters of the film and substrate material. In these simulations, when the lattice parameter of the film is smaller than the lattice parameter of the substrate, a nonshearing form of embrittlement results. If the nature of the lattice parameter mismatch is reversed, dislocation nucleation is favored, and an enhanced localized shear form of embrittlement results. The relative moduli can further affect this general behavior.

Paskin et al. based their computer simulations of the propagation of cracks coated with a thin solid film on a molecular dynamic technique $[104,105]$. Atoms were assumed to be arranged in a triangular lattice and to interact with the 6-12 L.ennard-Jones potential:

$\Phi_{i j}=\varepsilon\left[\left(d / r_{i j}\right)^{12}-2\left(d / r_{i j}\right)^{6}\right]$

where all energies are measured in units of the well depth $\varepsilon$ and distances in units of the equilibrium spacing $d$. The calculations were performed using the Verlet central difference method for solving Newton's equation of motion. The atomic positions, velocities, and forces, and the total energy, work, potential energy, and modulus of elasticity were monitored throughout the simulations. The external tensile load was applied as an external tensile force on each atom of the uppermost row and the lowermost row of the sample. In the majority of the simulations, the crack was assumed to be coated with a film of three layers of atoms. Two parameters were used to characterize the film, i.e., the interatomic spacing, $d$, and the depth of the interatomic potential, $\varepsilon$, which determines the elasti = modulus of the film.

These computer simulations have given significant insight into experimental observations. For example, consider the TGSCC of alpha-brass in ammoniacal solutions. There is considerable evidence that crack propagation in this system occurs discontinuously by a series of brittle-fracture events. In such environments, zinc is preferentially dissolved out from the alloy, leaving a defective yet coherent copper-rich film around the crack tip. This film has a thickness of approximately 20 to $50 \mathrm{~nm}$. Since the dealloyed layer is brittle, it fractures. Simulations predict that the crack should continue to propagate into the unaffected alpha-brass via a dynamic embrittlement mechanism. Eventually, the crack tip would encounter a preexisting slip band and stop. Analogous situations could arise in dealloyed surface layers on aluminum bronze. 
As discussed above, dealloying of alloy surfaces can result in brittle layers, which may undergo film-induced cleavage. Sieradzki et al. discuss the relationship between TGSCC of copper-aluminum and dealloying [106]. In view of this relationship, it is important to develop an understanding of this mode of degradation in copper alloys. Pryor and Fister have studied the mechanisms and kinetics of the dealloying of copper solid solutions and intermetallic phases [107]. Potentiostatic experiments in $0.5 \mathrm{~N} \mathrm{NaCl}$ at $-0.25 \mathrm{~V}, \mathrm{SCE}$, showed that the rates of dealloying of copper-base binary alloys fall in the following order: copper-aluminum > copper-manganese $>$ copper-zinc > copper-nickel. Copper-nickel alloys are less susceptible to dealloying than copper-aluminum alloys. The kinetics of the dealloying of copper-aluminum alloys obey the following relationship:

$\log S_{\varepsilon}=K C_{s}$

where $S_{\varepsilon}$ is the excess solute concentration ( $\mathrm{mg} / \mathrm{cm}^{2}$ per 20-h exposure) dissolved from the alloy, and $C_{s}$ is the atom percent of solute in the alloy. $K$ is related qualitatively to the reversible potential of the solute element. Pryor and Fister concluded that the rate of dealloying is primarily controlled by electrochemical factors and not by solid-state diffusion. The rate of dealloying of copper-nickel was several orders of magnitude less than that of copper-aluminum, so small that a kinetic expression could not be developed from the data.

Lennox and Peterson have studied the corrosion and dealloying of copper-aluminum and copper-nickel alloys in seawater [108]. They found that copper-aluminum alloys such as CDA 612 and 614 (similar to CDA 613) are susceptible to dealloying. However, dealloying could be prevented by cathodic protection. In contrast, copper-nickel alloys such as CDA 706 and 715 are essentiaily immune to dealloying. Ferrara and Caton studied the dealloying of cast aluminum and nickel-aluminum bronzes in seawater [109]. They concluded that dealloying in duplex-phase aluminum bronze castings is a significant problem and is often undetectable by visual inspection. Dealloying depths in excess of $13 \mathrm{~mm}$ were observed in some castings. More recently, Tuthill has reviewed the iterature on the application of copper alloys in seawater service [110]. He also cited the work of Ferrara and Caton and noted that dealuminification of aluminum bronzes is not a significant problem until the aluminum content reaches 9 to 11 at.\%. Tuthill states that denickelification occurs occasionally in high-nickel-content overhead condensers used in refineries where hydrocarbon streams condense at temperatures above $149^{\circ} \mathrm{C}$.

Gleekman and Swandby have documented the massive dealuminization and failure of aluminum-bronze rotating drums used to dry $\mathrm{CaCO}_{3}$ pastes having $\mathrm{pH}$ values of approximately 8 [111]. Minor impurities of $\mathrm{Cl}^{-}$and $\mathrm{SO}_{4}^{2-}$ in the paste were found to significantly enhance the rate of dealuminification.

Hydrogen embrittlement has been invoked as a source of TGSCC because many of the materials that undergo conventional hydrogen embrittlement are susceptible to SCC. However, copper and its alpha-phase alloys are an exception since there is no evidence for conventional hydrogen embrittlement in these materials. It is speculated that SCC results from absorption of cathodically generated hydrogen at the crack tip. The absorbed hydrogen is thought to embrittle the region immediately in front of the crack and thus allow for further crack propagation.

It may be possible for adsorbate layers to promote SCC by film-induced cleavage. This mechanism accounts for SCC by assuming that embrittlement results from a reduction in bond strength causer by the adsorption of certain species at strained bonds at the crack tip. This model differs from the hydrogen embrittlement model in that embrittlement is assumed to occur at the surface and not in the bulk. The embrittling species are assumed to be specific ions or molecules in the aqueous environment. Unfortunately, there is no independent evidence to confirm or refute the hypothesized reduction in bond strength. Criticisms of the adsorption model have been summarized previously [80].

Lynch has suggested a radically different form of the adsorption model [112]. According to this approach, the cleavage-like surfaces do not result from brittle fracture, but rather from a plastic process involving the adsorption-enhanced generation of dislocations at the crack tip. This view is based on the claim that the transgranular fracture surfaces, while macroscopically brittle, exhibit fine slip steps and extremely small, shallow dimples that are characteristic of ductile fracture. 


\section{Crevice Corrosion}

Intense LC frequently occurs within crevices and other shielded areas on metal surfaces exposed to corrosives. After emplacement of the containers in the repository, crevices will form at points where the container is supported. Furthermore, natural deposits of sand, dirt, corrosion products, and other solids can form crevices.

An explanation of crevice corrosion is given by Fontana and Greene (Fig. 18) [113]. During uniform aqueous phase corrosion, the cathodic reduction of dissolved oxygen and the anodic dissolution of metal cations are galvanically coupled and proceed at rates that are independent of position on exposed metal surfaces. In contrast, oxygen reduction on metal surfaces in crevices eventually ceases because of the lack of this reactant. Oxygen becomes depleted in such recesses, and mass transport rates (diffusion-limited) are insufficient to replenish it. Consequently, the only process that occurs at an appreciable rate within the crevice is the anodic dissolution of metal. This process tends to produce an excess of positive charge in the crevice solution $\left(\mathrm{M}^{\mathbf{z}}\right)$, which is necessarily balanced by the migration of halide ions, such as $\mathrm{Cl}^{-}$, into the recess. The increased concentration of metal halide in the crevice results in undesirable localized chemistry:

$\mathrm{MCl}+\mathrm{H}_{2} \mathrm{O} \rightarrow \mathrm{MOH}$ (prec.) $+\mathrm{HCl}$

The halide salt hydrolizes in water to form a precipitate and free acid. Repassivation in the high- chloride, low-pH environment found in crevices is virtually impossible. The anodic dissolution of most metals is accelerated in such environments.

In addition to the large differences in concentration inside and outside of crevices, there are large differences in current density. Oxygen reduction continues at relatively low current densities on all passivated (oxide-covered) metal surfaces outside of the crevice. This large overall cathodic current must be balanced by the anodic dissolution current on metal surfaces inside the crevice. Given the small active area within crevices, corresponding current densities are typically very large. Therefore, local penetration rates within crevices also tend to be very large (far greater than on unobscured surfaces).

The modeling approach developed by Tumbull and Thomas for SCC on active surfaces, discussed in Sec. 4.6, is also ideally suited to crevice corrosion problems [35]. Vermilyea and Tedmon [114] have also developed a simple theory for the variation of concentration and potential in a crevice and compared predictions with experimental data. A consequence of their theory, confirmed by experiments, is that a small difference in potential in a crevice can cause a large change in concentration and a corresponding large increase in corrosion current at a given applied potential.

France categorizes crevice corrosion mechanisms on the basis of the type of concentration cell established by the crevice [115]. The mechanisms

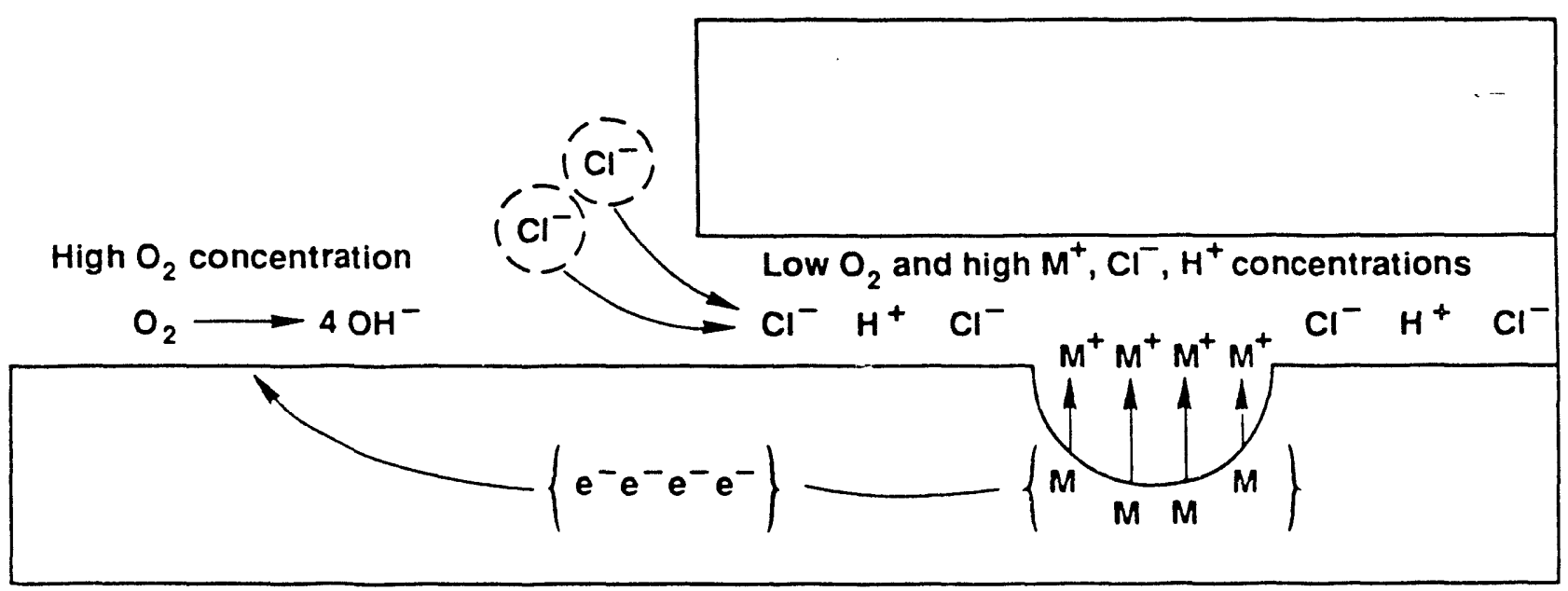

Figure 18. Proposed mechanism of crevice corrosion [113]. 
discussed include (1) metal-ion, (2) differentialacration, (3) active-passive, (4) hydrogen-ion, (5) neutral-salt, and (6) inhibitor cells. Activepassive ceils are governed by Eqs. (92) and (93). Equation (92) defines the length of an activepassive crevice that can be passivated:

$L_{\mathrm{p}}=\delta E_{\mathrm{p}} \sqrt{W / \rho i_{\mathrm{c}} \delta E_{\mathrm{a}}}$ (active-passive)

where $L_{\mathrm{p}}$ is the passive length, $\delta E_{\mathrm{p}}$ is the passive potential range, $W$ is the crevice width, $\rho$ is the solution resistivity, $i_{c}$ is the critical anodic current density, and $\delta E_{\mathrm{a}}$ is the active potential range.

Equation (93) defines the length of a passivated crevice that can be maintained passive.

$L_{\mathrm{p}}=\sqrt{W \delta E_{\mathrm{p}} / \rho i_{\mathrm{p}}} \quad$ (passive)

where $i_{\mathrm{p}}$ is the passive current density. A comparison of experimental and calculated passive crevice lengths for Type 304 stainless steel and Alloy CF-8 showed good correlation.

\section{Effects of Gamma Irradiation}

\subsection{Possible Effect on Resistance to Pitting}

It has been known for many years that the irradiation of liquid water by gamma rays produces ionic, free radical, and molecular products. Because of the fast reaction of ionic species, the "primary products" of water radiolysis are considered to be $\mathrm{H}^{+}, \mathrm{OH}^{-}, e_{a}^{-}, \mathrm{HO}_{2}, \mathrm{H}_{2} \mathrm{O}_{2}$ and $\mathrm{H}_{2}$ where the first four are called the radical products, and the last two are the molecular products. The radical products are very chemically reactive, reacting with the molecular products or with dissolved solutes in the water, if present. If oxygen is dissolved in the water, both $\mathrm{H}$ and $\mathrm{e}_{\mathrm{aq}}^{-}$react with it rapidly to form $\mathrm{HO}_{2}$ and $\mathrm{O}_{2}^{-}$, respectively. At $\mathrm{pH}$ near neutral, the $\mathrm{HO}_{2}$ ionizes rapidly to form $\mathrm{H}^{+}$and $\mathrm{O}_{2}$. The result of all these reactions is that in irradiated oxygenated water, steady-state concentrations are present of the oxidizing species $\mathrm{OH}, \mathrm{O}_{2}^{-}$, and $\mathrm{H}_{2} \mathrm{O}_{2}$. There is also a low steady-state concentration of $\mathrm{H}_{2}$ (which is effectively inert to stainless steel at temperatures at which water is liquid). The obvious implication is that each of the models of LC must include equations for the mass transport, homogeneous reaction, and electrochemical reaction of each radiolytic species. Note that the generation term in Eq. (49) is significant in such cases.

When an electrode is inserted into such an irradiated solution, a corrosion potential, $E_{\text {corr }}$, is observed which reflects the composite of the reactions of all the reactive species in the solution with the material of the electrode. Several research groups, including Glass et al. [116, 117], Marsh et al. [118], Kim and Oriani [119], Clarke and Jacobs [120], and Ruther et al. [121] have observed that $E_{\text {corr }}$ of stainless steel shifts to more positive (noble) values in the presence of gamma irradiation.

The initial understanding of this radiolytic effect on corrosion potential is attributed to Glass et al. of the Nevada Nuclear Waste Storage Investigations Project [116, 117]. Their study found that the positive shift in $E_{\text {corr }}$ was composed of three parts. The major part was found to persist after the irradiation was terminated, but most of it was removed if the irradiated solution was replaced by a new solution. This part was attributed to hydrogen peroxide, $\mathrm{H}_{2} \mathrm{O}_{2}$. The part that remained after the solution was changed was attributed to permanent changes in the oxide layer on the stainless steel. The third part was only present during irradiation and was attributed to the transient radical species.

According to Glass et al., the following anodic and cathodic reactions are believed to be of major importance in determining the corrosion potentials of austenitic stainless steels under gamma irradiation [116]. The cathodic reactions are as follows:

$$
\begin{aligned}
& \mathrm{H}_{2} \mathrm{O}_{2} \rightarrow 2(\cdot \mathrm{OH})_{\mathrm{ADS}} \\
& (\cdot \mathrm{OH})_{\mathrm{ADS}}+\mathrm{e}^{-} \leftrightarrow \mathrm{OH}^{-} \\
& \mathrm{O}_{2}+2 \mathrm{H}_{2} \mathrm{O}+4 \mathrm{e}^{-} \rightarrow 4 \mathrm{OH}^{-} \\
& \mathrm{O}_{2}^{-}+\mathrm{H}_{2} \mathrm{O}+\mathrm{e}^{-} \rightarrow \mathrm{HO}_{2}^{-}+\mathrm{OH}^{-} \\
& \mathrm{HO}_{2}^{-}+\mathrm{H}_{2} \mathrm{O}+2 \mathrm{e}^{-} \rightarrow 3 \mathrm{OH}^{-}
\end{aligned}
$$

where ADS denotes adsorbed species. Equation (94), not given explicitly by Glass et al., has been included for completeness. The reactions represented by Eqs. (97) and (98) are believed to be ler.s 
important than those represented by Eqs. (95) and (96). The cathodic reactions are:

$\mathrm{Fe} \rightarrow \mathrm{Fe}^{2+}+2 \mathrm{e}^{-}$

$\mathrm{Cr} \rightarrow \mathrm{Cr}^{3+}+3 \mathrm{e}^{-}$

$\mathrm{Ni} \rightarrow \mathrm{Ni}^{2+}+2 \mathrm{e}^{-}$

The coupling of the cathodic processes with metal dissolution reactions results in the observed mixed corrosion potential, $E_{\text {corr }}$.

The effect of a single radiolysis product such as hydrogen peroxide on the corrosion potential can be understood by comparing its reduction potential with that of the usual depolarizer, dissolved oxygen [122]:

$\mathrm{H}_{2} \mathrm{O}_{2}+2 \mathrm{H}^{+}+2 \mathrm{e}^{-} \rightarrow 2 \mathrm{H}_{2} \mathrm{O}(1535 \mathrm{mV}, \mathrm{SCE})$

$\mathrm{O}_{2}+4 \mathrm{H}^{+}+4 \mathrm{e}^{-} \rightarrow 2 \mathrm{H}_{2} \mathrm{O}(988 \mathrm{mV}, \mathrm{SCE})$

Preferential reduction of hydrogen peroxide would shift the corrosion potential to more positive values; it is evident that hydrogen peroxide is a more effective depolarizer than oxygen. It is reasonable to expect that such shifts in the corrosion potential would result in a corresponding decrease in the pitting resistance, which is quantified as the difference between the pitting and corrosion potentials, $E_{\mathrm{c}}-E_{\mathrm{corr}}$. However, despite the radiation-induced shift in $E_{\text {corr }}$, Glass et al. found that gamma irradiation had little effect on pitting potential [116].

Marsh et al. have also found increases in $E_{\text {corr }}$ for both oxygenated and de-oxygenated solutions, but the de-oxygenated solutions respond more slowly [118]. Their study concludes that the increase is caused by oxidizing radicals and molecular species, and that the presence of oxygen enhances the production of oxidizing products. Their study finds further that irradiation inhibits the initiation of LC at relatively low electrode potentials. Marsh et al. tentatively suggest that this inhibition occurs because the adsorption of oxidizing radiolysis products enhances the protective properties of the passivate oxide film.

\subsection{Effects of Gamma Irradiation on SCC}

It is widely recognized that IGSCC occurs in stainless steels when three conditions are simul- taneously present: (1) the material must be sensitized, i.e., the concentration of dissolved chromium in the grain boundaries must be depleted to less than $12 \mathrm{w}$ \% by the formation of chromium carbide precipitates, (2) the material must be placed under sufficient tensile stress, and (3) the environment must be sufficiently corrosive to attack the material in the grain boundaries. Since gamma irradiation of aqueous solutions produces several oxidizing and reducing species by radiolysis, it might be expected to affect SCC. IGSCC was observed in 1967 in the heat-affected zone (HAZ) of Type 304 stainless steel piping used in the recirculation circuit of a boiling water reactor [123]. Since then, the problem has been found in many reactors of this type.

Kuribayashi and Okabayashi conducted experiments to examine the influence of gamma irradiation on SCC of sensitized austenitic stainless steel [124]. Their tests were conducted with gamma irradiation in boiling $12 \% \mathrm{NaCl}$ solution, $\mathrm{pH}$ adjusted to 3 with $\mathrm{HCl}$, and a hightemperature $\left(230^{\circ} \mathrm{C}\right)$ pure water. They found that gamma irradiation increased the susceptibility of sensitized Type 304 stainless steel to ICSCC in the acidic $\mathrm{NaCl}$ environment. Ferric ions $\left(\mathrm{Fe}^{3+}\right)$ are radiolytically formed by gamma irradiation from ferrous ions $\left(\mathrm{Fe}^{2+}\right)$ in acid solution, and this phenomenon is the widely know'n principle of the Fricke dosimeter. The ferric ions may act as a strong oxidizing agent and may have increased the susceptibility to IGSCC in the boiling acid chloride solution. Gamma radiation also increased the susceptibility of sensitized Type 304 steel to IGSCC in high-temperature oxygenated pure water.

Furuya et al. reported experiments on the effects of gamma irradiation on SCC in boiling deionized water [125]. The alloys studied were Types 304, 304L, 304EL, and 309S stainless steels, Alloys 825,600 , and 625 , and SMA 50 (a low-alloy steel containing small amounts of manganese and copper). The materials were sensitized by heat treatments at $700^{\circ} \mathrm{C}$ for $100 \mathrm{~min}$ and then at $500^{\circ} \mathrm{C}$ for $24 \mathrm{hr}$. The samples were formed into double $\mathrm{U}$-bends, some with $\mathrm{V}$-notches. All the materials were included in the first test series, which lasted 180 days. Furuya et al. found that the samples made of Types 304, 304 L, and $309 \mathrm{~S}$ exhibited SCC, while the others (Type 304EL and Alloys 825, 600, and 625, and SMA 50) did not. This was found to be the case both with and without gamma irradiation, but the number of failures with Type 304, particularly at V-notches, was much greater in the 
irradiated samples. The chloride concentrations in the first series were between 0.2 and $3.8 \mathrm{ppm}$.

Furuya et al. performed a second series of tests on Type 304 only, in which care was taken to keep the chloride and dissolved oxygen at lower concentrations by using a closed refluxing system rather than a flowing system. In this series, which ran for 60 days, IGSCC was observed on the irradiated samples but not on the nonirradiated ones. The chloride concentrations were less than $0.7 \mathrm{ppm}$ in this series. Oxygen concentrations were not reported.

It should be noted that nuclear-waste containers will not be subjected to significant fluences of neutrons. However, it is of interest to note that a program has been conducted by Clarke and Jacobs to study the effects of prior neutron irradiation on the effects of gamma irradiation on the
SCC behavior of Type 304 stainless steel in hightemperature water [120]. A series of constant extension rate tests (CERT tests) were completed at $288^{\circ} \mathrm{C}$ in oxygenated water on annealed materials machined from neutron-irradiated reactor components. These tests confirm that high fluences of prior neutron irradiation promote IGSCC in Type 304 stainless steel, and that a threshold fluence $\mathrm{cx}$ ists for high plastic strain levels at about $5 \times 10^{20}$ $\mathrm{n} / \mathrm{cm}^{?} \cdot(E>1 \mathrm{MeV})$. This enhancement of IGSCC is believed to be due to neutron-induced segregation at grain boundaries.

Gamma radiolysis of moisture films in air may generate nitrous acid (acidic nitrite), as was shown in Table 7 above. Nitrite ions are known to promote the SCC of copper and copper-based alloys. This possibility was discussed in Sec. 5.3.

\section{Summary and Conclusions}

We have reviewed the literature extensively and found several models relevant to the uniform corrosion, localized corrosion, and stress corrosion cracking of metal cuntainers for disposal of high-level radioactive waste. The applicability of these models to the candidate materials in the anticipated repository environment has been discussed. The models fall into the following categories: (1) initiation of pits on passive austenitic surfaces; (2) propagation of pits on active metal surfaces; (3) propagation of pits on surfaces covered by salt films; (4) initiation of cracks at pits; (5) propagation of cracks on active metal surfaces; (6) propagation of cracks due to periodic fracture of passive films at crack tips; (7) propagation of cracks due to film-induced cleavage of the base metal; (8) crevice corrosion on active metal surfaces; and (9) crevices that behave like activepassive concentration cells.
Our review of the literature on available models has revealed several needs:

- A model of the local environment must be developed. This model should be capable of prt dicting the temperature of the container wall, the levels of species in ground water that have been concentrated by thermal refluxing, the concentrations of radiolysis products, and the effects of $\mathrm{mi}$ crobial growth on the local environment.

- Parameters in corrosion models should be quantified for the candidate materials, where appropriate.

- A quantitative model applicable to the initiation and pitting of copper should be developed.

- Possible crevice geometries must be determined.

- Finally, statistical techniques should be introduced into models.

\section{Acknowledgments}

This work was performed under the auspices of the U.S. Department of Energy by Lawrence Livermore National Laboratory under contract No. W-7405-ENG-48, and was supported by the Yucca Mountain Project. The authors thank Jay C. Cherniak for his editorial assistance. 


\section{References}

1. W.C. O'Neal and D. W. Gregg, Preclosure analysis of conceptual waste package designs for a nuclear waste repository in tuff, Lawrence Livermore National Laboratory, Livermore, Calif., UCRL53595 (November 1, 1984).

2. R. D. McCright, An annotated history of container candidate material selection, Lawrence Livermore National Laboratory, Livermore, Calif., UCID-21472 (July, 1988).

3. J. C. Farmer et al., Survey of degradation modes of candidate materials for high-level radioactivewaste disposal containers, 8 vols. and an overview, Lawrence Livermore National Laboratory, Livermore, Calif., UCID-21362 (June 1988).

4. J. C. Farmer and R. D. McCright, Locaiized corrosion and stress corrosion cracking of candidate materials for high-level radioactive waste disposal containers in U.S.: a critical literature review, Niat. Res. Soc. Symp. Proc. (Materials Research Society, 1989) Vol. 127, pp. 359-371. NN1.881121.0061

5. "Disnosal of High-Level Radioactive Wastes in Geologic Repositories, Technical Criteria," 10 CFR Part 60, Nuclear Regulatory Agency, Federal Register, Rules and Regulations, Vol. 48, No. 120, pr . 28194-28229, Tuesday, June 21, 1983. HQ2.870302.3019

6. "En rironmental Standards for the Management and Disposal of Spent Nuclear Fuel, High-Level and Transuranic Radioactive Wastes," 40 CFR Part 191, Environmental Protection Agency, Federal Register, Rules and Regulations, Vol. 50, No. ?92, nn. 38066-38089, Thursday, September 19, 1985. HQ2.870301.5394

7. J. C. Farmer and R. D. McCright, A review of models relevant to the prediction of performance of high-level radioactive waste disposal. containers, CORROSION '89, New Orleans, Louisiana, April 17-21, 1989 (National Association of Corrosion Engineers, 1989), paper No. 519.

8. J. N. Hockman and W. C. ONeal, Thermal modeling of nuclear waste package designs for disposal in tuff, Lawrence Livermore National Laboratory, Livermore, Calif., UCRL-89820 (September 1983); Proc. ANS/ASME Waste Management '84, Tucson, Ariz., March 11-15, 1984.

9. W. E. Glassley, Reference waste package environment report, Lawrence Livermore National Laboratory, Livermore, Calif., UCRL-53726 (October 1, 1986). HQS.880517.2445

10. R. D. McCright, W. G. Halsey and R. A. Van Konynenburg, Progress report on the results of testing advanced conceotual design metal barrier materials under relevant environmental conditions for a tuff repository, Lawrence Livermore National Laboratory, Livermore, Calif., UCID-21044 (December 1987). HQX.880201.0016, HQS.880517.2494

11. G. E. Gdowski and D. B. Bullen, Survey of degradation modes of candidate materials for high-level radioactive-waste disposal containers, vol. 2, oxidation and corrosion, Lawrence Livermore National Laboratory, Livermore, Calif., UCID-21362 (August 1988).

12. M. G. Fontana and N. D. Greene, Corrosion Engineering, 2nd ed. (McGraw-Hill Book Company, New York, 1378). NNA.891018.0176

13. H. H. Uhlig, Currosion and Corrosion Control: An Introduction to Corrosion Science and Engineering, 2nd ed. (John Wiley and Sons, New York, 1971). NNA.891018.0177

14. T. Okada, Halide nuclei theory of pit initiation in passive metals, J. Electrochem. Soc. 131(2) (1984) 241-247. NNA.891005.0087

15. T. Okada, A theory of perturbation-initiated pitting, Proceedings of an International Symposium Honoring Professor Marcel Pourbaix on His Eightieth Birthday: Equilibrium Diagrams and Localized Corrosion, Robert P. Frankenthal and Jerome Kruger, Eds. (The Electrochemical Society, Pennington, New Jersey, 1984) Vol. 84-9, pp. 402-431. NNA.891005.0088

16. T. Shibata and T. Takeyama, Stochastic theory of pitting corrosion, Corrosion 33(7) (July 1977) $243-$ 251. NNA.891005.0090

17. G. P. Marsh, K. J. Taylor and Z. Sooi, The kinetics of pitting corrosion of carbon steel, Swedish Nuclear Fuel and Waste Management Company, Box 5864, S-102 48 Stockholm, Sweden, SKB Technical Report 88-09 (February 1988).

18. H. J. Engell and N. D. Stolica, Die Kinetik der Entstehung und des Wachstums von Lochfrass-stellen auf passiven Eisenelektroden, Z. Phys. Chem. 20 (1959) 113-120. NNA.891005.0091 
19. M. Janik-Czachor, An assessment of the processes leading to pit nucleation on iron, Reviews and News, J. Electrochem. Soc. 128(12) (December 1981) 513C-519C. NNA.891005.0092

20. G. Matamala R., Correlation model of the AISI 316 stainless steel pitting potential with cellulose bleach process variables, Corrosion 43(2) (February 1987) 97-100. NNA.890831.0063

21. C. Y. Chao, L. F. Lin and D. D. McDonald, A point defect m:odel for anodic passive films, II. chemical breakdown and pit initiation, J. Electrochemical Soc. 128(6) (June 1981) 1194-1198. NNA.891005.0093

22. N. Sato, Electrochimica Acta 19 (1971) 1683.

23. Z. Szklarska-Smialowska, Theories of pitting corrosion, chap. 19 in: Pitting Corrosion of Metals (National Association of Corrosion Engineers, Houston, Texas, 1986) pp. 377-407.

24. P.E. Manning, D. J. Duquette and W. F. Savage, The role of sulfide inclusion morphology in pit initiation of several type 300 series stainless steels, Corrosion 36(6) (June 1980) 313-319. NNA.891005.0094

25. H. W. Pickering and R. P. Frankenthal, On the mechanism of localized corrosion of iron and stainless steel: I. electrochemical studies, J. Electrochem. Soc. 119(10) (October 1972) 1297-1304. NNA.891005.0089

26. J. R. Gr'vele, Transport processes and the mechanism of pitting of metals, J. Electrochem. Soc. 123(4) April (1976) 464-474.

27. T. R. Beck and R. C. Alkire, Occurrence of salt films during initiation and growth of corrosion pits, J. Electrochem. Soc. 126(1) (October 1979) 1662-1666.

28. L. Hagn, Lifetime prediction for parts in corrosion environments, in: Corrosion in Power Generating Equipment (Plenum Press, 1983). NNA.891005.0095

29. O. Buck and R. Ranjan, Evaluation of a crack-tip-opening displacement model under stresscorrosion conditions, in: Modeling Environmental Effects on Crack Growth Processes, R. H. Jones and W. W. Gerberich, Eds. (The Metallurgical Society, 1986) p. 209. NNA.891005.0096

30. R. L. Fullman, Modeling of composition effects or, the SCC of stainless steels, Proceedings: Seminar on Countermeasures for Pipe Cracking in BWRs, Palo Alto, Calif., May, 1980, Vol. 1, paper No. 6, 8 pages. NNA.891005.0103

31. E. C. Bain, R. H. Aborn and J. J. B. Rutherford, The nature and prevention of intergranular corrosion in austenitic steels, Trans. Am. Soc. Steel Treat. 21 (1933) 481. NNA.891005.0143

32. C. Stawstrom and $M$. Hillert, An improved depleted-zone theory of intergranular corrosion of 18-8 stainless steel, J. Iron Steel Inst. 207 (1969) 77. NNA.891005.0144

33. C. S. Tedmon, Jr., D. A. Vermilyea and J. H. Rosolowski, Intergranular corrosion of austenitic stainless steel, J. Electrochem. Soc. 118 (1971) 192. NNA.891005.0145

34. R. L. Fullman, A thermodynamic model of the effects of composition on the susceptibility of austenitic stainless steels to intergranular stress corrosion cracking, Acta Metallurgica 30 (1982) 1407-1415. NNA.891005.0146

35. A. Turnbull and J. G. N. Thomas, A model of crack electrochemistry for steels in the active state based on mass transport by diffusion and ion migration, J. Electrochem. Soc. 129(7) (July 1982) $1412-1422$.

36. R. H. Jones, M. J. Danielson and C. A. Oster, Modeling environmental effects on crack growth, Symposium Proceedings, Metallurgical Society, Warrendale, Penn., 1986, 41-53. NNA.891005.0106

37. J.S. Newman, (Transport in) infinitely dilute solutions, in: Electrochemical Systems (Prentice-Hall, Inc., Englewood Cliffs, N.J., 1973) pp. 217-238.

38. T. Nakayama and M. Takano, Application of slip dissolution-repassivation model for stress corrosion cracking of AISI 304 stainless steel in a boiling $42 \% \mathrm{MgCl}_{2}$ solution, Corrosion 42(1) (January 1986) 10-14. NNA.891005.0194

39. P. L. Ardresen, Modeling of water and material chemistry effects on crack tip chemistry and resulting crack growth kinetics, 3rd Int. Conference, Degradation of Materials in Nuclear Power Industry, Traverse City, Mich., August 31-September 4, 1987. NNA.891005.0107 
40. F. P. Ford, Current understanding of the mechanisms of stress corrosion and corrosion fatigue, Symposium on Environment-Sensitive Fracture: Evaluation and Comparison of Test Methods, Gaithersburg, Maryland, April 26-28, 1982, S. W. Dean, E. N. Pugh, G. M. Ugiansky, Eds., American Society for Testing and Materials, Philadelphia, Penn., ASTM Special Technical Publication 821, ASTM Publication Code Number (PCN) 04-821000-27 (1982), pp. 32-51. NNA.891005.0102

41. P. L. Andresen and F. P. Ford, Modeling of irradiation effects on stress corrosion crack growth rates, presented at the International Cooperative Group on Irradiation Assisted Stress Corrosion Cracking, 1988 Summer Meeting, Abisko, Sweden, June 7-8, 1988.

42. I. Maier and J. R. Galvele, Straining metal electrode technique as a SCC test, type 304 stainless steel in $\mathrm{NaCl}+\mathrm{H}_{2} \mathrm{SO}_{4}$ solutions, Corrosion, 36(2) (February 1980) 60-66. NNA.891005.0108

43. P. 1. Marshall and G. T. Burstein, Repassivation of stainless steels, Proc. Int. Congress on Metallic Corrosion, Toronto, Canada, June 3-7, 1984 (National Research Council of Canada, 1986), vol. 2, pp. 121-128. NNA.891005.0109

44. R. H. Jones, Stress corrosion cracking, in: ASM Metals Handbook (ASM, Metals Park, Ohio), September 1987, 9 th ed., vol. 13, p. 160. NNA.891005.0097

45. H.S. Campbell, A review: pitting corrosion of copper and its alloys, Proceedings of the U. R. Evans Conference on Localized Corrosion, Williamsburg, Va., December 6-10, 1971, R. W. Staehle, B. F. Brown, J. Kruger and A. Agrawal, Eds. (National Association of Corrosion Engineers, Houston, Texas, 1974), pp. 625-635. NNA.891004.0333

46. C. Breckon and J. R. T. Baines, The significance of apparently minor factors in corrosion problems affecting condenser and cooler tubes, Trans. Inst. Marine Eng. 67(10) (1955) 1.

47. H. S. Campbell, A review: pitting corrosion of copper and its alloys, in: Localized Corrosion, NACE-3, R. W. Staehle, B. F. Brown, J. Kruger and A. Agrawal, Eds. (National Association of Corrosion Engineers, Houston, Texas, 1974), pp. 625-635. NNA.891004.0333

48. G. L. Bailey, Copper-nickel-iron alloys resistant to sea water corrosion, J. Inst. Metals, 79(5) (1951) 243. NNA.891004.0334

49. J. G. N. Thomas and A. K. Tiller, Formation and breakdown of surface films on copper in sodium hydrogen carbonate and sodium chioride solutions, British Corr. J. 7 (Novernber 1972) 256-262. NNA.891101.0013

50. H. S. Campbell, Corrosion, water composition and water treatment, J. Water Treatment and Examination, 20 Part 1 (1971) 11-25. (Secondary reference, quoted in Ref. 36.)

51. British Non-Ferrous Metals Research Association (BNFMRA) Miscellaneous Publication 568 (December 1971). (Secondary reference, quoted in Ref. 36.)

52. E. Mattsson, Corrosion of copper and brass: practical experience in relation to basic data, Brit. Corr. J. 15(1) (1980) 13. NNA.891004.0335

53. Z. Szklarska-Smialowska, Pitting of copper, zinc, and other metals and alloys, in: Pitting Corrosion of Metals (National Association of Corrosion Engineers, Houston, Texas, 1986) Chap. 10. NNA.891004.0336

54. M. Pourbaix, Rapports Techniques, CEBELCOR Rapport Technique No. 100 (1965) 126. (Secondāry reference, quoted in Ref. 36.$)$

55. R. May, Some observations on the mechanism of pitting corrosion, J. Inst. Metals 32 (1953) 65-74. NNA.891004.0339

56. H. S. Campbell, Water Treatment and Examination 3 (1954) 100. (Secondary reference, quoted in Ref. 36.)

57. V. F. Lucey, Mechanism of pitting corrosion of copper in supply waters, Brit. Corros. J. 2 (September 1967) 175-185.

58. V.F. Lucey, Developments leading to the present understanding of the mechanism of pitting corrosion of copper, Brit. Corros. J. 7 (January 1972) 36-41. NNA.891004.0341

59. E. J. Cornwell, G. Wildsmith and P. T. Gilbert, Pitting corrosion in copper tubes in cold water service, Brit. Corros. J. 8 (September 1973) 202-209. NNA.891004.0342

60. H. Kristiansen, Werkst. Korros. 28 (1977) 143. (Secondary reference, quoted in Ref. 36.)

61. M. Pourbaix, Some applications of potential-pH diagrams to the study of localized corrosion, J. Electrochem. Soc. 123(2) (February 1976) 25c-36c. NNA.891004.0345 
62. M. Pourbaix, The electrochemical basis for localized corrosion, in: Localized Corrosion, NACE-3, R. Staehle, B. Brown, J. Kruger and A. Agrawal, Eds. (National Association of Corrosion Engineers, Houston, Texas, 1974), p. 12. NNA.891004.0343

63. M. Pourbaix, J. van Muylder and P. van Laer, Sur la tension d'electrode du cuivre en presence d'eau de Bruxelles: influence de la lumiere et des conditions de circulation de l'eau, CEBELCOR Rapport Technique No. 125 (1965); Corros. Sci. 7 (1967) 795-806. NNA.891004.0344

64. J. van Muylder, M. Pourbaix, N. de Zoubov and A. Pourbaix, Relationship between electrode voltage and mechanism of copper corrosion in presence of Brussels water, CEBELCOR Rapport Technique No. 126 (1965). (Secondary reference, quoted in Ref. 36.)

65. J. van Muylder, M. Pourbaix and P. van Laer, Electrochemical characteristics of corrosion pitting of copper in presence of water and aqueous chloride solutions, CEBELCOR Rapport Technique No. 127 (1965). (Secondary reference, quoted in Ref. 36.)

66. P. van Laer, J. van Muylder, N. de Zoubov and M. Pourbaix, Measurement of risk of copper pitting in presence of water, CEBELCOR Rapport Technique No. 128 (1965). (Secondary reference, quoted in Ref. 36.)

67. N. de Zoubov, J. van Muylder, P. van Laer and M. Pourbaix, CEBELCOR Rapport Technique No. 133 (1965). (Secondary reference, quoted in Ref. 36.)

68. M. F. Obrecht and M. Pourbaix, Proc. 3rd Int. Congress on Metallic Corrosion, 1967, p. 228. (Secondary reference, quoted in Ref. 36.)

69. J. C. Angus and C. T. Angus, Computation of Pourbaix diagrams using virtual species: implementation on personal computers, Proceedings of an International Symposium Honoring Professor Marcel Pourbaix on His Eightieth Birthday (The Electrochemical Society, Inc., Pennington, N.J., 1984) Proceedings Vol. 84-9, pp. 109-134. NNA.890920.0294

70. H.S. Campbell, Water Treatment and Examination 3 (1954) 100.

71. E. N. Pugh, W. G. Montague and A. R. C. Westwood, Stress-corrosion cracking of copper, Corros. Sci. 6 (1966) 345-346. NNA.890920.0269

72. S. P. Pednekar, A. K. Agrawal, H. E. Chaung and R. W. Staehle, Transgranular cracking of copper in $1 \mathrm{M} \mathrm{NaNO} 2$ solution, J. Electrochem. Soc. 126(4) (1979) 701-702. NNA.890920.0270

73. E. Escalante and J. Kruger, Stress corrosion cracking of pure copper, J. Electrochem. Soc. 118(7) (July 1971) 1062-1066. NNA.890920.0271

74. Y. Suzuki and Y. Hisamatsu, Stress corrosion cracking of pure copper in dilute ammoniacal solutions, Corros. Sci. 21(5) (1981) 353-368. NNA.890920.0272

75. E. N. Pugh, J. V. Craig and W. G. Montague, Factors influencing the path of stress-corrosion cracking in alpha-phase copper alloys exposed to aqueous ammonia environments, Trans. ASM 61 (1968) 468-473. NNA.890831.0070

76. Y. Suzuki and Y. Hisamatsu, Stress corrosion cracking of pure copper in ammoniacal solutions, Boshoku Gijutsu 23 (1974) 29. NNA.891018.0188

77. Y. Suzuki, Y. Hisamatsu and S. Morishima, Stress corrosion cracking of pure copper and copper zinc alloys in dilute ammoniacal solutions, Boshoku Gijutsu 23 (1974) 477. NNA.891018.0193

78. J. R. Myers, Corrosion and oxidation of copper and selected copper alloys in air, steam and water at temperatures up to $300^{\circ} \mathrm{C}$, a review of the literature, draft report, Copper Development Association, Inc., Greenwich, Conn. (July 18, 1986). NNA.890920.0273

79. K. Sieradzki, R. L. Sabatini and R. C. Newman, Stress-corrosion cracking of copper single crystals, Met. Trans. A 15A (October 1984) 1941-1946. NNA.890920.0274

80. N. Bertocci and E. N. Pugh, Chemical and electrochemical aspects of SCC of alpha brass in aqueous ammonia, Proceedings of the International Congress on Metallic Corrosion, Toronto, Canada, June 3-7, 1984 (National Research Council of Canada, 1986) Vol. 1. NNA.890920.0276

81. E. N. Pugh, J. V. Craig and A. J. Sedriks, The stress corrosion cracking of copper, silver and gold alloys, Proceedings of the Conference on Fundamental Aspects of Stress Corrosion Cracking, The Ohio State University Department of Metallurgical Engineering, September 11-15, 1967, pp. 118-154. NNA.890920.0277

82. E. N. Pugh, W. G. Montague and A. R. C. Westwood, On the role of complex ions in the seasoncracking of alpha-brass, Trans. ASM 58 (1965) 665-671. NNA.890920.0278 
83. E. N. Pugh and A. R. C. Westwood, Complex ions and stress-corrosion cracking in alpha-brass, Philoscphy Magazine 13 (1966) 167-183. NNA.890920.0279

84. H. Uhlig, K. Gupta and W. Liang, Critical potentials for stress corrosion cracking of 63-37 brass in ammoniacal and tartrate solutions, J. Electrochem. Soc. 122(3) (1975) 343-350. NNA.890920.0280

85. R. P. M. Procter and G. N. Stevens, The formation of cuprous oxide films on alpha-brass stresscorrosion fracture surfaces, Corros. Sci. 15 (1975) 349-539. NNA.890920.0232

86. V. Ashworth, K. Lyth and R. P. M. Proctor, The inhibitive effect of benzotriazole on stress corrosion cracking of alpha-brass in Mattsson's solution, Corrosion 35(4) April (1979) 190-191. NNA.890920.0281

87. R. C. Newman and G. T. Burstein, The anodic behavior of freshly generated alpha-brass surfaces, Corros. Sci. 21 (1981) 119-128. NNA.890920.0282

88. L. H. Jenkins and R. B. Durham, Film formation on copper and alpha brass in aqueous cupricammonia systems, J. Electrochem. Soc. 117(6) (June 1970) 768-774. NNA.890920.0283

39. T. P. Hoar and G. P. Rothwell, The potential-pH diagram for a copper-water-ammonia system: its significance in the stress-corrosion cracking of brass in ammoniacal solutions, Electrochimica Acta 15 (1970) 1037-1045. NNA.890831.0068

90. H. E. Johnson and J. Leja, On the potential-pH diagrams of the $\mathrm{Cu}-\mathrm{NH}_{3}-\mathrm{H}_{2} \mathrm{O}$ and $\mathrm{Zn}-\mathrm{NH}_{3}-\mathrm{H}_{2} \mathrm{O}$ systems, J. Electrochem. Soc. 112(6) (June 1965) 638-641. NNA.890920.0292

91. P. Aaltonen, $\mathrm{H}$. Hanninen, $\mathrm{H}$. Illi and $\mathrm{M}$. Kemppainen, On the mechanisms of environment sensitive cracking of pure OFHC-copper, in: Predictive Capabilities in Environmentally Assisted Cracking, Winter Meeting of the American Society of Mechanical Engineers, Miami Beach, Florida, November 17-22, 1985, PVP-99, pp. 329-340. NNA.890920.0284

92. R. C. Newman and G. T. Burstein, Anion effects in the stress-corrosion cracking of copper and brass, J. Electrochem. Soc. 127(11) (November 1980) 2527. NNA.890920.0285

93. P. Aaltonen, $\mathrm{H}$. Hanninen and $\mathrm{M}$. Kemppainen, Stress corrosion testing of pure OFHC-copper in simulated ground water conditions, Nuclear Waste Commission of Finnish Power Companies, Report YJT-84-21 (November 1984). NNA.890920.0286

94. J. F. Klement, R. E. Maersch and P. A. Tully, Stress corrosion crack paths in alpha aluminum bronze in ammonia and steam atmospheres, Corrosion 15(6) (June 1959) 29-32. NNA.890920.0287

95. M. Pourbaix, Atlas of Electrochemical Equilibria in Aqueous Solutions (Pergamon Press, New York, 1966). NNA.891005.0098

96. A. J. Bard and L. R. Faulkner, Electrochemical Methods, Fundamentals and Applications (John Wiley and Sons, New York, 1980).

97. G. E. McGuire, A. L. Bacarella, J. C. Griess, R. E. Clausing and L. D. Hulett, Analysis of protective oxide films on copper-nickel alloys by Auger spectroscopy, J. Electrochem. Soc. 125 (1978) 18011804. NNA.890920.0288

98. P. A. Candela and L. L. Y. Chang, Solid solution, order disorder, and the thermodynamics of alloy corrosion, Proceedings of an International Sympcsium Honoring Professor Marcel Pourbaix on His Eightieth Birthday, Equilibrium Diagrams and Localized Corrosion, R. P. Frankenthal and J. Kruger, Eds. (The Electrochemical Society, Inc., Pennington, N.J., 1984) Proceedings Vol. 84-9, pp. 125-134. NNA.891005.0373

99. A. J. Forty and P. Humble, The influence of surface tarnish on the stress-corrosion of alpha brass, Philosophy Magazine 8 (1963) 247-264. NNA.890920.0289

100. A. J. McEvily and A. P. Bond, On the initiation and growth of stress corrosion cracks in tarnished brass, J. Electrochem. Soc. 112(2) (February 1965) 131-138. NNA.890920.0290

101. J. F. Newman, The stress corrosion of steel in sodium hydroxide solution: a film-rupture model, Corros. Sci. 21(7) (1981) 487-503. NNA.891005.0105

102. R. C. Newman and K. Sieradzki, Correlation of acoustic racking of alpha-brass, Scripta Met. 17 (1983) 621-624. NNA.890920.0291

103. A. Paskin, K. Sieradzki, D. K. Som and G. J. Dienes, Dislocation enhancement and inhibition induced by films on crack surfaces, Acta Metallurgica 31(8) (1983) 1253-1265. NNA.890920.0299

104. A. Paskin, K. Sieradzki, D. K. Som and G. J. Dienes, Environmentally induced crack nucleation and brittle fracture, Acta Metallurgica 30 (1982) 1781-1788. NNA.890920.0300 
105. A. Paskin, A. Gohar and G. J. Dienes, Computer simulation of crack propagation, Phys. Rev. Lett. 44 (1980) 940-943. NNA.890920.0301

106. K. Sieradzki, J. S. Kim, A. T. Cole and R. C. Newman, The relationship between dealloying and transgranular stress corrosion cracking of $\mathrm{Cu}-\mathrm{Zn}$ and $\mathrm{Cu}-\mathrm{Al}$ alloys, J. Electrochem. Soc. 134 (1987) 1635-1639. NNA.890920.0302

107. M. J. Pryor and J. C. Fister, The mechanism of dealloying of copper solid solutions and intermetallic phases, J. Electrochem. Soc. 131(6) (June 1984) 1230-1235. NNA.890920.0303

108. T. J. Lennox and M. H. Peterson, De-alloying of copper alloys and response to cathodic protection in quiescent sea water, Mater. Perf. 10(7) (July 1971) 31-37. NNA.890920.0304

109. R. J. Ferrara and T. E. Caton, Review of dealloying of cast aluminum bronze and nickel-aluminum bronze alloys in sea water service, Mater. Perf. 21(2) (February 1982) 30-34. NNA.890920.0305

110. A. H. Tuthill, Guidelines for the use of copper alloys in seawater, Mater. Perf. 26(9) (September 1987) 12-22. NNA.890920.0238

111. L. W. Gleekman and R. K. Swandby, Massive de-aluminization of aluminum bronze by chloride attack, Corrosion 2 (March 1961) 116-120.

112. S. P. Lynch, Concerning the mechanism of transcrystalline stress-corrosion cracking of alpha-brass, Scripta Met. 18 (1984) 321-326. NNA.890920.0307

113. M. G. Fontana and N. D. Greene, Corrosion Engineering, 2nd ed. (McGraw-Hill Book Company, New York, 1978).

114. D. A. Vermilyea and C. S. Tedmon, Jr., A simple crevice corrosion theory, J. Electrochem. Soc. 117(4) (1970) 437-440. NNA.891004.0355

115. W. D. France, Jr., Crevice corrosion of metals, in: Localized Corrosion, Cause of Metal Failure, American Society for Testing and Materials, Special Technical Publication No. 516 (1972), pp. 164200. NNA.891004.0353

116. R. S. Glass, G. E. Overturf, R. A. Van Konynenburg and R. D. McCright, Gamma radiation effects on corrosion: I. electrochemical mechanisms for the aqueous corrosion processes of austenitic stainless steels relevant to nuclear waste disposal in tuff, Corros. Sci. 26(8) (1986) 577-590. NNA.891005.0162

117. R. S. Glass, R. A. Van Konynenburg and G. E. Overturf, Corrosion processes of austenitic stainless steels and copper-based materials in gamma-irradiated aqueous environments, CORROSION/86 (National Association of Corrosion Engineers, Houston, Texas, 1986), paper No. 258. NNA.891005.0163

118. G. P. Marsh, K. J. Taylor, G. Bryan and S. E. Worthington, The influence of radiation on the corrosion of stainless steel, Corros. Sci. 26(11) (1986) 971. NNA.891005.0164

119. Y. J. Kim and R. A. Oriani, Brine radiolysis and its effect on the corrosion of grade 12 titanium, Corrosion 43(2) (February 1987) 92-96. NNA.891005.0166

120. W. L. Clarke and A. J. Jacobs, Effect of radiation environment on SCC of austenitic materials, Proceedings of the Conference on Environmental degradation of Materials in Nuclear Power SystemsWater Reactors, Myrtle Beach, South Carolina, August 22-25, 1983 (National Association of Corrosion Engineers, Katy, Texas, 1984) 451-461. NNA.891005.0167

121. W. E. Ruther, W. K. Soppet and T. F. Kassner, Influence of gamma radiation on the ECP of type $304 \mathrm{SS}, \mathrm{Ti}$, and $\mathrm{Pt}$ in $289^{\circ} \mathrm{C}$ water, presented at the Meeting of the International Cooperative Group on Irradiation on Stress Corrosion Cracking, Traverse City, Michigan, September 3-4, 1987, sponsored by the American Nuclear Society, The Metallurgical Society, and the National Association of Corrosion Engineers. NNA.891005.0168

122. A. J. Bard and L. R. Faulkner, Electrochemical Systems, Fundamentals and Applications (John Wiley and Sons, New York, 1980), pp. 699-702.

123. N. Fujita, M. Akiyama and T. Tamura, Stress corrosion cracking of sensitized type 304 stainless steel in high temperature water under gamma ray irradiation, Corrosion 37(6) (June 1981) 335-341. NNA.891005.0169

124. M. Kuribayashi and $\mathrm{H}$. Okabayashi, Influence of gamma-ray radiation on stress corrosion cracking of austenitic stainless steel, J. Japan Institute of Metals, Sendai, 462(2) (1982) 170-175.

NNA.891005.0170 
125. T. Furuya, T. Fukuzuka, K. Fujiwara and H. Tomari1, Gamma-ray irradiation effects on stress corrosion cracking of alloys for a high level liquid waste package, R-D Kobe Siekosho Gijutsu Hokoku, 33(1) (January 1983) 43-46. NNA.890831.0067

126. ASM Metals Handbook (ASM, Metals Park, Ohio), September 1987, 9th ed., vol. 13, p. 559. NNA.890921.0078 
The following number is for Office of Civilian Radioactive Waste Management Records Management purposes only and should not be used when ordering this document:

Accession Number: NNA.911115.0021 

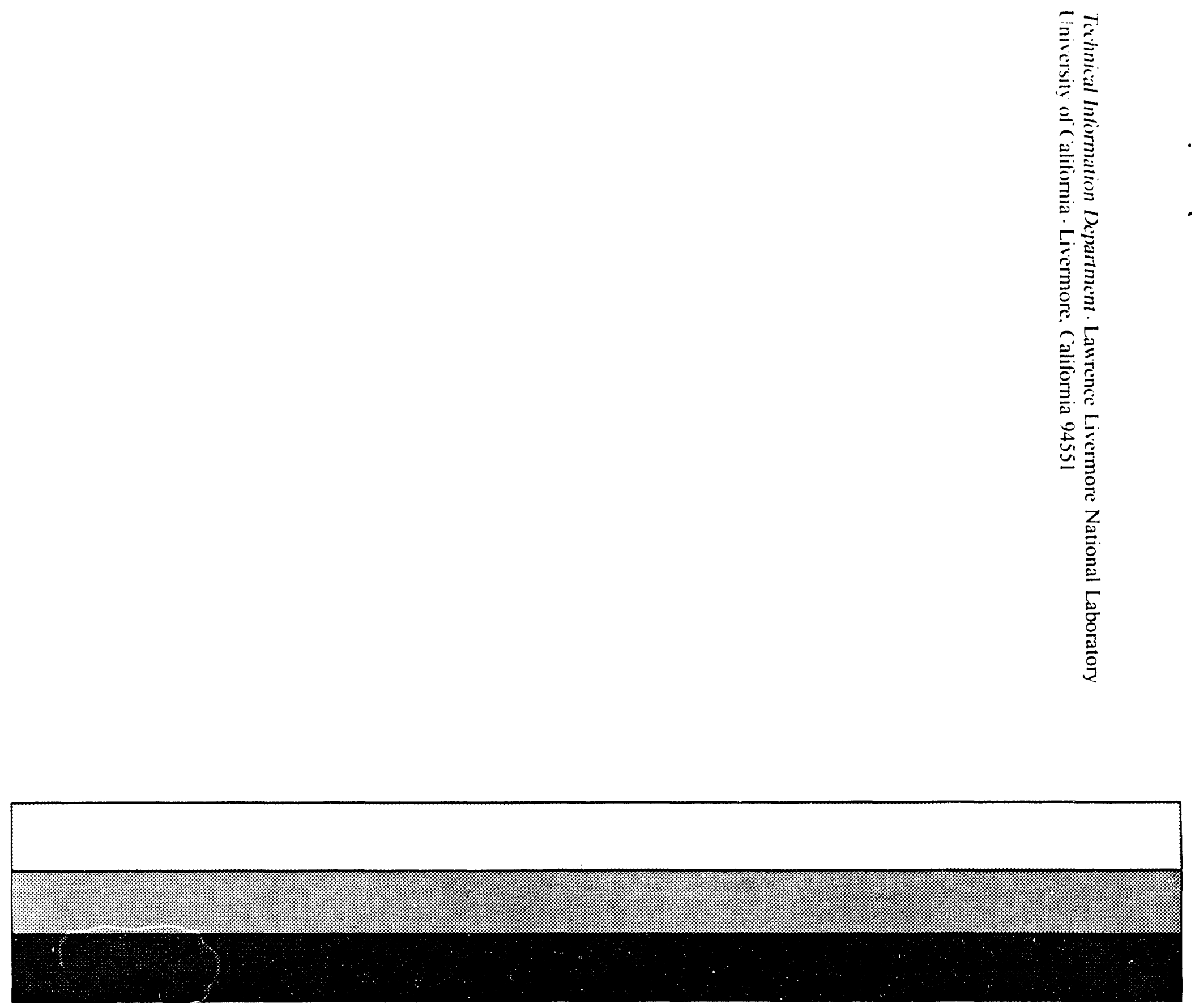

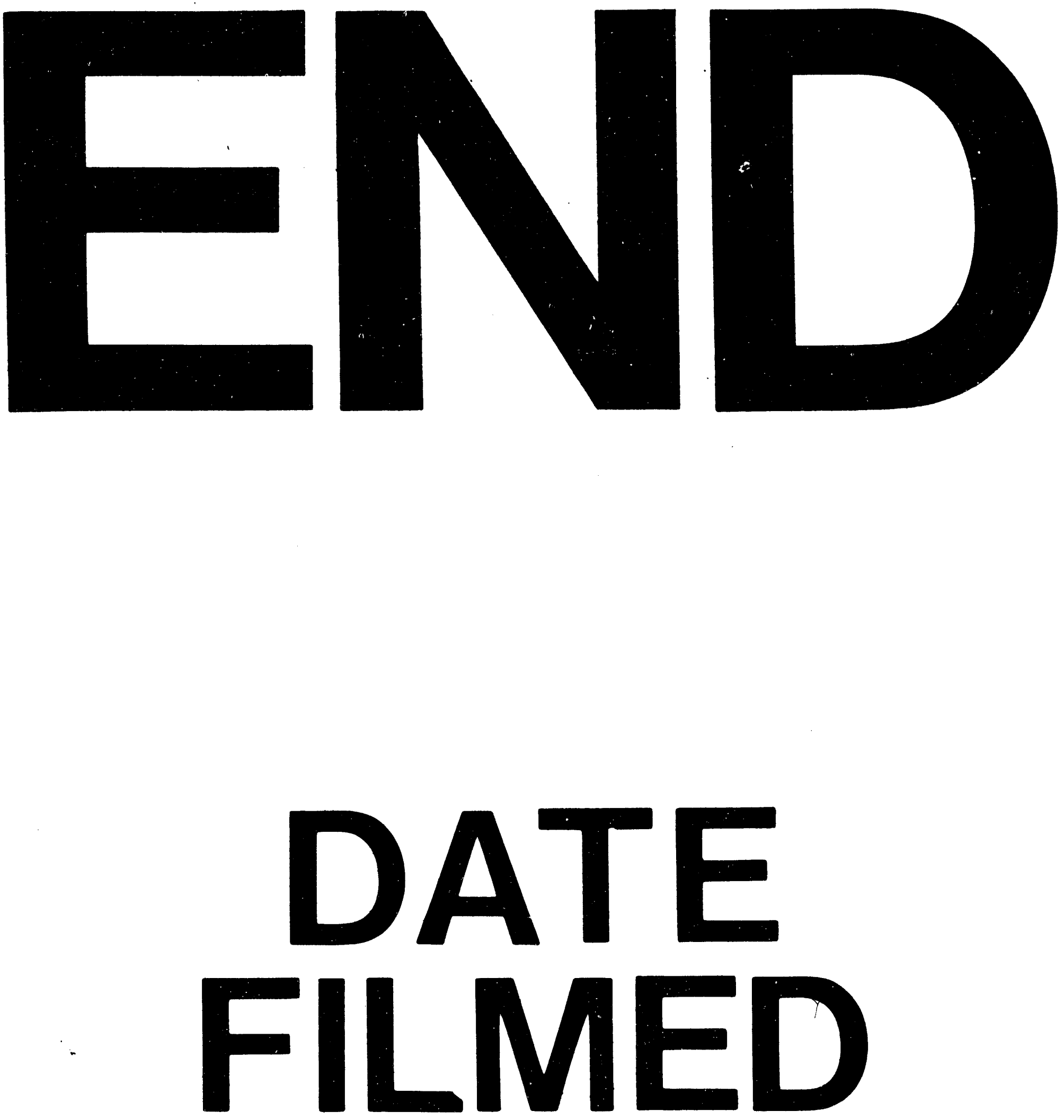

I

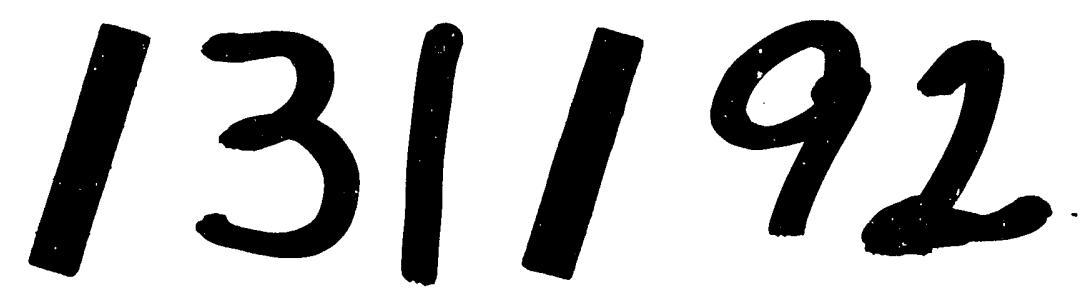


